FERNANDO PARANAIBA FILGUEIRA

\title{
CARACTERIZAÇÃO DA RESPOSTA VASORELAXANTE DO EQUILIN EM ARTÉRIAS MESENTÉRICAS \\ DE RATAS ESPONTANEAMENTE HIPERTENSAS
}

Tese apresentada ao Programa de PósGraduação em Farmacologia do Instituto de Ciências Biomédicas da Universidade de São Paulo, para obtenção do Título de Doutor em Ciências. 


\section{FERNANDO PARANAIBA FILGUEIRA}

\section{CARACTERIZAÇÃO DA RESPOSTA VASORELAXANTE DO EQUILIN EM ARTÉRIAS MESENTÉRICAS \\ DE RATAS ESPONTANEAMENTE HIPERTENSAS}

Tese apresentada ao Programa de PósGraduação em Farmacologia do Instituto de Ciências Biomédicas da Universidade de São Paulo, para obtenção do Título de Doutor em Ciências.

Área de Concentração: Farmacologia

Orientadora: Profa. Dra. Maria Helena Catelli de Carvalho

Versão original 
DADOS DE CATALOGAÇÃO NA PUBLICAÇÃO (CIP)

Serviço de Biblioteca e Informação Biomédica do

Instituto de Ciências Biomédicas da Universidade de São Paulo

reprodução não autorizada pelo autor

Filgueira, Fernando Paranaiba.

Caracterização da resposta vasorelaxante do equilin em artérias mesentéricas de ratas espontaneamente hipertensas / Fernando Paranaiba Filgueira. -- São Paulo, 2012.

Orientador: Profa. Dra. Maria Helena Catelli de Carvalho.

Tese (Doutorado) - Universidade de São Paulo. Instituto de Ciências Biomédicas. Departamento de Farmacologia. Área de concentração:

Farmacologia. Linha de pesquisa: Mecanismos de ação de hormônios sexuais sobre o sistema vascular.

Versão do título para o inglês: Characterization of vasorelaxant response to equilin mesenteric arteries from spontaneously hypertensive rats.

$\begin{array}{lll}\text { 1. Equilin 2. Artérias mesentéricas de resistência } 3 \text {. Efeito } & \end{array}$ vasorelaxante 4. Ratas espontaneamente hipertensas I. Carvalho, Profa. Dra. Maria Helena Catelli de II. Universidade de São Paulo. Instituto de Ciências Biomédicas. Programa de Pós-Graduação em Farmacologia III. Título. 
Candidato(a): $\quad$ Fernando Paranaiba Filgueira.

Título da Tese: $\quad$ Caracterização da resposta vasorelaxante do equilin em artérias mesentéricas de ratas espontaneamente hipertensas.

Orientador(a): $\quad$ Profa. Dra. Maria Helena Catelli de Carvalho.

A Comissão Julgadora dos trabalhos de Defesa da Tese de Doutorado, em sessão pública realizada a considerou
( ) Aprovado(a)
( ) Reprovado(a)

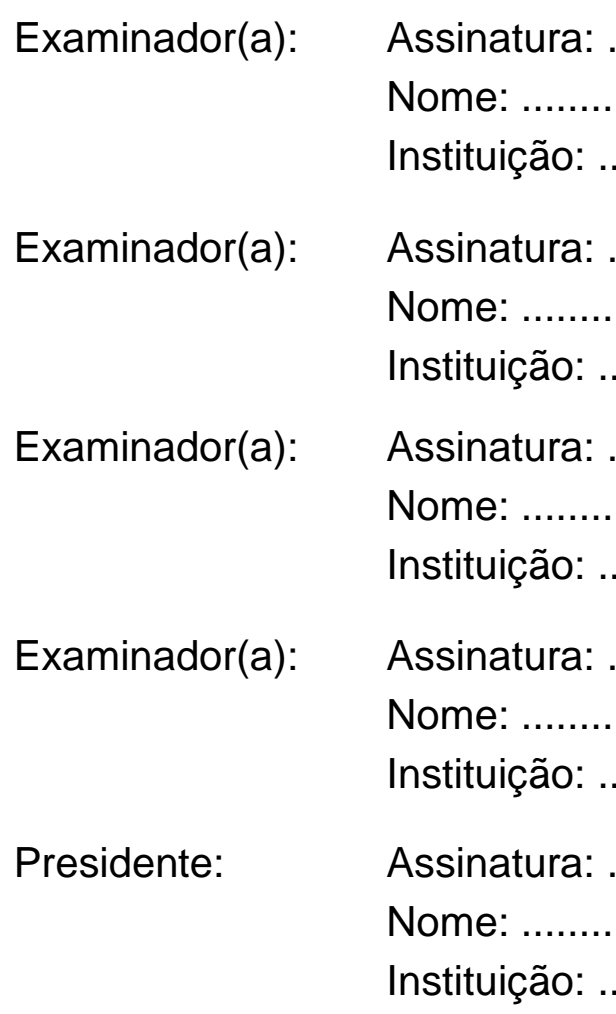




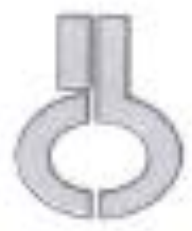

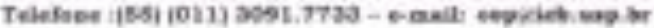

\section{Certificado}

Certificamos que o protocolo registrado sob $\mathrm{n}^{*} \mathbf{1 4 5}$ nas fls, 95 do livro 02 para Lso de animais em experimentaçá, sob a responsabilidade do Proffa] Drial Maria Helena Catelli de Carvalho, Coondenadoriaj da Linha de pesquisa Reatividade de maero e mierovasos em patologias experimentais. Papel do endotélio do qual participam o(s) ulunus Graziela Scalianti Ceravolo, Rosana Marangoni,Fernando Paranaiba Filgueira, Gisele Facholi Bomfim, Lueiana des Reis Rigueiral Giaquinto, Thiago Januário da Costa, Priscila Xavier de Araujo, Cynthia Echem de Souza Pereiru, Murilo Lombardo Lopes Pereira, està de acordo com os Principios Etscos de Experimentaçño Animal adotado pela Sociedade Brasileira de Ciencia de Animais de Laboranorio (SBCAL) e foi aprovado pela COMSSACO DE ETTCA NO USO DE ANMAAIS (CEUA) em 06.12.2010, com validade de 3 anos.

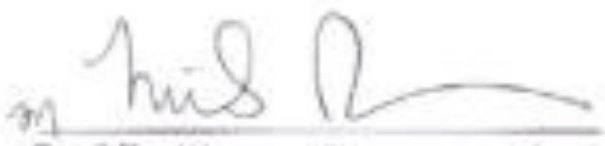

Prof Dr.Wotran Tavares de tima Coordenador CEUA - ICB/USP

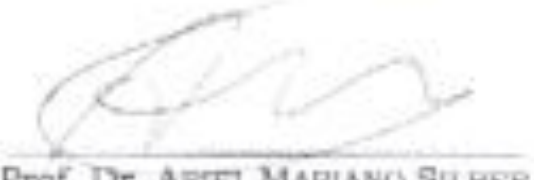

Prof. Dr. AnTEL MARIANoS SII.HFR Secretario-8uplente CEUA - ICB/USP 
Dedico este trabalho à minha esposa Núbia e à minha filha Clara, as minhas principais razões para persistir e prosseguir.

Dedico ainda aos meus pais e irmãos, por todo amor e incentivo. 


\section{AGRADECIMENTOS}

Agradeço especialmente à minha orientadora, Dra. Maria Helena C. Carvalho, por todos os valiosos ensinamentos e diversas oportunidades que possibilitaram a realização desses sonho, sonho de poder seguir com a carreira acadêmica.

À professora Dra. Zuleica Bruno Fortes, pelo exemplo de dedicação e de compromisso, além da convivência agradável durante os anos de pós-graduação.

À professora Dra. Rita de Cássia Tostes, pela excelente co-orientação prestada durante o período de estágio que realizei em seu laboratório na Georgia Health Sciences University.

À professora Dra. Eliana Hiromi Akamine, pelas contribuições diretas do meu desenvolvimento científico e pela amizade agradável.

Os meus mais profundos agradecimentos ao professor Dr. Clinton Webb (professor da Georgia Health Sciences University, Augusta, GA) pela confiança prestada durante o período de estágio que realizei em seu laboratório.

Aos amigos e técnicos do laboratório: Rosa, Cidora Manécas, Bazinha, Ritinha, Martinha e Antônio, pela grande amizade e auxílio prestados.

Aos meus amigos e colegas de laboratório, por terem me proporcionado tantos momentos felizes: Simone, Gisele, Gra Hagihara, Tiago, Eveline, Graziela Ceravolo, Bia, Vanessa, Rossana, Paula, Cíntia, Luciana, Murilo.

A todos os colegas dos Estados Unidos, em especial à Kênia, Hichan e Brandi e aos "velhos" amigos Fernando, Zidônia, Vitor e Fernanda, pela acolhida e momentos inesquecíveis que passamos juntos.

Às secretárias do departamento de Farmacologia, Selma, Julieta, Camila e Mônica, pelo auxílio com os assuntos burocráticos.

Agradeço também às agências de financiamento que proporcionaram o suporte financeiro para o desenvolvimento desta pesquisa: a Fundação de Amparo à Pesquisa do Estado de São Paulo (FAPESP) e o Conselho Nacional de Desenvolvimento Científico e Tecnológico (CNPq).

A todos aqueles que, embora não nomeados, me brindaram com seus inestimáveis apoios em distintos momentos e por suas presenças afetivas, o meu reconhecido e carinhoso MUITO OBRIGADO!!! 


\section{RESUMO}

Filgueira FP. Caracterização da resposta vasorelaxante do equilin em artérias mesentéricas de ratas espontaneamente hipertensas [tese (Doutorado em Farmacologia)]. São Paulo: Instituto de Ciências Biomédicas, Universidade de São Paulo; 2012.

As ações vasculares dos hormônios sexuais feminimos têm sido amplamente investigadas, entretanto, grande parte dos estudos utilizaram o 17ß-estradiol como alvo de investigação. O Premarin, medicamento utilizado na terapia de reposição hormonal há mais de 60 anos, contém pelo menos dez tipos de substâncias estrogênicas em sua composição, entretanto pouco se sabe sobre a ação vascular direta da maioria desses componentes, dentre os quais destaca-se o equilin, que representa cerca de $25 \%$ da composição do premarin. Deste modo, o objetivo deste estudo foi investigar a ação do equilin em artérias mesentéricas de resistência de ratas espontaneamente hipertensas, bem como o mecanismo envolvido neste efeito, comparando com 0 17 $\beta$-estradiol. Foram utilizadas ratas espontaneamente hipertensas (12 semanas de idade), ovariectomizadas 30 dias antes dos experimentos e seus respectivos controles (intactas). A reatividade de artérias mesentéricas de resistência foi avaliada utilizando miógrafo para estudo de tensão isométrica. Foram realizadas curvas concentração-efeito $(10 \mathrm{nM}-100 \mu \mathrm{M})$ ao equilin, ao $17 \beta$-estradiol, à estrona e ao $17 \alpha$-estradiol. Dentre estes compostos, apenas o equilin produziu resposta máxima vasodilatadora equivalente à do $17 \beta$-estradiol. Não houve diferença nas respostas promovidas pelos estrógenos entre ratas intactas e ovariectomizadas. O antagonista específico de receptores de estrógeno (ICl $182,780)$ não afetou o relaxamento ao equilin. De modo similar, este efeito não foi alterado pela incubação com inibidores da adenilato ciclase e da PKA. A resposta ao equilin não foi alterada pela remoção do endotélio ou pela incubação com inibidores da óxido nítrico sintase, da guanilato ciclase e da PKG. A indometacina ou a associação de indometacina e L-NAME não alterou a ação do equilin. Além disso, o relaxamento a este hormônio não foi alterado pela incubação com: tetraetilamônio (bloqueador inespecífico de canal de $\mathrm{K}^{+}$), caribdotoxina (bloqueador de canal de $\mathrm{K}^{+}$ de alta e intermediária condutância ativado por $\mathrm{Ca}^{2+}$ ) + apamina (bloqueador de canal de $\mathrm{K}^{+}$de baixa condutância ativado por $\mathrm{Ca}^{2+}$ ), iberiotoxina (bloqueador de canal de $\mathrm{K}^{+}$de alta condutância ativado por $\mathrm{Ca}^{2+}$ ), glibenclamida (bloqueador de canal de $\mathrm{K}^{+}$sensível ao ATP) ou 4-aminopiridina (bloqueador de canal de $\mathrm{K}^{+}$ dependente de voltagem). $O$ equilin promoveu vasorelaxamento em preparações pré-contraídas tanto com U46619 quanto com endotelina-1 ou com $\mathrm{KCl}$ indicando efeito vasodilatador via bloqueio do influxo de $\mathrm{Ca}^{2+}$ por canais operados por voltagem ou por receptor. De fato, a incubação com equilin diminuiu a contração ao $\mathrm{Ca}^{2+}$, assim como ao BAY K 8644, ativador de canais de $\mathrm{Ca}^{2+}$ do tipo-L, porém, não modificou a contração à cafeína (que promove liberação de $\mathrm{Ca}^{2+}$ do retículo sarcoplasmático). Demonstramos com este estudo que o efeito vasorelaxante do equilin em artérias mesentéricas de ratas espontanemente hipertensas se deve predominantemente ao bloqueio de canais de $\mathrm{Ca}^{2+}$ do tipo $\mathrm{L}$.

Palavras-chave: Equilin. Artérias mesentéricas de resistência. Efeito vasorelaxante. Ratas espontaneamente hipertensas. 


\begin{abstract}
Filgueira FP. Characterization of vasorelaxant response to equilin in mesenteric arteries from spontaneously hypertensive rats. [Ph. D. thesis (Pharmacology)]. São Paulo: Instituto de Ciências Biomédicas, Universidade de São Paulo; 2012.

The vascular actions of female sex hormones have been widely explored; however, most of these studies have used $17 \beta$-estradiol as the choice drug for investigation. Premarin is a preparation used in postmenopausal hormone replacement therapy for over sixty years. At least ten types of estrogen compounds have been identified in Premarin, however, little is known about the direct vascular action of the majority of its components, among which, equilin stands out, representing $25 \%$ of Premarin composition. Based on these observations, the aim of the present study was to investigate the effects of equilin in mesenteric resistance arteries from female hypertensive rats. Mechanisms contributing to equilin-induced effects were determined, comparing with the vascular effects induced by $17 \beta$-estradiol. 12 weekold female spontaneously hypertensive rats (ovariectomized 30 days before initiation of the experimental protocols) and their counterparts (intact) were used. Vascular reactivity was evaluated in a myograph for isometric tension recording. Concentration-response curves $(10 \mathrm{nM}-100 \mu \mathrm{M})$ to equilin, $17 \beta$-estradiol, estrone and $17 \alpha$-estradiol were performed. Among these compounds, only equilin evoked a maximal relaxation response equivalent to that of $17 \beta$-estradiol. There was no difference in the responses evoked by the estrogen compounds between intact and ovariectomized rats. The estrogen receptor antagonist (ICI 182,780) failed to inhibit equilin-induced relaxation. Similarly, this effect was not affected by incubation with inhibitors of adenylyl cyclase and protein kinase A. Equilin response was not altered by endothelium removal or by incubation with inhibitors of eNOS, guanylate cyclase and protein kinase $\mathrm{G}$. Indomethacin or the association of indomethacin plus L-NAME did not alter equilin-induced effects. Furthermore, the relaxation to this hormone was not altered after incubation with: tetraethylammonium (a non-selective $\mathrm{K}^{+}$channel blocker); charybdotoxin (a large and intermediate conductance $\mathrm{Ca}^{2+}$-activated $\mathrm{K}^{+}$ channel blocker), glibenclamide (an ATP-dependent $\mathrm{K}^{+}$channel blocker) or 4aminopyridine (a voltage-dependent $\mathrm{K}^{+}$channel blocker). Equilin evoked relaxation in preparations pre-constricted with $\mathrm{U} 46619$ and also with $\mathrm{ET}-1$ or $\mathrm{KCl}$, indicating a vasodilator effect via blockade of $\mathrm{Ca}^{2+}$ influx from both voltage-operated $\mathrm{Ca}^{2+}$ channels and receptor-operated $\mathrm{Ca}^{2+}$ channels. In fact, equilin incubation reduced contraction induced by both $\mathrm{Ca}^{2+}$ and Bay K 8644, an L-type Ca2+ channel activator. However, equilin was unable to alter caffeine-induced contraction (via $\mathrm{Ca}^{2+}$ release from the intracellular stores). We have demonstrated in the present study that equilin vasorelaxant effect in mesenteric arteries from female spontaneously hypertensive rats occurs predominantly due to blockade of L-type $\mathrm{Ca}^{2+}$ channels.
\end{abstract}

Keywords: Equilin. Resistance mesenteric arteries. Vasorelaxant effect. Spontaneously hypertensive rat. 


\section{LISTA DE ILUSTRAÇÕES}

Figura 1 - Preparação em miógrafo para vasos de resistência isolados .................2 27

Figura 2 - Ilustração do procedimento de normalização ........................................ 28

Figura 3 - Peso relativo do útero seco de ratas intactas e ovariectomizadas .......... 33

Figura 4 - Resposta relaxante do equilin, do 17 $\beta$-estradiol, do $17 \alpha$-estradiol e da estrona em artérias mesentéricas de ratas intactas e ovariectomizadas ...................36 Figura 5 - Resposta relaxante do equilin e do $17 \beta$-estradiol em artérias mesentéricas de ratas intactas e ovariectomizadas incubadas com ICI 182,780...... 38 Figura 6 - Resposta relaxante do equilin e do 17ß-estradiol em artérias mesentéricas de ratas intactas incubadas com SQ 22536 ou KT 5720

Figura 7 - Resposta relaxante do equilin e do $17 \beta$-estradiol em artérias mesentéricas com ou sem endotélio de ratas intactas .......................................... 42 Figura 8 - Resposta relaxante do equilin e do $17 \beta$-estradiol em artérias mesentéricas de ratas intactas incubadas com L-NAME, ODQ ou KT 5823............. 44 Figura 9 - Resposta relaxante do equilin e do 17ß-estradiol em artérias mesentéricas de resistência de ratas intactas incubadas indometacina ou indometacina + L-NAME 46

Figura 10 - Resposta relaxante do equilin e do 17ß-estradiol em artérias mesentéricas de ratas intactas incubadas com bloqueadores dos canais de $\mathrm{K}^{+} \ldots . . .48$ Figura 11 - Resposta relaxante do equilin e do 17ß-estradiol em artérias mesentéricas de ratas intactas pré-contraídas com U46619, endotelina -1 ou cloreto de potássio

Figura 12 - Curvas concentração-efeito ao cloreto de cálcio em artérias mesentéricas de ratas intactas incubadas com equilin ou $17 \beta$-estradiol. 52 Figura 13 - Curvas concentração-efeito ao (S)-(-)-Bay K 8644 em artérias mesentéricas de ratas intactas incubadas com equilin ou $17 \beta$-estradiol. 54 Figura 14 - Resposta contrátil induzida pela cafeína em artérias mesentéricas de ratas intactas incubadas com equilin ou $17 \beta$-estradiol 56 


\section{LISTA DE TABELAS}

Tabela 1 - Massa corpórea de ratas intactas e ovariectomizadas 32

Tabela 2 - Diâmetro luminal efetivo das artérias mesentéricas de resistência de ratas intactas e ovariectomizadas 34

Tabela 3 - Contração ao cloreto de potássio em artérias mesentéricas de resistência de ratas intactas e ovariectomizadas 35

Tabela 4 - Resposta relaxante do equilin, do 17ß-estradiol, do 17a-estradiol e da estrona em artérias mesentéricas de ratas intactas e ovariectomizadas

Tabela 5 - Resposta relaxante do equilin e do 17ß-estradiol em artérias mesentéricas de ratas intactas e ovariectomizadas incubadas com ICI 182,780...... 39 Tabela 6 - Resposta relaxante do equilin e do 17ß-estradiol em artérias mesentéricas de ratas intactas incubadas com SQ 22536 ou KT 5720

Tabela 7 - Resposta relaxante do equilin e do 17ß-estradiol em artérias mesentéricas com e sem endotélio de ratas intactas

Tabela 8 - Resposta relaxante do equilin e do 17ß-estradiol em artérias mesentéricas de ratas intactas incubadas com L-NAME, ODQ ou KT 5823

Tabela 9 - Efeito da incubação com Indometacina ou Indometacina e L-NAME sobre o efeito relaxante do equilin e do $17 \beta$-estradiol em artérias mesentéricas de ratas intactas

Tabela 10 - Resposta relaxante do equilin e do 17ß-estradiol em artérias mesentéricas de ratas intactas incubadas com bloqueadores dos canais de $\mathrm{K}^{+}$

Tabela 11 - Resposta relaxante do equilin e do 17ß-estradiol em artérias mesentéricas de ratas intactas pré-contraídas com U46619, endotelina -1 ou cloreto de potássio.

Tabela 12 - Curvas concentração-efeito ao cloreto de cálcio em artérias mesentéricas de ratas intactas incubadas com equilin ou $17 \beta$-estradiol 53

Tabela 13 - Curvas concentração-efeito ao (S)-(-)-Bay K 8644 em artérias mesentéricas de ratas intactas incubadas com equilin ou $17 \beta$-estradiol.

Tabela 14 - Resposta contrátil induzida pela cafeína em artérias mesentéricas de ratas intactas incubadas com equilin ou $17 \beta$-estradiol 


\section{LISTA DE ABREVIATURAS E SIGLAS}

4-AP 4-Aminopiridina

AMPc Monofosfato de Adenosina Cíclico

ANOVA Análise de Variância

ATP Trifosfato de Adenosina

$\mathrm{Ca}^{2+} \quad$ Cálcio

$\mathrm{CaCl}_{2} \quad$ Cloreto de Cálcio

CEE Conjugated Estrogenic Equine (Estrogênios Conjugados Equinos)

CEUA Comissão de Ética no Uso de Animais

ChTX Caribdotoxina

$\mathrm{CO}_{2} \quad$ Dióxido de Carbono

COBEA Colégio Brasileiro de Experimentação Animal

COX Ciclooxigenase

DCV Doença Cardiovascular

DES Dietilestilbestrol

E+ Com Endotélio Intacto

E- $\quad$ Com Endotélio Removido

$\mathrm{EC}_{50} \quad$ Concentração que promove $50 \%$ da resposta máxima

EDTA Ácido Etilenodiamino Tetra-Acético

EGFR Receptor do Fator de Crescimento Epidermal

EGTA Ácido Etilenoglicol Tetra-Acético

eNOS Óxido Nítrico Sintase endotelial

epm Erro Padrão da Média

ER Receptores Estrogênicos

ERE Elementos Responsivos ao Estrógeno

FE Fenilefrina

g Gramas

GHSU Georgia Health Sciences University

GMPc Monofosfato de Guanosina Cíclico

GPER Receptor de Estrógeno Acoplado a Proteína G

HA Hipertensão Arterial

HERS Heart and Estrogen/Progestin Replacement Study

HSP Heat Shock Protein (Proteína de Choque Térmico) 


\begin{tabular}{|c|c|}
\hline $\mathrm{lbTX}$ & Iberiotoxina \\
\hline IC & Circunferência Interna \\
\hline ICB & Instituto de Ciências Biomédicas \\
\hline $\mathrm{K}^{+}$ & Potássio \\
\hline $\mathrm{KCl}$ & Cloreto de Potássio \\
\hline $\mathrm{KH}_{2} \mathrm{PO}_{4}$ & Fosfato de Potássio Monobásico \\
\hline L-NAME & $\mathrm{N} \omega$-nitro-L-arginine methyl ester (Éster de N-metil-L-arginina) \\
\hline $\mathrm{mg}$ & Miligrama \\
\hline $\mathrm{MgSO}_{4}$ & Sulfato de Magnésio \\
\hline MLC & Cadeia Leve de Miosina \\
\hline $\mathrm{mmHg}$ & Milímetro de Mercúrio \\
\hline $\mathrm{NaCl}$ & Cloreto de Sódio \\
\hline $\mathrm{NaHCO}_{3}$ & Bicarbonato de Sódio \\
\hline NO & Óxido Nítrico \\
\hline $\mathrm{O}_{2}$ & Oxigênio \\
\hline ODQ & 1H-[1,2,4]-oxadiazole-[4,3- $\alpha]$-quinoxalin-1-one \\
\hline PA & Pressão Arterial \\
\hline $\mathrm{pD}_{2}$ & Logaritmo negativo da $\mathrm{EC}_{50}$ \\
\hline PEPI & Postmenopausal Estrogen/Progestin Intervention \\
\hline PKA & Proteína Quinase A \\
\hline PKG & Proteína Quinase G \\
\hline $\mathrm{R}_{\mathrm{MAX}}$ & Resposta máxima \\
\hline ROCCs & Canais de Cálcio Operados por Receptor \\
\hline SERMS & Moduladores Seletivos de Receptores Estrogênicos \\
\hline SHR & Ratos Espontaneamente Hipertensos \\
\hline TEA & Tetraetilamônio \\
\hline TRE & Terapia de Reposição Estrogênica \\
\hline TRH & Terapia de Reposição Hormonal \\
\hline USP & Universidade de São Paulo \\
\hline VOCCs & Canais de Cálcio Operados por Voltagem \\
\hline WHI & Women's Health Initiative \\
\hline
\end{tabular}


1 INTRODUÇÃO

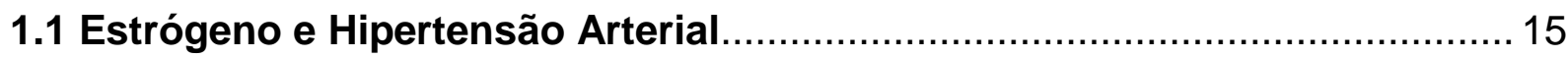

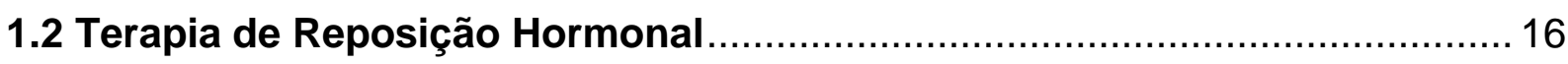

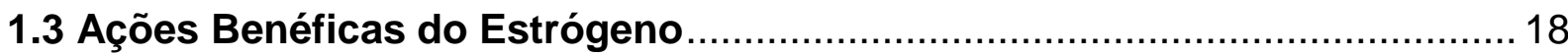

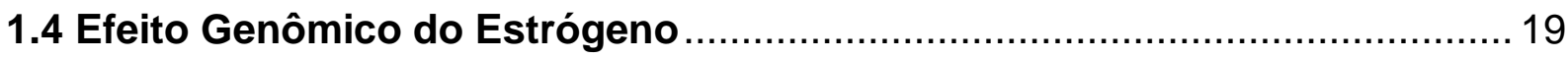

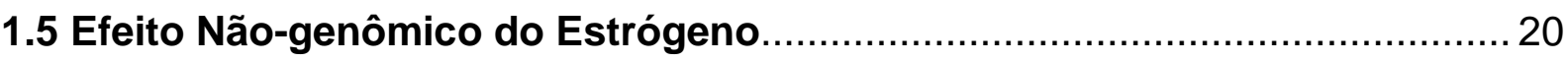

1.6 Ação Vascular Direta de Diferentes Estrógenos ...................................... 22

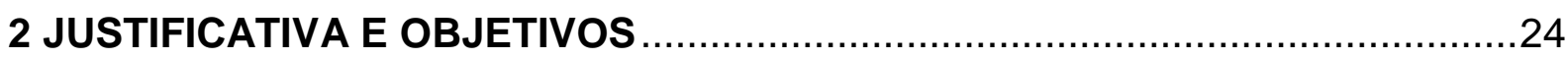

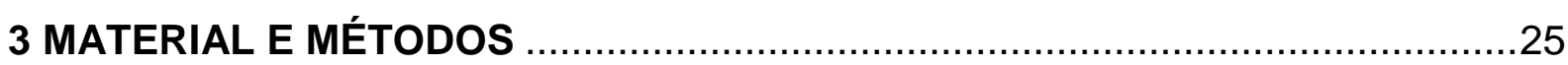

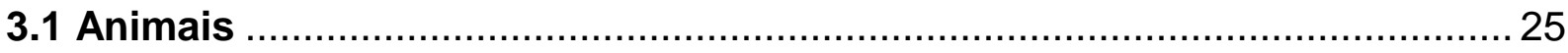

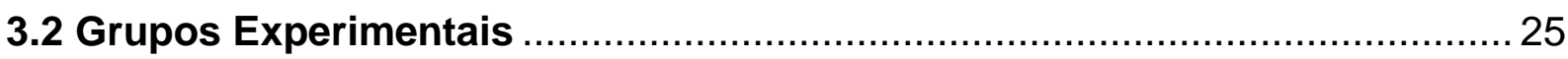

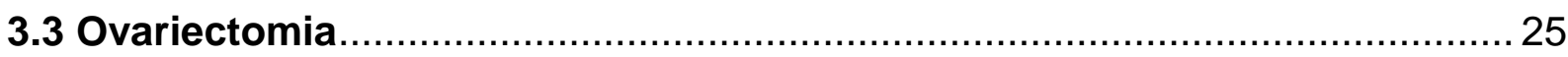

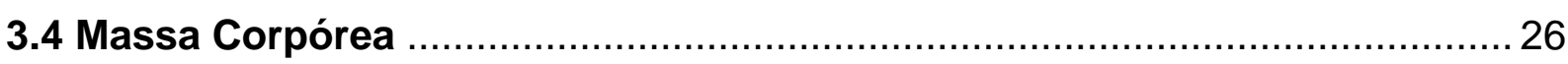

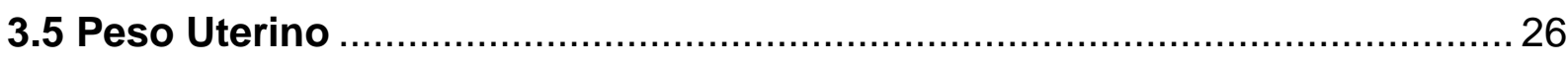

3.6 Reatividade Vascular em Artérias Mesentéricas de Resistência ................. 26

3.6.1 Normalização das artérias de resistência........................................................ 27

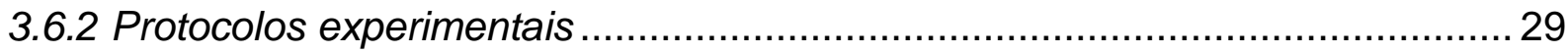

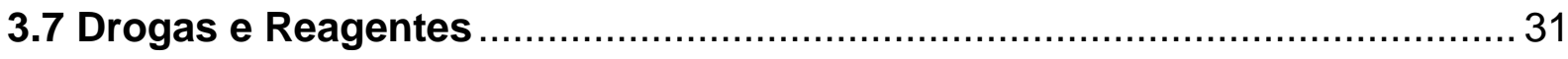

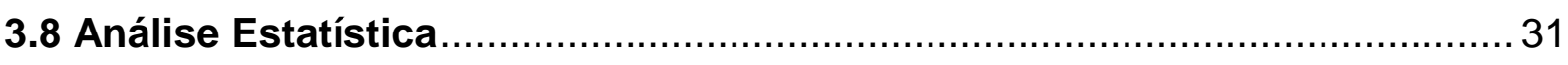

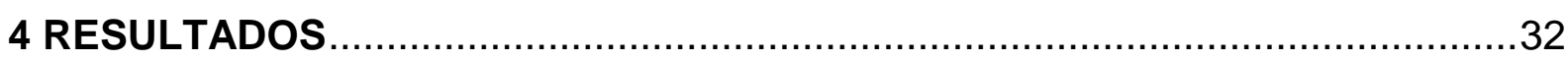

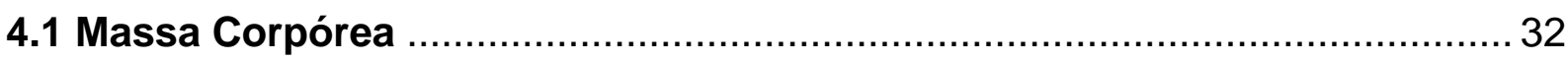

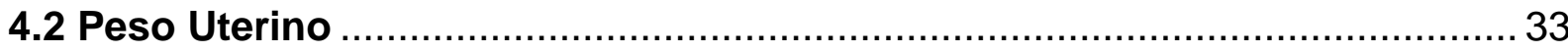

4.3 Medida do Diâmetro Luminal Efetivo das Artérias Mesentéricas de

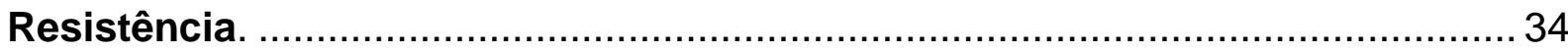

4.4 Avaliação da Contração ao Cloreto de Potássio em Artérias Mesentéricas

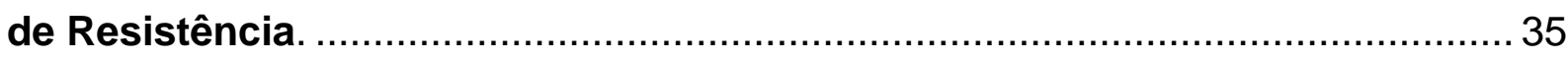

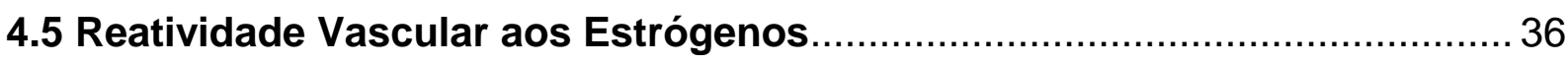

4.6 Participação dos Receptores Estrogênicos no Efeito Vasorelaxante do

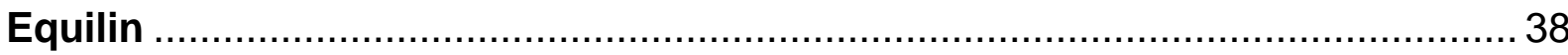

4.7 Participação da Via Adenilato Ciclase/Proteína Quinase A no Efeito

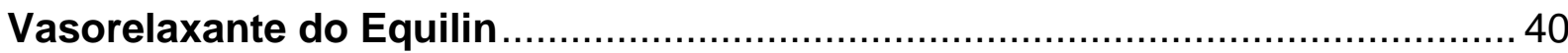

4.8 Participação do Endotélio no Efeito Vasorelaxante do Equilin ..................... 42 
4.9 Participação da Via Óxido Nítrico/Guanilato Ciclase/Proteína Quinase G no

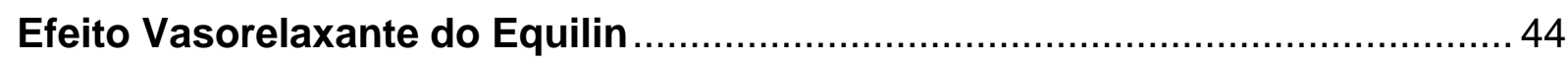

4.10 Participação dos Prostanóides no Efeito Vasorelaxante do Equilin .......... 46

4.11 Efeito do Equilin sobre os Canais de Potássio ......................................... 48

4.12 Efeito Vasorelaxante do Equilin Frente a Diferentes Agentes Pré-

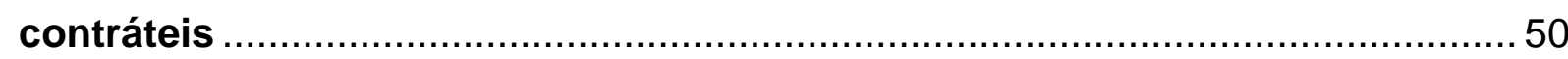

4.13 Efeito do Equilin sobre os Canais de Cálcio.............................................. 52

4.14 Efeito do Equilin sobre os Canais de Cálcio do Tipo-L …....................... 54

4.15 Efeito do Equilin Sobre a Liberação de Cálcio do Retículo

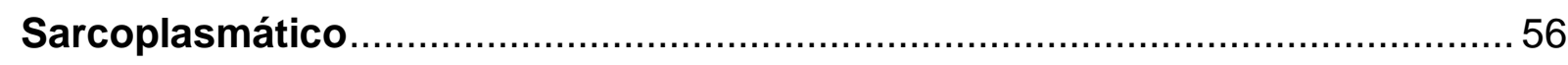

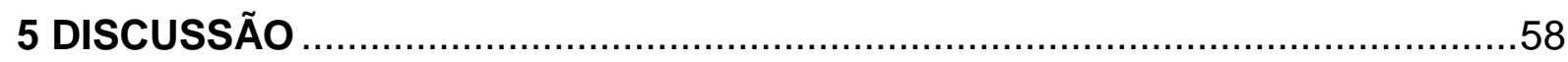

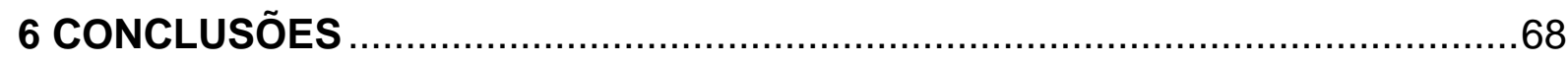

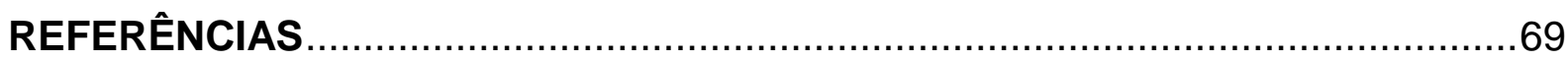

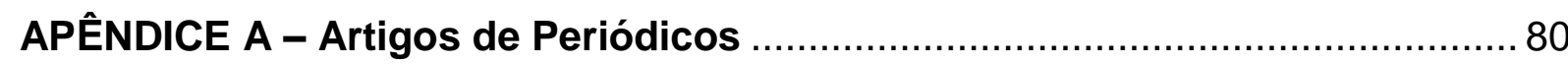




\section{INTRODUÇÃO}

O hormônio sexual feminino estrógeno tem seu nome derivado da palavra "oistros" que significa "desejo louco", e do sufixo "-gen" que significa "que produz"1. Há mais de um século, havia indícios de que a função vascular periférica poderia ser influenciada por "efeitos maléficos" provenientes do aparelho reprodutor feminino. Deste modo, as primeiras investigações relacionadas aos efeitos farmacológicos do estrógeno foram cercadas de expectativas um tanto temerosas. Entretanto, a compreensão das ações deste hormônio cresceu de maneira substancial, diminuindo consideravelmente estes conceitos temerosos frente à terapia com estrogênio exógeno, principalmente em relação aos efeitos colaterais. Neste sentido, dados apontados por Richard White $(2002)^{2}$ mostram que o número de trabalhos investigando o efeito cardioprotetor do estrógeno era de apenas 100 entre os anos de 1900 e 1975. Esse número foi dez vezes maior entre os anos de 2000 e 2001. Como ressalta muito bem este autor, é evidente que o estudo dos efeitos do estrógeno sobre a função vascular será por muito tempo um dos principais alvos de investigação da área cardiovascular, com o objetivo de compreender de modo seguro o potencial benefício deste hormônio na terapia de reposição hormonal $(\mathrm{TRH})$.

\subsection{Estrógeno e Hipertensão Arterial}

A hipertensão arterial (HA) é definida como uma doença de etiologia multifatorial que se caracteriza por níveis elevados e sustentados de pressão arterial (PA), com a PA sistólica igual ou superior a $140 \mathrm{mmHg}$ e a diastólica igual ou superior a $90 \mathrm{mmHg}$. Esta doença é a causa mais frequente de morbidade e mortalidade por doença cardiovascular (DCV), sendo responsável por uma a cada três mortes em todo o mundo. De acordo com dados do ano de 2000, a prevalência global de HA foi de aproximadamente 1 bilhão de pessoas, e para 2025, estima-se que mais de 1,5 bilhão de adultos serão hipertensos ${ }^{3}$.

Estudos epidemiológicos e clínicos demonstraram de maneira evidente a menor prevalência de HA em mulheres no período fértil quando comparadas aos homens de mesma idade. Após a menopausa, período de queda abrupta dos níveis de hormônios sexuais femininos, ocorre um aumento no número de mulheres 
hipertensas ${ }^{4}$. Além disso, mulheres cirurgicamente menopausadas apresentam maior incidência de DCVs quando na ausência de reposição hormonal ${ }^{5}$. Em conjunto, estas observações tornam evidente a importância do estrógeno na saúde da mulher como hormônio protetor contra DCVs.

Pesquisas experimentais com diferentes modelos de HA como, por exemplo, ratos espontaneamente hipertensos $(\mathrm{SHR})^{6}$, ratos DOCA-sal ${ }^{7}$, ratos Dahl salsensível $^{8}$ e ratos geneticamente hipertensos New Zealand ${ }^{9}$, demonstram também que fêmeas apresentam níveis pressóricos reduzidos em comparação aos machos de mesma idade. Nesses modelos, sugere-se que os hormônios sexuais femininos podem proteger contra as complicações da HA. De fato, dados de nosso laboratório confirmaram esses achados utilizando os modelos SHR e DOCA-sal, e demonstraram um agravamento da HA em fêmeas ovariectomizadas, elevando a PA a níveis semelhantes aos observados em machos. O tratamento hormonal com $17 \beta$ estradiol corrigiu a PA para níveis semelhantes aos encontrados em fêmeas falsooperadas $^{10-11}$.

\subsection{Terapia de Reposição Hormonal}

Por muitos anos, tem sido sugerido que a TRH pode proporcionar proteção contra DCVs em mulheres na pós-menopausa. A maioria dos estudos indica que mulheres no período pós-menopausa que fazem uso de alguma forma de TRH apresentam redução de $30-50 \%$ do risco de mortalidade cardiovascular ${ }^{12-16}$. Por outro lado, é importante mencionar resultados obtidos em estudos clínicos mais recentes, incluindo o Heart and Estrogen/Progestin Replacement Study (HERS) e o Women's Health Initiative (WHI), os quais levantaram dúvidas a respeito dos efeitos protetores do estrógeno sobre o sistema cardiovascular. Nestes estudos, a TRH não reduziu o risco de eventos vasculares em mulheres na pós-menopausa ${ }^{17-18}$.

O HERS, um estudo clínico randomizado, avaliou a eficácia da associação de estrogênios conjugados equinos ( $\mathrm{CEE}$ - conjugated estrogenic equine) com acetato de medroxiprogesterona na prevenção secundária de doenças coronarianas em pacientes com coronariopatia prévia. Os resultados mostraram uma tendência de aumento de eventos coronarianos e um aumento significativo de eventos tromboembólicos venosos no primeiro ano do estudo no grupo de mulheres que faziam uso da $\mathrm{TRH}^{17}$. No seguimento deste estudo (HERS II), os resultados 
mostraram que a TRH não deve ser utilizada por mulheres na pós-menopausa para reduzir o risco de eventos cardiovasculares ${ }^{19}$.

O WHI, realizado em 2002, foi um dos estudos mais discutidos em sociedades de ginecologistas de todo o mundo. Este estudo tinha como um de seus objetivos avaliar o efeito da TRH na prevenção primária de DCV, diferentemente do HERS, que avaliou a prevenção secundária. Neste estudo, as pacientes receberam o mesmo esquema terapêutico utilizado no HERS e os resultados indicaram incidência superior (29\%) de eventos cardiovasculares em mulheres que receberam o tratamento hormonal ${ }^{18}$. Em 2004, foram publicados outros resultados do estudo WHI que avaliou o uso isolado de CEE em mulheres na pós-menopausa e histerectomizadas. Os resultados mostraram que 0 uso isolado de estrogênios conjugados nessas mulheres promoveu redução de quatro eventos coronarianos/ano para cada dez mil mulheres. Entretanto, uma vez que não se observou diferença significativa entre os grupos estudos, a conclusão deste estudo foi que o CEE não deve ser recomendado para prevenção de DCV em mulheres na pós-menopausa ${ }^{20}$.

É importante destacar que estes estudos sofrem críticas em relação a alguns aspectos, dentre estes, a seleção das pacientes, que incluiu mulheres com idade em média uma década superior àquelas em que normalmente a TRH é recomendada. Além disso, como mencionado, essas mulheres apresentavam fatores de risco para as complicações observadas ${ }^{21}$. Evidências de estudos em primatas ${ }^{22}$ e em outros modelos animais ${ }^{23-24}$ indicam que os efeitos benéficos da TRH na prevenção da aterosclerose ocorrem somente se a terapia for iniciada antes do seu desenvolvimento. Considerando que as complicações cardiovasculares clínicas geralmente apresentam-se por volta dos 65 anos de idade ${ }^{25}$ e que esses estudos alocaram pacientes em sua maioria com idade acima de 60 anos, é aceitável considerar que durante o período inicial da pós-menopausa exista uma "janela de oportunidade", momento em que a TRH pode conferir cardioproteção ${ }^{26}$. Esta crítica comentada, juntamente com outras ${ }^{27}$, demonstram possíveis pontos falhos na interpretação final destes estudos que concluíram ausência de efeitos cardiovasculares benéficos com a TRH.

Assim, permanecem controversos os verdadeiros efeitos promovidos pela TRH sobre os riscos cardiovasculares no período da pós-menopausa, tornando-se indispensável a realização de novos estudos, tanto clínicos quanto experimentais. 
Uma ampla variedade de terapias de reposição estrogênica (TRE) e TRH (estrógeno e progesterona) está disponível. As formulações estrogênicas utilizadas na terapia hormonal contêm formas distintas de estrógeno obtidas de fontes animais (naturais) ou quimicamente modificadas (sintéticas). As únicas preparações verdadeiramente "naturais" são os fitoestrógenos e o CEE, sendo este último extensivamente utilizado para TRE, isoladamente, ou associado à progesterona.

Uma importante consideração que se faz necessária em relação aos estudos comentados (HERS e WHI), é o fato de ambos utilizarem o Premarin como o medicamento de escolha para TRH. O Premarin é um CEE que contém pelo menos 10 tipos de estrógenos quimicamente diferentes, sendo um dos medicamentos mais prescritos nos Estados Unidos para mulheres na menopausa ${ }^{28}$. A porcentagem de distribuição dos 10 componentes estrogênicos descritos no Premarin é: estrona (48\%); equilin (24\%); 17ß-dihidroequilin (15\%); delta8,9-dehidroestrona (4,3\%); 17aestradiol (3,8\%); 17a-dihidroequilin (1,8\%); equilenin $(1,1 \%) ; 17 \beta$-estradiol $(0,68 \%)$; $17 \alpha$-dihidroequilenin $(0,45 \%)$ e $17 \beta$-dihidroequilenin $(0,3 \%)^{29}$.

Apesar do Premarin ser utilizado na clínica há mais de 60 anos, pouco se sabe sobre a ação vascular individual de seus componentes. A literatura está repleta de trabalhos que investigaram a ação vascular de diversos hormônios estrogênicos, dentre estes o principal é o 17ß-estradiol. Entretanto, há poucos estudos que investigaram o efeito vascular do equilin, hormônio este responsável por aproximadamente $25 \%$ da composição do Premarin.

\subsection{Ações Benéficas do Estrógeno}

O estrógeno atua em diversos sistemas do organismo. De importância para o presente estudo, destaca-se a ação deste hormônio influenciando diretamente a função vascular ${ }^{30-31}$. O estrógeno exerce efeito regulador sobre a estrutura vascular, inibindo a proliferação de células do músculo liso vascular ${ }^{32}$. A proliferação de células endoteliais após lesão encontra-se aumentada depois do tratamento das mesmas com estrógeno, sendo demonstrado em experimentos realizados in vitro ${ }^{33} \mathrm{e}$ in vivo ${ }^{33-34}$. Foi demonstrado também que o processo apoptótico da célula endotelial humana é inibido pelo tratamento com este hormônio ${ }^{35}$. Além disso, o estrógeno reduz a adesão leucocitária sobre as células endoteliais e a migração 
transendotelial, inibindo a expressão de moléculas de adesão induzidas por citocinas inflamatórias ${ }^{36-37}$.

Um importante avanço da ciência para o entendimento das ações vasculares do estrógeno foi a descoberta dos receptores estrogênicos (ERs - estrogen receptors) denominados $\mathrm{ERa}^{38}$ e ER $\beta^{39}$. Estes receptores foram caracterizados tanto nas células endoteliais quanto nas células musculares lisas vasculares de humanos $^{40-41}$ e de ratos ${ }^{42-43}$. A partir dessas descobertas, surgiu um desafio aos pesquisadores de entender o papel funcional desses subtipos de receptores e o impacto dos mesmos sobre a fisiologia e fisiopatologia vascular.

Além dos receptores nucleares clássicos, recentemente novos receptores foram descritos, como o ER-X, um receptor de estrógeno associado à membrana plasmática e cujo papel nas ações dos estrógenos ainda não foi investigado ${ }^{44}$. Outra proteína de membrana caracterizada recentemente e nomeada inicialmente de GPR30 (um receptor acoplado à proteína $\mathrm{G}$ ) tem sido descrita como mediador das ações estrogênicas ${ }^{45}$.

Outro efeito estrogênico bastante investigado é a influência desses hormônios sobre o perfil lipídico. O estrógeno reduz os níveis de colesterol LDL e aumenta os níveis de colesterol HDL em aproximadamente 15\%, porém, aumenta também os níveis de triglicérides em cerca de $20 \%$, efeitos estes proporcionais à dose utilizada no tratamento ${ }^{46-47}$. Além disso, foi demonstrado o efeito da TRH com estrógeno sobre a tolerância à glicose, a sensibilidade insulínica, a massa corpórea e a distribuição de gordura. $O$ estudo randomizado PEPI (Postmenopausal Estrogen/Progestin Intervention), realizado durante 3 anos, demonstrou 0 efeito benéfico da THR em reduzir os níveis séricos de insulina (-16\%) e as concentrações de glicose $(-2 \mathrm{mg} / \mathrm{dL})$. Além deste, outros estudos ${ }^{48-50}$ mostram ainda que a TRH promove diminuição da massa corpórea e da distribuição de gordura, reduzindo ainda o risco de desenvolvimento de diabetes tipo 2. Estima-se que 25 a $30 \%$ da proteção cardiovascular atribuída ao estrógeno seja promovida pelos efeitos comentados acima.

\subsection{Efeito Genômico do Estrógeno}

Os efeitos do estrógeno podem ser classificados como: efeito transcricional clássico ou genômico e efeito extranuclear ou não-transcricional, também 
denominado de não-genômico. Os efeitos genômicos dos estrogenos são mediados pelos ERs, os quais pertencem à superfamília de receptores nucleares, que são fatores de transcrição regulados por ligantes. Estes receptores, localizados preferencialmente no citoplasma, formam um complexo com proteínas de choque térmico (HSPs - heat shock protein). A ligação com o estrógeno dissocia os receptores deste complexo e induz a formação de homodímeros que se dirigem ao núcleo onde se ligam aos elementos responsivos ao estrógeno (ERE - estrogen response element) que estão localizados na região promotora dos genes a serem transcritos. Finalmente, com a contribuição de co-ativadores e outros fatores de transcrição ${ }^{51}$, o complexo hormônio-receptor promoverá a transcrição de genes alvos $^{52-53}$.

A modulação da função vascular pelos estrógenos pode envolver efeitos genômicos. Neste sentido, a grande importância da modulação da reatividade vascular exercida pelo estrógeno, no que tange aos efeitos a longo prazo, é a regulação da transcrição do gene que codifica a síntese da enzima óxido nítrico sintase endotelial (eNOS), demonstrada em trabalhos in vitro ${ }^{54}$ e in vivo ${ }^{55}$. Outros genes que codificam substâncias relacionadas à regulação do tônus vascular e que também podem sofrer influência do hormônio feminino são os genes da ciclooxigenase $-1^{56}$, da prostaglandina $\mathrm{H}$ sintase ${ }^{57}$ e da endotelina- $1^{58}$.

\subsection{Efeito Não-genômico do Estrógeno}

Além do efeito clássico sobre a transcrição gênica, estudos têm demonstrado que o ER estão envolvidos em um efeito vascular rápido do estrógeno, denominado efeito não-genômico. É importante mencionar que esse efeito ocorre de maneira independente da transcrição gênica, ou seja, ocorre em questão de segundos ou minutos, diferentemente da ação genômica que necessita de algumas horas ${ }^{59}$.

A resposta celular rápida do estrógeno está também associada com receptores de superfície celular, incluindo os receptores do fator de crescimento epidermal (EGFRs - epidermal growth factor receptors); com receptores acoplados a proteína G; e também estão ligados a vias de sinalização incluindo a mobilização de cálcio, a ativação de quinases e a produção de óxido nítrico ${ }^{60}$. Desse modo, estudos demonstraram que esta ação não-genômica do estrógeno mediada via receptor e independente da transcrição gênica, está associada à ativação da eNOS através de 
diferentes vias de sinalização como MAP quinases ${ }^{61-62}$ e a via $\mathrm{Pl}_{3}-\mathrm{K} / \mathrm{Akt}^{63-65}$, resultando na geração de óxido nítrico. Considerando que a disfunção endotelial é considerada um dos principais componentes das doenças cardiovasculares e, associado ao fato da eNOS ser uma enzima vital na manutenção da integridade das células endoteliais, a regulação da mesma torna-se um evento importante na compreensão dos mecanismos envolvidos na proteção vascular promovida pelo estrógeno.

Como comentado anteriormente, a caracterização do GPR30, agora denominado GPER (receptor de estrógeno acoplado a proteína G), criou novas oportunidades de estudo sobre o modo de ação não-genômica promovido pelos hormônios femininos. Trabalhos recentes demonstraram a ação vasodilatadora direta do G1 (agonista do GPER) em artérias coronárias de porcos ${ }^{66-67}$. Além disso, demonstrou-se que a infusão deste agonista promove redução da pressão arterial em ratos Sprague-Dawley. Em artérias mamárias de humanos, a resposta relaxante induzida pelo $G 1$ demonstrou ser superior àquela promovida pelo $17 \beta$-estradiol ${ }^{68}$. Embora a ampla expressão do GPER em artérias tenha sido descrita por estudos recentes ${ }^{69}$, o papel deste receptor na regulação da homeostase vascular ainda não se encontra totalmente elucidado.

Dentre as ações não-genômicas, existem também as ações que ocorrem de maneira independente de receptores, principalmente aquelas decorrentes da regulação de fluxo iônico. O estado contrátil das células musculares lisas é determinado pela diferença de potencial elétrico da membrana celular, gerada pela regulação dinâmica de fluxo iônico de potássio, cálcio e sódio através de canais iônicos específicos. Dados da literatura demonstraram que o efeito vasorelaxante do estrógeno envolve o bloqueio de canais de cálcio na membrana plasmática de células do músculo liso vascular, levando à redução de cálcio intracelular e consequente dilatação dos vasos sanguíneos. Embora a natureza molecular dos canais de cálcio envolvidos na resposta estrogênica não tenha sido elucidada, esses estudos demonstraram que o estrógeno reduz o influxo de cálcio e/ou estimula o efluxo deste íon ${ }^{70-71}$. Além disso, embora apenas um estudo tenha demonstrado o efeito do estrógeno em bloquear a liberação de cálcio do retículo endoplasmático ${ }^{72}$, outros encontraram que a ação vasorelaxante do estrógeno não envolve efeito significante sobre a liberação de cálcio intracelular ou sobre a sensibilidade do aparato contrátil ${ }^{70,73}$. 
Outro mecanismo pelo qual o estrógeno promove seu efeito vasodilatador se dá através da abertura de canais de potássio ativados por cálcio e sensíveis à voltagem, levando à hiperpolarização de células do músculo liso vascular ${ }^{74}$. Estes mecanismos comentados, dentre outros, evidenciam os efeitos independentes do endotélio, promovidos por este hormônio, sobre a reatividade vascular.

\subsection{Ação Vascular Direta de Diferentes Estrógenos}

Não há dúvidas de que grande parte dos estudos avaliando o efeito vasodilatador dos estrógenos utilizem o 17ß-estradiol como principal alvo de investigação, uma vez que ele é considerado o hormônio feminino mais potente e presente em maior concentração na circulação. Além do $17 \beta$-estradiol, diversos outros estrógenos foram e estão sendo investigados com o objetivo de se compreender melhor a ação vascular dos mesmos e, consequentemente, o potencial benefício cardioprotetor, uma vez que estes efeitos podem se diferenciar conforme o composto estrogênico investigado.

Trabalhos que investigaram o efeito vasodilatador de outros compostos estrogênicos, utilizaram o 17ß-estradiol como controle do estudo. Naderali et al. $(1999)^{75}$, avaliando a ação do $17 \alpha$-estradiol, um estereoisômero do $17 \beta$-estradiol e presente em pequenas concentrações na circulação de mamíferos, demonstraram uma ação vasorelaxante semelhante à do $17 \beta$-estradiol. Compostos sintéticos como dietilestilbestrol (DES), também apresentam efeito vasorelaxante, e foi demonstrado que em artérias coronárias este hormônio sintético foi mais potente que o $17 \beta$ estradiol $^{76}$. Outro hormônio feminino amplamente utilizado nas $\mathrm{TRH}$ é a progesterona $^{17}$, e assim como os estrógenos, também possui ação vasodilatadora ${ }^{77-}$

78. Agonistas específicos de receptores estrogênicos, como o composto o PPT (4,4',4"'-(4-propyl-[1H]-pyrazole-1,3,5-triyl) tris-phenol - agonista do ERa) e o DPN (2,3-bis(4-hydroxyphenyl)-propionitrile - agonista do ERß), tiveram também sua ação vasodilatadora demonstrada em artérias mesentéricas de rato. O agonista do ERa apresentou efeito vasorelaxante mais potente que o $17 \beta$-estradiol e este, por sua vez, foi mais potente que o $\mathrm{DPN}^{79}$.

Outra classe de compostos bastante estudada é a das substâncias sintéticas denominadas de moduladores seletivos de receptores estrogênicos (SERMs selective estrogen receptor modulators), que apresentam ações seletivas em 
diferentes tecidos, atuando como agonistas e/ou antagonistas. Em geral, os SERMs atuam como agonistas em tecidos como vasos sanguíneos (promovendo ação vasodilatadora) e ossos, e apresentam ações antagonistas sobre tecidos reprodutivos como mamas e útero ${ }^{80}$.

Assim como os SERMs, os fitoestrógenos apresentam propriedades tanto estrogênica quanto antiestrogênica, embora consideradas de baixa potência ${ }^{81}$. Esses compostos são derivados de plantas, e são estruturalmente e funcionalmente semelhantes aos estrógenos clássicos. Dentre as plantas consideradas como fontes de fitoestrógenos, a soja (Glycine max (L.) Merr.) é a que apresenta maiores proporções de isoflavonas, que são os fitoestrógenos mais comuns. Estas substâncias podem ainda ser encontradas em beterrabas (Beta vulgaris L.), batatas (Solanum tuberosum L.) e arroz (Oryza sativa L.). As isoflavonas mais estudadas são a genisteína e a daidzeína, que apresentaram ações benéficas sobre o sistema cardiovascular $^{82}$.

Os principais estrógenos produzidos naturalmente na mulher são o estradiol, a estrona e o estriol. As mulheres no período pré-menopausa produzem estradiol em grandes quantidades pelo ovário e, em virtude deste hormônio apresentar alta afinidade pelos ERs, é considerado o hormônio mais potente ${ }^{28}$. Por esta e outras características, o estradiol é o estrógeno mais utilizado nos estudos científicos, e portanto, as ações cardiovasculares deste hormônio estão bem caracterizadas, como já comentado anteriormente. O estriol é o principal estrógeno produzido pela placenta durante a gravidez mas ainda pode ser encontrado em quantidades menores se comparado ao estradiol e a estrona. A ação vascular deste hormônio tem sido pouco investigada. A estrona é menos potente que o estradiol e também é um metabólito deste último, sendo produzida a partir da androstenediona no tecido adiposo $^{28}$. Existem poucos estudos avaliando o efeito vascular direto desse composto, porém o interesse por este hormônio aumentou nos últimos anos.

É importante ressaltar ainda, como já comentado anteriormente, que o Premarin apresenta além da estrona, o equilin como substância presente em grande quantidade em sua composição ( 25\%). Este hormônio, entretanto, tem sido muito negligenciado, uma vez que a literatura apresenta poucos dados sobre a ação deste no sistema cardiovascular. Deste modo, torna-se importante a realização de um estudo que avalie o efeito vascular direto do equilin. 


\section{JUSTIFICATIVA E OBJETIVOS}

O Premarin e o $17 \beta$-estradiol são amplamente utilizados na TRH. Apesar do Premarin ser indicado por profissionais da saúde há mais de 60 anos, pouco se sabe sobre a ação vascular individual das diversas substâncias que compõem este medicamento. Neste contexto destaca-se o equilin, composto que equivale a aproximadamente um quarto da composição total do premarin e cujo efeito vascular direto ainda não foi investigado. Portanto, o presente estudo teve como objetivo avaliar o efeito vascular do equilin em artérias mesentéricas de resistência de ratas geneticamente hipertensas, bem como investigar o mecanismo de ação vascular promovido por este hormônio. O hormônio $17 \beta$-estradiol foi utilizado como controle do nosso estudo, uma vez que grande parte dos mecanismos envolvidos em sua resposta vasorelaxante encontra-se bem caracterizada. 


\section{MATERIAL E MÉTODOS}

Todos os procedimentos experimentais deste trabalho foram aprovados pela Comissão de Ética no Uso de Animais (CEUA) do Instituto de Ciências Biomédicas (ICB) da Universidade de São Paulo (USP) e realizados de acordo com os princípios éticos na experimentação animal adotados pelo Colégio Brasileiro de Experimentação Animal (COBEA) e pelo comitê institucional para uso e cuidado de animais em experimentação do Georgia Health Sciences University (GHSU Augusta, GA, EUA).

\subsection{Animais}

Para a realização dos experimentos, foram utilizadas ratas espontaneamente hipertensas (SHR) provenientes do laboratório Harlan (Indianápolis, IN, EUA). A partir da $10^{\text {a }}$ semana de vida, os animais foram mantidos no Biotério do Departamento de Fisiologia do GHSU. As ratas tiveram livre acesso à água e ração e foram mantidas em sala com temperatura constante de $22 \pm 2 \stackrel{\circ}{ } \mathrm{C}$, com ciclos claro/escuro de 12/12 horas.

\subsection{Grupos Experimentais}

As ratas foram divididas em dois grupos:

- Ratas intactas e

- Ratas ovariectomizadas.

\subsection{Ovariectomia}

Após anestesia com isoflurano (via inalatória), as ratas (12 semanas de idade) foram submetidas à incisão abdominal e tiveram os ovários totalmente removidos. Os experimentos foram realizados 30 dias após o procedimento cirúrgico. 


\subsection{Massa Corpórea}

Para a avaliação da massa corpórea (g), as ratas foram pesadas antes da ovariectomia (12 $2^{\mathrm{a}}$ semana de idade) e 30 dias após a cirurgia (16 ${ }^{\mathrm{a}}$ semana de idade).

\subsection{Peso Uterino}

O peso seco do útero foi avaliado após $24 \mathrm{~h}$ de secagem em estufa a $37^{\circ} \mathrm{C}$. Os resultados foram expressos em miligrama $(\mathrm{mg})$ do tecido por $100 \mathrm{~g}$ de peso corporal.

\subsection{Reatividade Vascular em Artérias Mesentéricas de Resistência}

Foi utilizado o método descrito por Mulvany e Halpern (1977) ${ }^{83}$. O leito mesentérico foi removido e colocado em uma placa de Petri contendo solução de Krebs-Henseleit a $4{ }^{\circ} \mathrm{C}$ (composição em mM: NaCl 130; $\mathrm{NaHCO}_{3}$ 14,9; $\mathrm{KCl} 4,7$; $\mathrm{KH}_{2} \mathrm{PO}_{4}$ 1,18; $\mathrm{MgSO}_{4} .7 \mathrm{H}_{2} \mathrm{O}$ 1,18; $\mathrm{CaCl}_{2} .2 \mathrm{H}_{2} \mathrm{O}$ 1,56; EDTA 0,026 e glicose 5,5). O terceiro ramo da artéria mesentérica superior foi dissecado e cortado em segmentos de 2,0 mm de comprimento com o auxílio de um microscópio de dissecação. Foram obtidos de 8-12 segmentos vasculares do leito mesentérico de cada uma do total de 20 ratas utilizadas. Dois fios de tungstênio (40 $\mu \mathrm{m}$ de diâmetro) foram então inseridos no lúmen das artérias e fixados em um miógrafo (modelo 610M, Danish MyoTech, Aarhus, Dinamarca - Figura 1) para vasos de resistência para o estudo da tensão isométrica. O miógrafo, por sua vez, foi conectado a um sistema para aquisição de dados (PowerLab / 8SP, ADinstruments, Austrália) e este a um computador. 
Figura 1 - Preparação em miógrafo para vasos de resistência isolados.

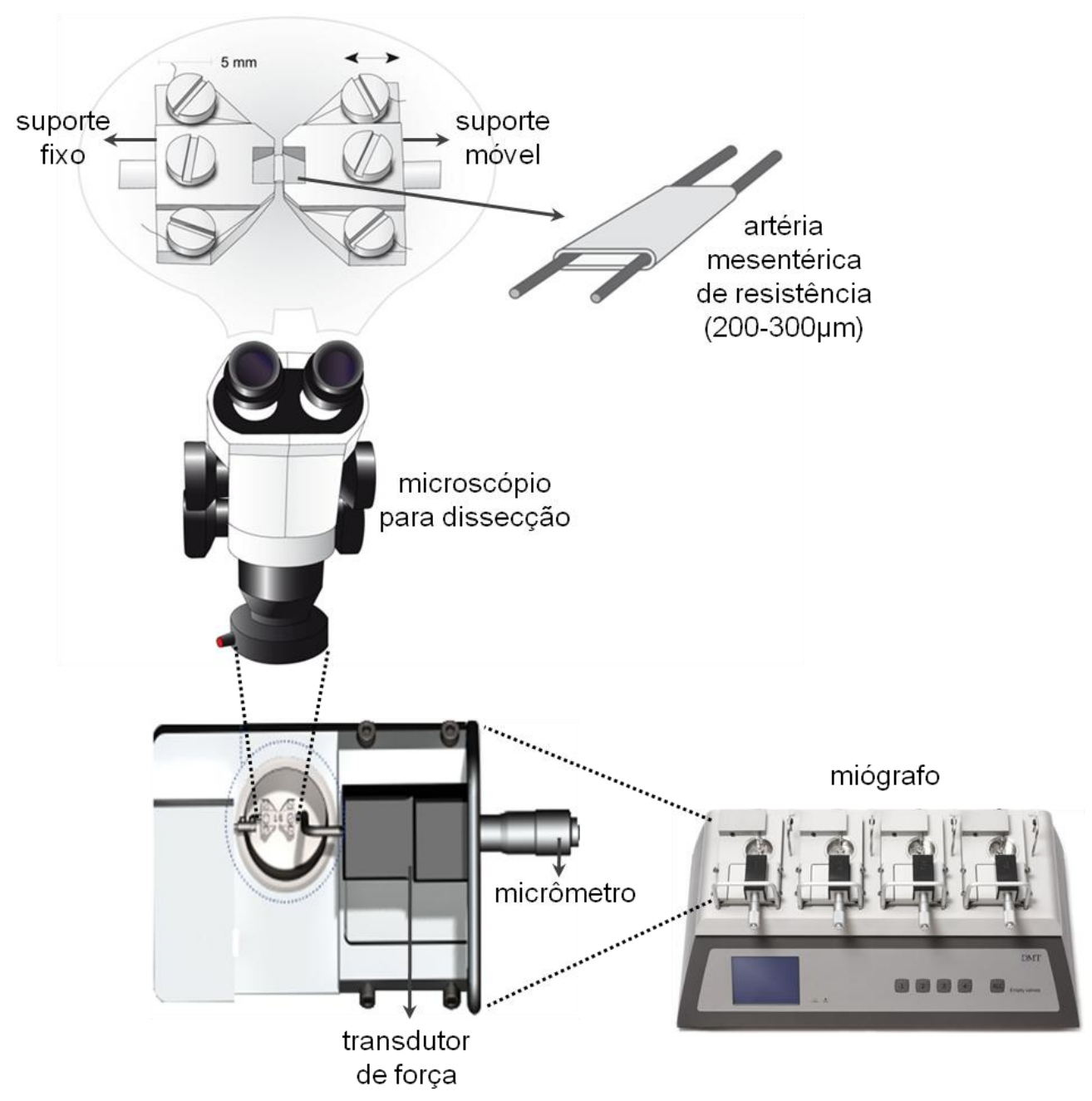

Fonte: Filgueira (2012)

\subsubsection{Normalização das artérias de resistência}

O propósito do procedimento de normalização é distender o segmento vascular até que se atinja a chamada circunferência interna normalizada (IC1): definida como uma fração determinada da circunferência interna (IC100) que um segmento totalmente relaxado teria em uma determinada pressão transmural. Para artérias mesentéricas de resistência, a pressão transmural alvo é de $100 \mathrm{mmHg}$, que corresponde a 13,3 $\mathrm{kPa}$.

Após o período de estabilização e aquecimento dos segmentos vasculares (15 minutos) em solução de Krebs-Henseleit ( $\mathrm{pH} 7,4$ saturada com $95 \%$ de $\mathrm{O}_{2}$ e 5\% de $\mathrm{CO}_{2}$ e mantida a $37^{\circ} \mathrm{C}$ ), as artérias mesentéricas foram distendidas de forma gradativa e a leitura do micrômetro e da força aplicada foram registrados a cada 
ponto (Figura 2). Estes dados foram então convertidos em valores de circunferência interna $(\mu \mathrm{m})$ e de tensão na parede vascular $(\mathrm{mN} / \mathrm{mm})$, respectivamente. A plotagem da tensão na parede do vaso contra a circunferência interna revela uma curva exponencial e pela aplicação da curva de isobarra correspondente a $100 \mathrm{mmHg}$, a IC100 é calculada a partir do ponto de interseção, utilizando o software específico para normalização de artérias de resistência (DMT Normalization Module, ADInstruments, Austrália - Figura 2). A IC1 foi calculada a partir da IC100 por meio da fórmula $\mathrm{IC} 1=0,90 \times \mathrm{IC} 100$, dando uma circunferência interna na qual a produção de força ativa bem como a sensibilidade do segmento a agonistas é máxima. O diâmetro interno normalizado foi calculado dividindo-se IC1 por ח. Após 30 minutos do processo de normalização, as artérias foram contraídas com a administração de cloreto de potássio $(\mathrm{KCl} 120 \mathrm{mM})$, com a finalidade de se avaliar a integridade funcional das mesmas.

Após a avaliação da integridade funcional, os segmentos vasculares foram submetidos a um período de estabilização de 30 minutos e em seguida foi avaliada a função endotelial frente ao efeito vasorelaxante da acetilcolina $(1 \mu \mathrm{M})$ em preparações pré-contraídas com fenilefrina $(1 \mu \mathrm{M})$. Foram considerados vasos com endotélio íntegro aqueles com relaxamento superior a $90 \%$. Os anéis previamente submetidos à retirada da camada íntima com o auxílio de um pelo de rato, e que não relaxaram à acetilcolina $(<10 \%)$, foram considerados como preparações sem endotélio.

Figura 2 - Ilustração do procedimento de normalização.

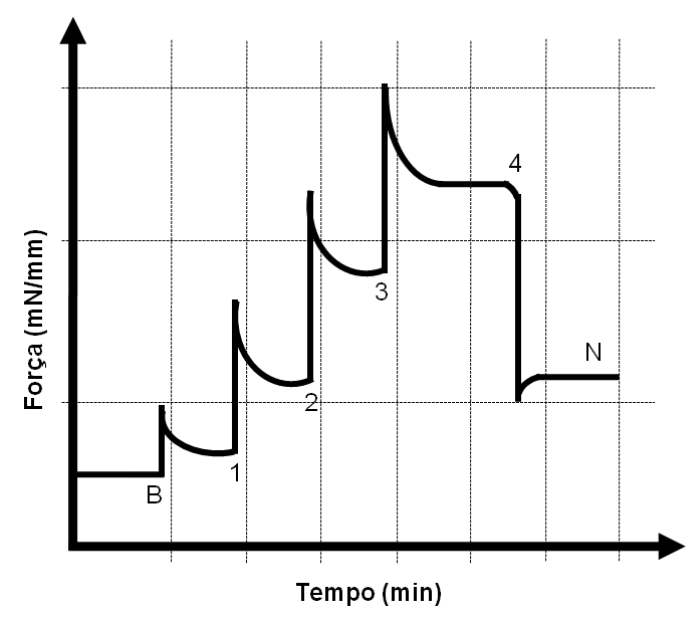

Fonte: Filgueira (2012) 


\subsubsection{Protocolos experimentais}

Após a avaliação da função endotelial (30 minutos), os anéis de artéria mesentérica com endotélio $(E+)$ foram pré-contraídos com o mimético do tromboxano $\mathrm{A}_{2}(\mathrm{U} 46619,1 \mu \mathrm{M})$. Quando a resposta contrátil a este agente atingiu um platô (usualmente após 10 minutos), concentrações crescentes de equilin, 17ßestradiol, 17a-estradiol, estrona (10 nM - $100 \mu \mathrm{M})$ ou veículo foram adicionadas.

Diante dos primeiros resultados obtidos, os protocolos realizados na sequência envolveram apenas os estrógenos que apresentaram maior resposta vasodilatadora: o equilin e o $17 \beta$-estradiol (utilizado como controle no presente estudo). Para examinar a participação dos receptores clássicos de estrógeno ERa e $E R \beta$ no relaxamento induzido pelo equilin, anéis de artéria mesentérica $(E+)$ foram incubados com ICl 182,780 (antagonista dos receptores clássicos de estrógeno, 10 $\mu \mathrm{M}) 30$ minutos antes da pré-contração com U46619.

O papel da via adenilato ciclase/proteína quinase $A$ (PKA) na resposta vasodilatadora do equilin foi avaliado em preparações vasculares previamente incubadas (30 minutos) com SQ 22536 (inibidor da adenilato ciclase, $100 \mu \mathrm{M}$ ) e KT 5720 (inibidor da PKA, $1 \mu \mathrm{M}$ ), respectivamente.

Com o intuito de avaliar a participação das células endoteliais na resposta promovida pelo equilin, a resposta vasorelaxante a este composto foi também avaliada também em preparações sem endotélio (E-). A participação da via do óxido nítrico (NO)/guanilato ciclase/proteína quinase G (PKG) foi investigada através da incubação dos segmentos arteriais (30 minutos) com $\mathrm{N} \omega$-nitro-L-arginine methyl ester (L-NAME - inibidor da NO sintase, $100 \mu \mathrm{M}$ ), 1H-[1,2,4]-oxadiazole-[4,3-a]quinoxalin-1-one (ODQ - inibidor seletivo da guanilato ciclase solúvel, $10 \mu \mathrm{M})$ e KT 5823 (inibidor da PKG, $1 \mu \mathrm{M}$ ), respectivamente.

$O$ envolvimento dos metabólitos da ciclooxigenase (COX) nos efeitos do equilin foi examinado incubando os segmentos das artérias mesentéricas (30 minutos) com indometacina (inibidor inespecífico da COX, $10 \mu \mathrm{M}$ ) ou a associação de indometacina com L-NAME.

Para examinar o envolvimento dos canais de potássio $\left(\mathrm{K}^{+}\right)$na resposta vasorelaxante ao equilin, anéis de artéria mesentérica $E+$ foram incubados (30 minutos) com tetraetilamônio (TEA - bloqueador inespecífico de canal de $\mathrm{K}^{+}, 1 \mathrm{mM}$ ), caribdotoxina (ChTX - bloqueador de canal de $\mathrm{K}^{+}$de alta e intermediária condutância 
ativado por cálcio, $100 \mathrm{nM}$ ), apamina (bloqueador de canal de $\mathrm{K}^{+}$de baixa condutância ativado por cálcio, $100 \mathrm{nM}$ ), iberiotoxina (IbTX - bloqueador de canal de $\mathrm{K}^{+}$de alta condutância ativado por cálcio, $100 \mathrm{nM}$ ), glibenclamida (bloqueador de canal de $\mathrm{K}^{+}$sensível ao ATP, $10 \mu \mathrm{M}$ ) ou 4-aminopiridina (4-AP - bloqueador de canal de $\mathrm{K}^{+}$dependente de voltagem, $1 \mathrm{mM}$ ).

Com o objetivo de investigar o efeito vasodilatador do equilin frente à contração induzida por diferentes mecanismos de entrada de cálcio no músculo liso vascular, curvas concentração-efeito ao equilin e ao 17ß-estradiol foram realizadas frente à diferentes agentes pré-contráteis. Além do U46619 (mimético do tromboxano $A_{2}$ ), foi utilizado o agonista de receptores de endotelina (endotelina-1, $10 \mathrm{nM})$ e ainda um agente contrátil eletroquímico $(\mathrm{KCl}, 120 \mathrm{mM})$ que promove despolarização da membrana, levando à ativação de canais para cálcio dependentes de voltagem e consequente contração vascular.

Para investigar o efeito do equilin sobre o influxo de cálcio, anéis de artéria mesentérica E- foram incubados com solução de Krebs livre de cálcio e em altas concentrações de potássio $(60 \mathrm{mM})$. Em seguida, curvas concentração-efeito ao $\mathrm{CaCl}_{2}$ foram realizadas na ausência (veículos: etanol) ou presença de diferentes concentrações de equilin ou $17 \beta$-estradiol $(1 \mu \mathrm{M}, 10 \mu \mathrm{M}$ e $100 \mu \mathrm{M}-30$ minutos de pré-incubação). Além disso, para examinar o efeito do equilin sobre os canais de cálcio do tipo-L, curvas concentração-efeito ao (S)-(-)-BAY K 8644 (ativador de canal de cálcio do tipo-L) em solução despolarizante $(10 \mathrm{mM}$ de $\mathrm{KCl}$ ) foram realizadas na ausência (veículos: etanol) ou presença de diferentes concentrações de equilin ou 17ß-estradiol ( $1 \mu \mathrm{M}, 10 \mu \mathrm{M}$ e $100 \mu \mathrm{M}$ - 30 minutos de pré-incubação).

Por último, para avaliar o efeito do equilin sobre a liberação de cálcio pelo retículo sarcoplasmático, anéis de artéria mesentérica E- foram primeiramente estimulados com FE $(1 \mu \mathrm{M})$ em solução de Krebs-Henseleit normal $(1,56 \mathrm{mM}$ de cálcio) até que a resposta contrátil atingisse o platô. A preparação foi então incubada (15 minutos) em solução de Krebs-Henseleit livre de cálcio, contendo EGTA (1 mM), um agente quelante utilizado para remover o cálcio residual. Esta etapa inicial do protocolo proporciona o esvaziamento dos estoques de cálcio do retículo sarcoplasmático. Seguiu-se então a reintrodução de Krebs-Henseleit normal (1,56 $\mathrm{mM}$ de cálcio), o que ocasiona o influxo de cálcio e o repreenchimento dos estoques intracelulares (15 minutos). Novamente, a solução do banho foi substituída por solução de Krebs-Henseleit livre de cálcio sem EGTA e após 5 minutos, a resposta 
contrátil à cafeína $(20 \mathrm{mM})$ foi induzida. Este efeito resulta em uma contração transitória devido à rápida liberação de cálcio do retículo sarcoplasmático, a partir da ativação de receptores de rianodina. As preparações foram incubadas com equilin ou $17 \beta$-estradiol $(1 \mu \mathrm{M}, 10 \mu \mathrm{M}$ e $100 \mu \mathrm{M}) 15$ minutos antes da estimulação com cafeína com o intuito de avaliar a capacidade desses compostos em bloquear a liberação de cálcio do retículo sarcoplasmático.

\subsection{Drogas e Reagentes}

Acetilcolina, fenilefrina, L-NAME, indometacina, tetraetilamônio, caribdotoxina, apamina, iberiotoxina, glibenclamida, 4-aminopiridina, equilin, 17ß-estradiol, 17aestradiol, estrona, EGTA e cafeína foram obtidos da Sigma Chemical Co (St. Louis, MO). U46619, endotelina-1, SQ 22536, ODQ, KT 5720, KT 5823, (S)-(-)-BAY K 8644 e ICl 182,780 foram obtidos da Tocris (Ellisville, MO).

\subsection{Análise Estatística}

Os resultados foram expressos como média \pm erro padrão da média (epm). As análises estatísticas foram realizadas utilizando-se teste " $\mathrm{t}$ " de Student no caso de comparação de duas médias ou análise de variância (ANOVA) de uma via seguido do teste de Bartlett para a homogeneidade das variâncias e teste de múltiplas comparações Tukey para o caso de comparação de mais de duas médias. No caso de comparação dos diversos tratamentos com o grupo controle, foi utilizado o teste de Dunnett's. Além disso, utilizou-se ANOVA de duas vias seguida pelo teste de múltiplas comparações Tukey para as análises que envolviam mais de uma variável. O nível de significância mínima aceitável foi $p<0,05$. 


\section{RESULTADOS}

\subsection{Massa Corpórea}

A massa corpórea das ratas, avaliada na $12^{\text {a }}$ semana de idade (Tabela 1), apresentou similaridade nos valores, demonstrando a homogeneidade dos pesos dos animais antes da ovariectomia. Após 4 semanas de cirurgia, as ratas ovariectomizadas (16 semanas de idade) apresentaram aumento da massa corpórea em relação ao grupo de ratas intactas (Tabela 1).

Tabela 1 - Massa corpórea de ratas intactas e ovariectomizadas com 12 e 16 semanas de idade.

\begin{tabular}{lcc}
\hline & $\begin{array}{c}\text { Intactas } \\
\text { massa corpórea }(\mathrm{g})\end{array}$ & $\begin{array}{c}\text { Ovariectomizadas } \\
\text { massa corpórea }(\mathrm{g})\end{array}$ \\
\hline 12 semanas & $161,4 \pm 2,2$ & $157,6 \pm 1,8$ \\
& $(13)$ & $(07)$ \\
16 semanas & $171,6 \pm 2,9$ & $190,9 \pm 3,0^{*}$ \\
& $(13)$ & $(07)$ \\
\hline
\end{tabular}

Cada valor representa a média \pm epm.

O número de ratas utilizadas em cada grupo encontra-se entre parênteses.

${ }^{*} \mathrm{p}<0,05$ vs Intactas com 16 semanas.

Fonte: Filgueira (2012) 


\subsection{Peso Uterino}

A remoção dos ovários promoveu redução significativa do peso relativo do útero seco das ratas hipertensas ovariectomizadas (15 $\pm 2 \mathrm{mg} / 100 \mathrm{~g}$ de peso) quando comparado com as ratas que não tiveram os ovários removidos (39 \pm 4 $\mathrm{mg} / 100 \mathrm{~g}$ de peso) (Figura 3).

Figura 3 - Peso relativo do útero seco $(\mathrm{mg} / 100 \mathrm{~g}$ de peso) de ratas intactas e ratas ovariectomizadas.

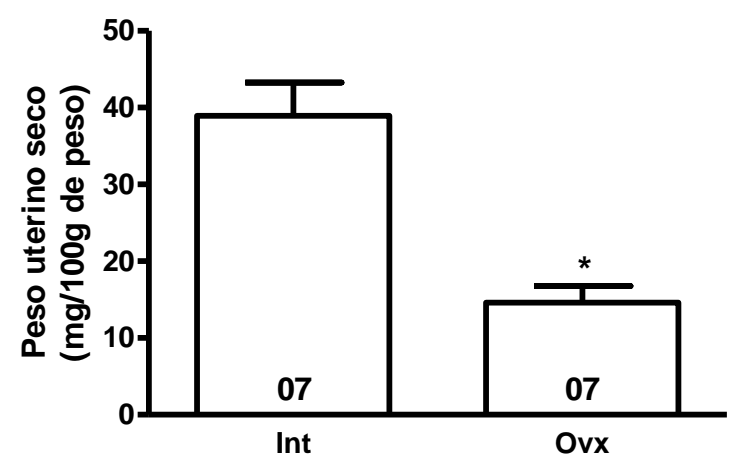

Cada barra representa a média \pm epm. $O$ número de ratas utilizadas em cada grupo encontra-se dentro das barras. ${ }^{*} \mathrm{p}<0,05$ vs Intactas.

Fonte: Filgueira (2012) 


\subsection{Medida do Diâmetro Luminal Efetivo das Artérias Mesentéricas de Resistência}

A tabela 2 mostra os valores do diâmetro luminal efetivo, correspondente à medida da circunferência interna das artérias mesentéricas de resistência isoladas de ratas intactas e de ratas ovariectomizadas. O diâmetro luminal efetivo das artérias mesentéricas das ratas ovariectomizadas não foi estatisticamente diferente daquele observado em artérias de ratas intactas.

Tabela 2 - Diâmetro luminal efetivo das artérias mesentéricas de resistência de ratas intactas e ovariectomizadas.

\begin{tabular}{ccc}
\hline & Intactas & Ovariectomizadas \\
\hline Diâmetro luminar efetivo & $268,4 \pm 13,2$ & $275,6 \pm 9,8$ \\
& $(08)$ & $(08)$ \\
\hline
\end{tabular}

Cada valor representa a média \pm epm.

O número de ratas utilizadas em cada grupo encontra-se entre parênteses.

Fonte: Filgueira (2012) 


\subsection{Avaliação da Contração ao Cloreto de Potássio em Artérias Mesentéricas de Resistência}

A resposta contrátil induzida pelo $\mathrm{KCl}$ foi semelhante em artérias mesentéricas de ratas intactas e de ratas ovariectomizadas (Tabela 3).

Tabela 3 - Contração ao cloreto de potássio em artérias mesentéricas de resistência de ratas intactas e ovariectomizadas.

\begin{tabular}{ccc}
\hline & Intactas & Ovariectomizadas \\
\hline Força $(\mathrm{mN})$ & $14,17 \pm 0,68$ & $14,13 \pm 0,78$ \\
& $(08)$ & $(08)$ \\
\hline
\end{tabular}

Cada valor representa a média \pm epm.

O número de ratas utilizadas em cada grupo encontra-se entre parênteses.

$\mathrm{KCl}$ : Cloreto de potássio

Fonte: Filgueira (2012) 


\subsection{Reatividade Vascular aos Estrógenos}

O equilin, o 17ß-estradiol, o 17a-estradiol e a estrona apresentaram ação vasodilatadora de modo dependente de concentração. Em segmentos de artérias mesentéricas de ratas intactas, o equilin produziu uma resposta vasodilatadora semelhante àquela produzida pelo $17 \beta$-estradiol (Figura 4 e Tabela 4). A resposta vasorelaxante ao $17 \alpha$-estradiol e à estrona foi reduzida quando comparada àquela promovida pelo equilin e pelo $17 \beta$-estradiol. Quando as respostas máximas promovidas por cada um dos estrógenos em ratas intactas (Figura 4A) foram comparadas àquelas observadas nas ratas ovariectomizadas (Figura 4B), nenhuma diferença estatística foi observada. Nenhuma diferença foi observada nos valores de $\mathrm{pD}_{2}$ entre as diferentes curvas (Tabela 4).

Figura 4 - Resposta relaxante do equilin, do 17ß-estradiol, do 17a-estradiol e da estrona em artérias mesentéricas de resistência de ratas intactas $(A)$ e ovariectomizadas $(B)$. Após uma pré-contração estável com o mimético do tromboxano (U46619 - 1 $\mu \mathrm{M})$, o veículo (etanol) ou os compostos foram adicionados ao banho de orgão em doses crescentes.

A

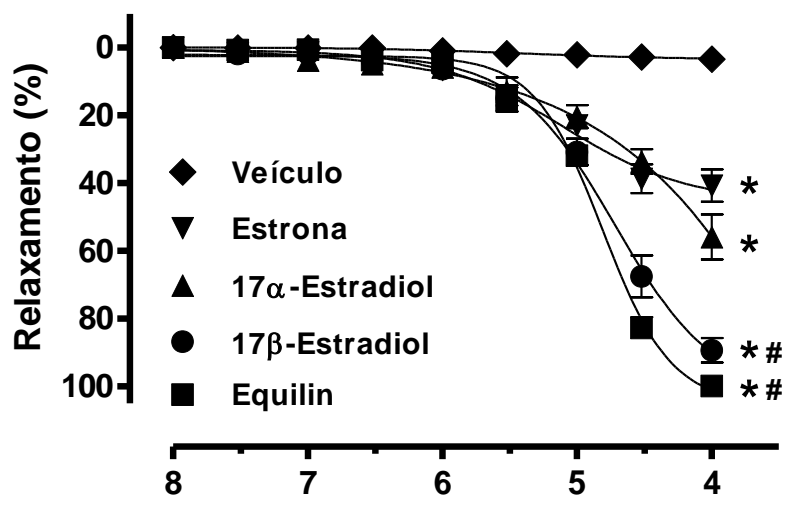

- $\log [\mathrm{M}]$ Estrógenos
B

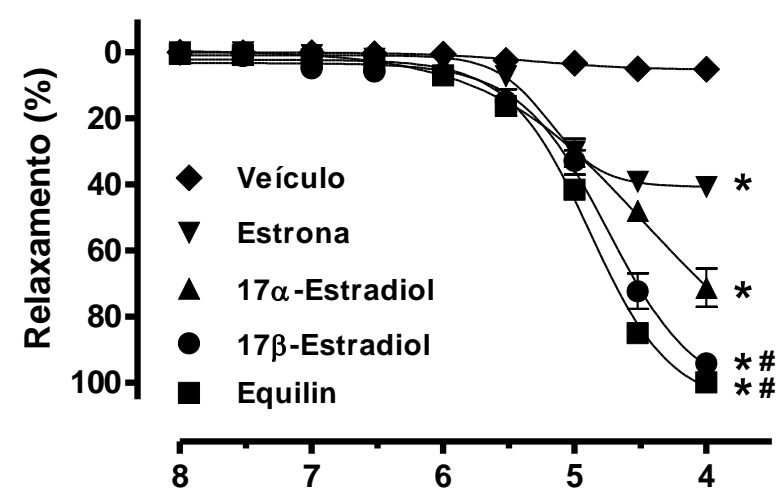

- $\log [\mathrm{M}]$ Estrógenos

Os resultados são representados como média \pm epm. O número de ratas utilizadas em cada grupo foi de 6 . ${ }^{*} p<0,05$ vs veículo. ${ }^{\#} p<0,05$ vs estrona e $17 \alpha$-estradiol do respectivo grupo. Fonte: Filgueira (2012) 
Tabela 4 - Resposta relaxante da estrona, do $17 \alpha$-estradiol, do $17 \beta$-estradiol e do equilin em artérias mesentéricas de ratas intactas e ovariectomizadas.

\begin{tabular}{ccccc}
\hline & \multicolumn{2}{c}{ Intactas } & \multicolumn{2}{c}{ Ovariectomizadas } \\
& $\mathrm{R}_{\mathrm{MAX}}$ & $\mathrm{pD}_{2}$ & $\mathrm{R}_{\mathrm{MAX}}$ & $\mathrm{pD}_{2}$ \\
Veículo (etanol) & $3,32 \pm 0,36$ & - & $5,05 \pm 0,78$ & - \\
Estrona & $40,74 \pm 4,81^{*}$ & $4,94 \pm 0,02$ & $40,75 \pm 2,35^{\star}$ & $5,09 \pm 0,02$ \\
17 -Estradiol & $55,92 \pm 6,65^{*}$ & $4,71 \pm 0,17$ & $71,26 \pm 5,78^{*}$ & $4,84 \pm 0,17$ \\
$17 \beta$-Estradiol & $92,67 \pm 2,05^{*} \#$ & $4,75 \pm 0,08$ & $94,14 \pm 1,54^{*} \#$ & $4,79 \pm 0,06$ \\
Equilin & $99,94 \pm 0,57^{*} \#$ & $4,79 \pm 0,02$ & $99,94 \pm 0,63^{*}$ & $4,88 \pm 0,01$ \\
\hline
\end{tabular}

Os valores de $\mathrm{R}_{\operatorname{MAX}}\left(\right.$ Resposta máxima) e $\mathrm{pD}_{2}$ (-log $\left.\mathrm{EC} 50\right)$ representam a média \pm epm.

O número de ratas utilizadas em cada grupo foi de 6 .

EC50: concentração que promove $50 \%$ da $R_{\text {MAX. }}$.

${ }^{*} \mathrm{p}<0,05$ vs veículo do respectivo grupo.

${ }^{\#} \mathrm{p}<0,05$ vs estrona e $17 \alpha$-estradiol do respectivo grupo.

Fonte: Filgueira (2012) 


\subsection{Participação dos Receptores Estrogênicos no Efeito Vasorelaxante do Equilin}

A incubação por 30 minutos com o antagonista específico de receptores de estrógeno (ICI 182,780 - $10 \mu \mathrm{M}$ ) não afetou o relaxamento induzido pelo equilin em segmentos de artéria mesentérica de ratas intactas e ovariectomizadas (Figura $5 \mathrm{~A} \mathrm{e}$ C, Tabela 5). As respostas promovidas pelo $17 \beta$-estradiol também não foram alteradas na presença do ICI 182,780 (Figura 5B e D, Tabela 5). Nenhuma diferença foi observada nos valores de $\mathrm{pD}_{2}$ entre as diferentes curvas (Tabela 5).

Figura 5 - Resposta relaxante do equilin ( $A$ e $C$ ) e do 17ß-estradiol (B e D) em artérias mesentéricas de resistência de ratas intactas (A e B) e ovariectomizadas ( $C$ e D) na ausência (controle) ou presença (30 minutos de incubação) de antagonista de receptores de estrógeno (ICl 182,780, $10 \mu \mathrm{m}$ ). Após uma précontração estável com o mimético do tromboxano (U46619 - $1 \mu \mathrm{M}$ ), os compostos foram adicionados ao banho de orgão em doses crescentes.

A

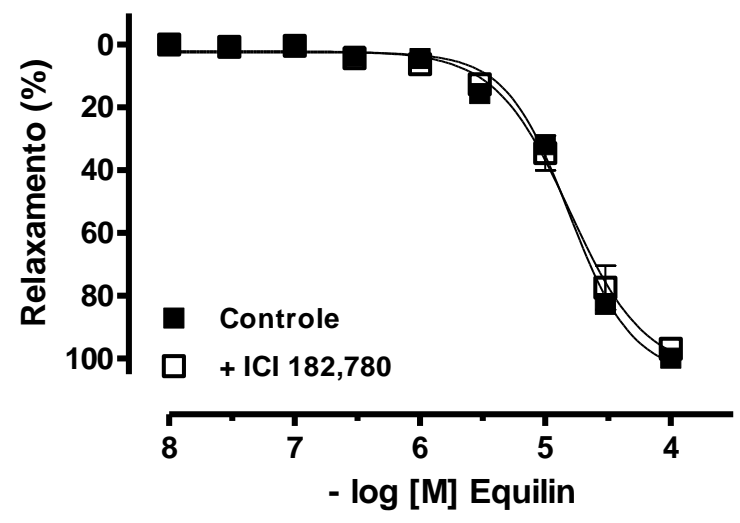

C

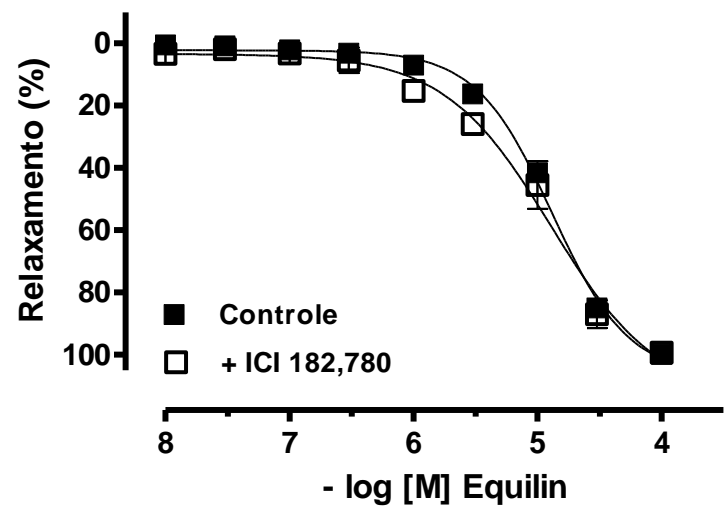

B

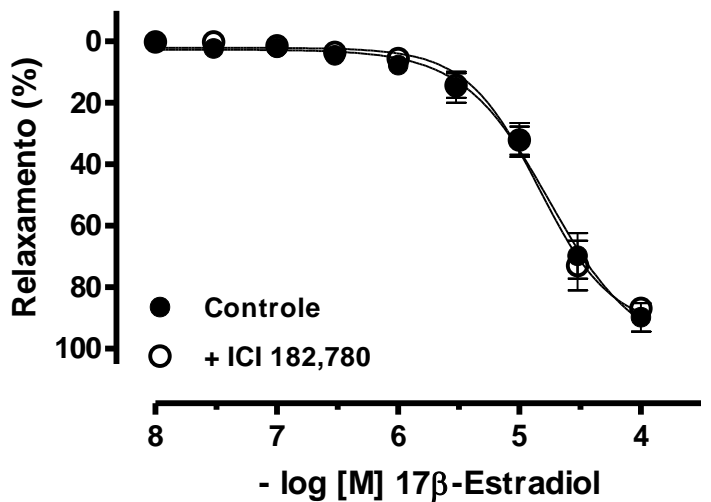

D

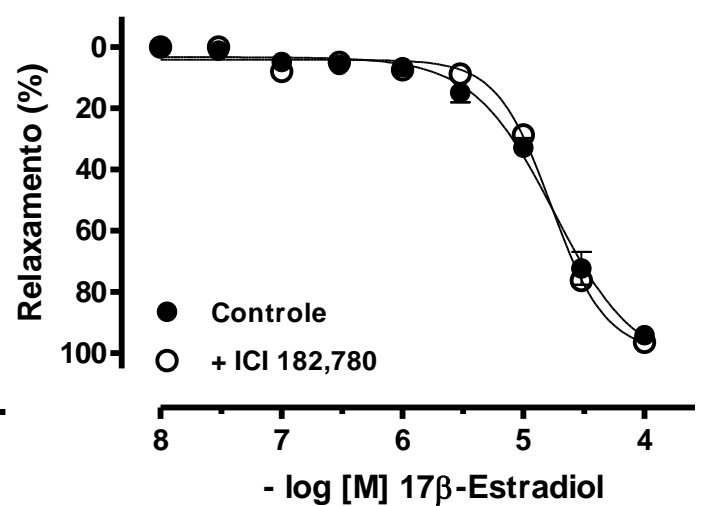

Cada curva representa a média \pm epm. O número de ratas utilizadas em cada grupo foi de 6 . Fonte: Filgueira (2012) 
Tabela 5 - Resposta relaxante do equilin e do 17ß-estradiol em artérias mesentéricas de resistência de ratas intactas e ovariectomizadas na ausência (controle) ou presença (30 minutos de incubação) de ICI 182,780 (antagonista de receptores de estrógeno - $10 \mu \mathrm{m})$.

\begin{tabular}{ccccc}
\hline & \multicolumn{2}{c}{ Intactas } & \multicolumn{2}{c}{ Ovariectomizadas } \\
& $\mathrm{R}_{\mathrm{MAX}}$ & $\mathrm{pD}_{2}$ & $\mathrm{R}_{\mathrm{MAX}}$ & $\mathrm{pD}_{2}$ \\
Equilin & $99,94 \pm 0,57$ & $4,79 \pm 0,02$ & $99,94 \pm 0,63$ & $4,88 \pm 0,01$ \\
Equilin $+\mathrm{ICl} 182,780$ & $98,02 \pm 1,06$ & $4,87 \pm 0,06$ & $99,40 \pm 0,03$ & $4,88 \pm 0,15$ \\
$17 \beta$-Estradiol & $92,67 \pm 2,05$ & $4,75 \pm 0,08$ & $94,14 \pm 1,54$ & $4,79 \pm 0,06$ \\
$17 \beta$-Estradiol $+\mathrm{ICl} 182,780$ & $87,00 \pm 3,01$ & $4,77 \pm 0,14$ & $96,53 \pm 2,55$ & $4,93 \pm 0,34$ \\
\hline
\end{tabular}

Os valores de $\mathrm{R}_{\mathrm{MAX}}\left(\right.$ Resposta máxima) e $\mathrm{pD}_{2}(-\log \mathrm{EC} 50)$ representam a média \pm epm. O número de ratas utilizadas em cada grupo foi de 6.

EC50: concentração que promove $50 \%$ da $\mathrm{R}_{\text {MAX }}$.

Fonte: Filgueira (2012)

Os resultados demonstrados a partir deste item foram realizados apenas em artérias mesentéricas de ratas intactas, uma vez que os resultados observados até esta etapa não demonstraram diferença no mecanismo de ação vasorelaxante ao equilin entre ratas intactas e ovariectomizadas. 


\subsection{Participação da Via Adenilato Ciclase/Proteína Quinase A no Efeito Vasorelaxante do Equilin}

O relaxamento vascular ao equilin em segmentos de artéria mesentérica de resistência de ratas intactas não foi alterado pela incubação com SQ 22536 (100 $\mu \mathrm{M})$ ou com KT $5720(1 \mu \mathrm{M})$, inibidores da adenilato ciclase e da PKA, respectivamente (Figura 6A, Tabela 6). O efeito produzido pelo $17 \beta$-estradiol também não foi modificado na presença desses inibidores (Figura 6B, Tabela 6). Nenhuma diferença foi observada nos valores de $\mathrm{pD}_{2}$ entre as diferentes curvas (Tabela 6).

Figura 6 - Resposta relaxante do equilin (A) e do 17ß-estradiol (B) em artérias mesentéricas de resistência de ratas intactas na ausência (controle) ou presença (30 minutos de incubação) de inibidor da adenilato ciclase (SQ 22536 - $100 \mu \mathrm{M}$ ) ou inibidor da proteína quinase A (KT $5720-1 \mu \mathrm{M})$. Após uma pré-contração estável com o mimético do tromboxano (U46619 - $1 \mu \mathrm{M}$ ), os compostos foram adicionados ao banho de orgão em doses crescentes.

A

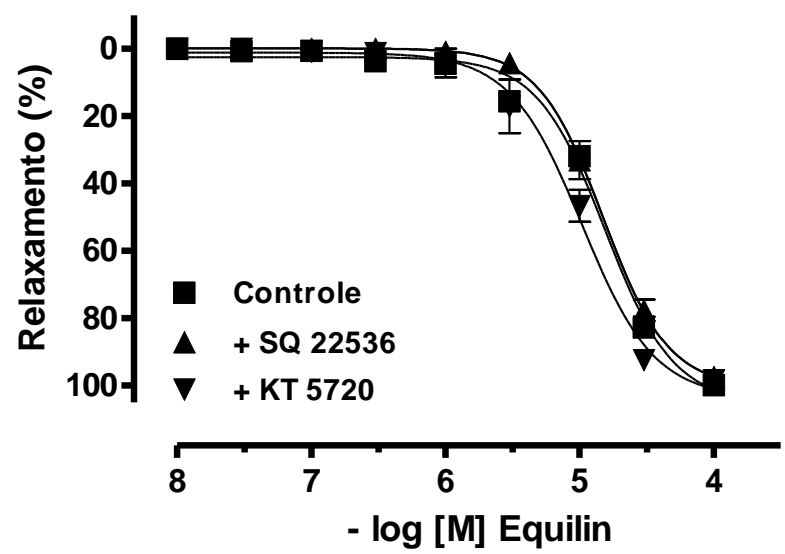

B

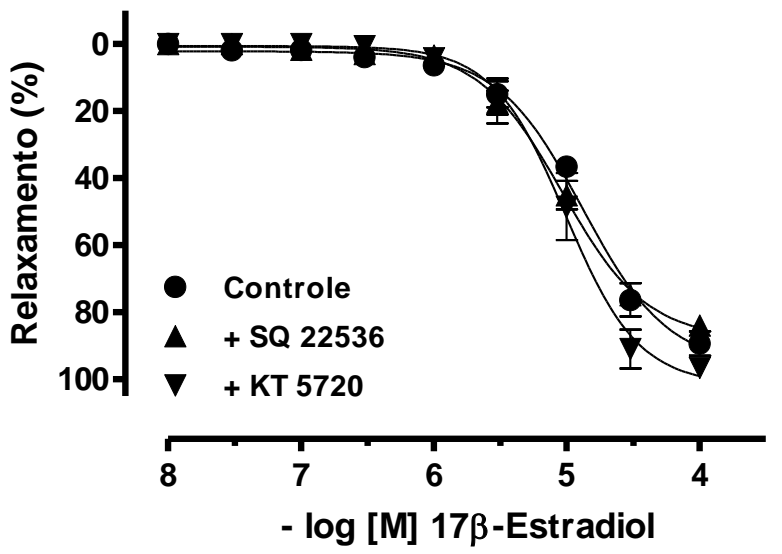

Cada curva representa a média \pm epm. O número de ratas utilizadas em cada grupo foi de 6 . Fonte: Filgueira (2012) 
Tabela 6 - Resposta relaxante do equilin e do 17ß-estradiol em artérias mesentéricas de resistência de ratas intactas na ausência (controle) ou presença (30 minutos de incubação) de SQ 22536 (inibidor da adenilato ciclase - $100 \mu \mathrm{M}$ ) ou KT 5720 (inibidor da PKA - $1 \mu \mathrm{m}$ ).

\begin{tabular}{ccccc}
\hline & \multicolumn{2}{c}{ Equilin } & \multicolumn{2}{c}{$17 \beta$-Estradiol } \\
& $\mathrm{R}_{\mathrm{MAX}}$ & $\mathrm{pD}_{2}$ & $\mathrm{R}_{\mathrm{MAX}}$ & $\mathrm{pD}_{2}$ \\
Controle & $99,94 \pm 0,57$ & $4,79 \pm 0,02$ & $92,67 \pm 2,05$ & $4,75 \pm 0,08$ \\
+ SQ 22536 & $97,47 \pm 1,14$ & $4,83 \pm 0,05$ & $83,92 \pm 2,21$ & $5,01 \pm 0,10$ \\
+ KT 5720 & $98,42 \pm 0,12$ & $4,96 \pm 0,06$ & $94,98 \pm 3,21$ & $5,02 \pm 0,09$ \\
\hline
\end{tabular}

Os valores de $\mathrm{R}_{\operatorname{MAX}}$ (Resposta máxima) e $\mathrm{pD}_{2}$ (-log EC50) representam a média \pm epm. O número de ratas utilizadas em cada grupo foi de 6.

EC50: concentração que promove $50 \%$ da $\mathrm{R}_{\mathrm{MAX}}$.

PKA: proteína quinase $A$.

Fonte: Filgueira (2012) 


\subsection{Participação do Endotélio no Efeito Vasorelaxante do Equilin}

A resposta relaxante induzida pelo equilin em ratas intactas foi independente da presença do endotélio (Figura 7A, Tabela 7). De modo similar, a resposta produzida pelo $17 \beta$-estradiol não foi alterada após a remoção do endotélio em artérias mesentéricas de ratas intactas (Figura 7B, Tabela 7). Nenhuma diferença foi observada nos valores de $\mathrm{pD}_{2}$ entre as diferentes curvas (Tabela 7).

Figura 7 - Resposta relaxante do equilin (A) e do 17ß-estradiol (B) em artérias mesentéricas de resistência com ou sem endotélio de ratas intactas. Após uma pré-contração estável com o mimético do tromboxano (U46619 - $1 \mu \mathrm{M})$, os compostos foram adicionados ao banho de orgão em doses crescentes.

A

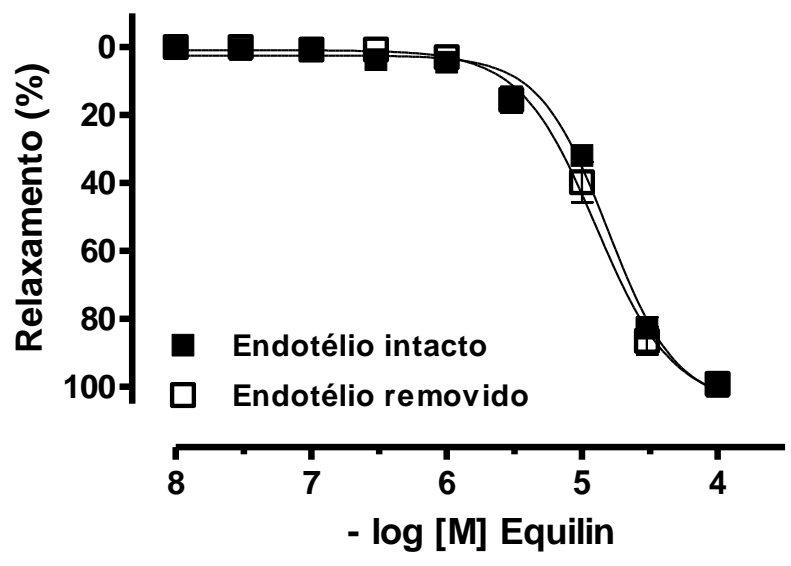

B
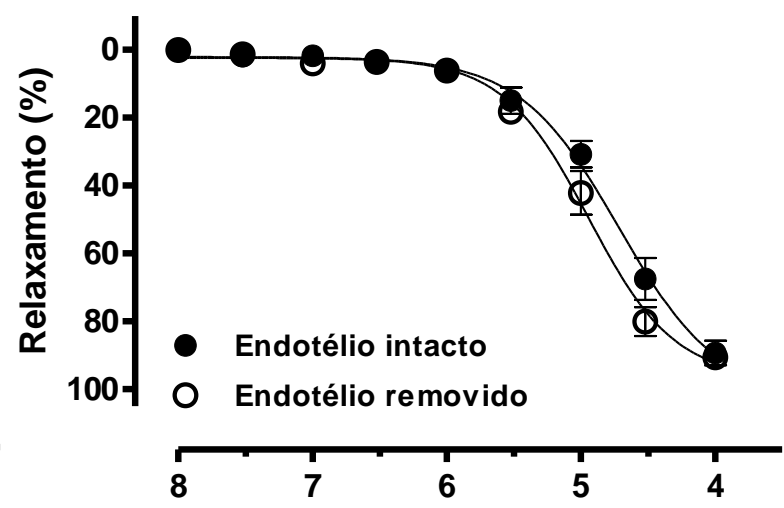

- $\log [\mathrm{M}] 17 \beta$-Estradiol

Cada curva representa a média \pm epm. O número de ratas utilizadas em cada grupo foi de 6 . Fonte: Filgueira (2012) 
Tabela 7 - Resposta relaxante do equilin e do 17ß-estradiol em artérias mesentéricas de resistência com ou sem endotélio de ratas intactas.

\begin{tabular}{ccccc}
\hline & \multicolumn{2}{c}{ Equilin } & \multicolumn{2}{c}{$17 \beta$-Estradiol } \\
& $\mathrm{R}_{\mathrm{MAX}}$ & $\mathrm{pD}_{2}$ & $\mathrm{R}_{\mathrm{MAX}}$ & $\mathrm{pD}_{2}$ \\
$\mathrm{E}+$ & $99,94 \pm 0,57$ & $4,79 \pm 0,02$ & $92,67 \pm 2,05$ & $4,75 \pm 0,08$ \\
$\mathrm{E}-$ & $100,00 \pm 0,48$ & $4,85 \pm 0,06$ & $91,65 \pm 2,47$ & $4,95 \pm 0,06$ \\
\hline
\end{tabular}

Os valores de $\mathrm{R}_{\text {MAX }}\left(\right.$ Resposta máxima) e $\mathrm{pD}_{2}$ (-log EC50) representam a média \pm epm. O número de ratas utilizadas em cada grupo foi de 6 .

EC50: concentração que promove $50 \%$ da $R_{\text {MAX }}$.

E+: com endotélio.

E-: sem endotélio.

Fonte: Filgueira (2012) 


\subsection{Participação da Via Óxido Nítrico/Guanilato Ciclase/Proteína Quinase G no Efeito Vasorelaxante do Equilin}

O relaxamento vascular ao equilin e ao $17 \beta$-estradiol em segmentos de artéria mesentérica de resistência de ratas intactas não foi alterado pelo L-NAME (100 $\mu \mathrm{M})$, pelo ODQ $(10 \mu \mathrm{M})$ ou pelo KT $5823(1 \mu \mathrm{M})$ (Figura 8A e B, Tabela 8), inibidores da óxido nítrico sintase, da guanilato ciclase solúvel e da proteína quinase $\mathrm{G}$, respectivamente. Nenhuma diferença foi observada nos valores de $\mathrm{pD}_{2}$ entre as diferentes curvas (Tabela 8).

Figura 8 - Resposta relaxante do equilin (A) e do 17ß-estradiol (B) em artérias mesentéricas de resistência de ratas intactas na ausência (controle) ou presença (30 minutos de incubação) de inibidor da NOS (L-NAME - $100 \mu \mathrm{M}$ ), inibidor da guanilato ciclase (ODQ - $10 \mu \mathrm{M})$ ou inibidor da proteína quinase G (KT $5823-1 \mu \mathrm{M})$. Após uma pré-contração estável com o mimético do tromboxano (U46619 - $1 \mu \mathrm{M}$ ), os compostos foram adicionados ao banho de orgão em doses crescentes.

A

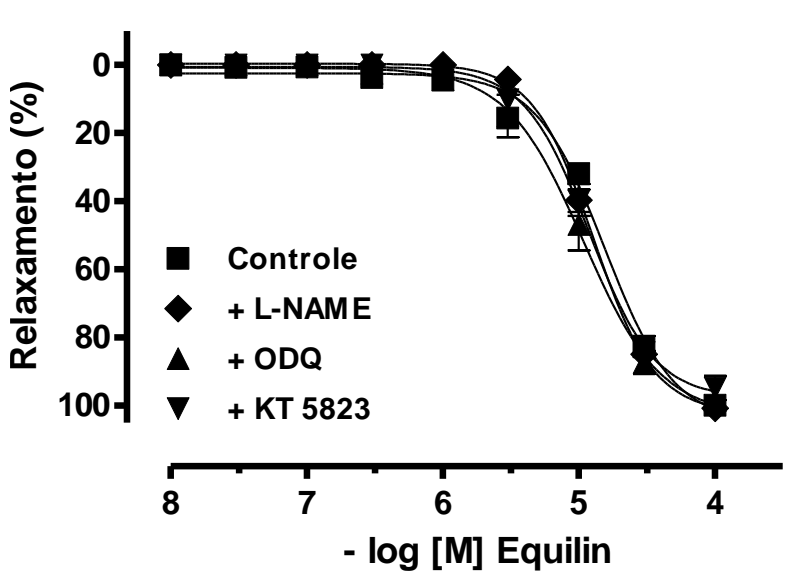

B

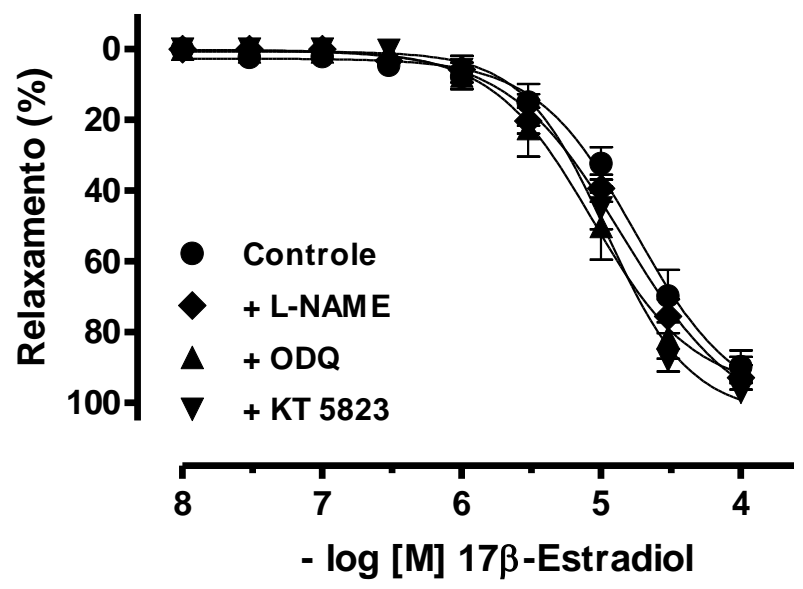

Cada curva representa a média \pm epm. O número de ratas utilizadas em cada grupo foi de 6 . NOS: óxido nítrico sintase.

L-NAME: N $\omega$-nitro-L-arginine methyl ester.

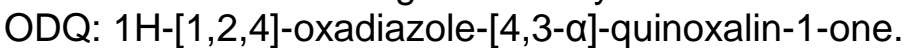

Fonte: Filgueira (2012) 
Tabela 8 - Resposta relaxante do equilin e do $17 \beta$-estradiol em artérias mesentéricas de resistência de ratas intactas na ausência (controle) ou presença (30 minutos de incubação) de L-NAME (inibidor da NOS - $100 \mu \mathrm{M}$ ), ODQ (inibidor da guanilato ciclase - $10 \mu \mathrm{M}$ ) ou KT 5823 (inibidor da PKG - $1 \mu \mathrm{M}$ ).

\begin{tabular}{ccccc}
\hline & \multicolumn{2}{c}{ Equilin } & \multicolumn{2}{c}{$17 \beta$-Estradiol } \\
& $\mathrm{R}_{\mathrm{MAX}}$ & $\mathrm{pD}_{2}$ & $\mathrm{R}_{\mathrm{MAX}}$ & $\mathrm{pD}_{2}$ \\
Controle & $99,94 \pm 0,57$ & $4,79 \pm 0,02$ & $92,67 \pm 2,05$ & $4,75 \pm 0,08$ \\
+ L-NAME & $100,80 \pm 0,20$ & $4,89 \pm 0,04$ & $90,46 \pm 4,80$ & $4,85 \pm 0,08$ \\
+ ODQ & $98,57 \pm 2,25$ & $4,94 \pm 0,09$ & $89,56 \pm 2,54$ & $5,08 \pm 0,12$ \\
+ KT 5823 & $94,85 \pm 3,60$ & $4,92 \pm 0,02$ & $97,11 \pm 1,19$ & $4,94 \pm 0,07$ \\
\hline
\end{tabular}

Os valores de $\mathrm{R}_{\text {MAX }}\left(\right.$ Resposta máxima) e $\mathrm{pD}_{2}$ (-log $\left.\mathrm{EC} 50\right)$ representam a média \pm epm. O número de ratas utilizadas em cada grupo foi de 6 .

EC50: concentração que promove $50 \%$ da $\mathrm{R}_{\mathrm{MAX}}$.

L-NAME: N $\omega$-nitro-L-arginine methyl ester.

NOS: óxido nítrico sintase.

ODQ: $1 \mathrm{H}-[1,2,4]$-oxadiazole-[4,3- $\alpha$-quinoxalin-1-one.

PKG: Proteína quinase G.

Fonte: Filgueira (2012) 


\subsection{Participação dos Prostanóides no Efeito Vasorelaxante do Equilin}

A incubação dos segmentos dos artérias mesentéricas com indometacina (10 $\mu \mathrm{M})$ ou com a associação de indometacina e L-NAME (100 $\mu \mathrm{M})$ não alterou a ação vasorelaxante do equilin em ratas intactas (Figura 9A, Tabela 9). O efeito produzido pelo $17 \beta$-estradiol também não foi modificado na presença desses inibidores (Figura 9B, Tabela 9). Nenhuma diferença foi observada nos valores de $\mathrm{pD}_{2}$ entre as diferentes curvas (Tabela 9).

Figura 9 - Resposta relaxante do equilin (A) e do 17ß-estradiol (B) em artérias mesentéricas de resistência de ratas intactas na ausência (controle) ou presença (30 minutos de incubação) de inibidor da COX (indometacina - $10 \mu \mathrm{M}$ ) ou inibidor da COX + inibidor da NOS (L-NAME - $100 \mu \mathrm{M})$. Após uma précontração estável com o mimético do tromboxano (U46619 - $1 \mu \mathrm{M})$, os compostos foram adicionados ao banho de orgão em doses crescentes.

A

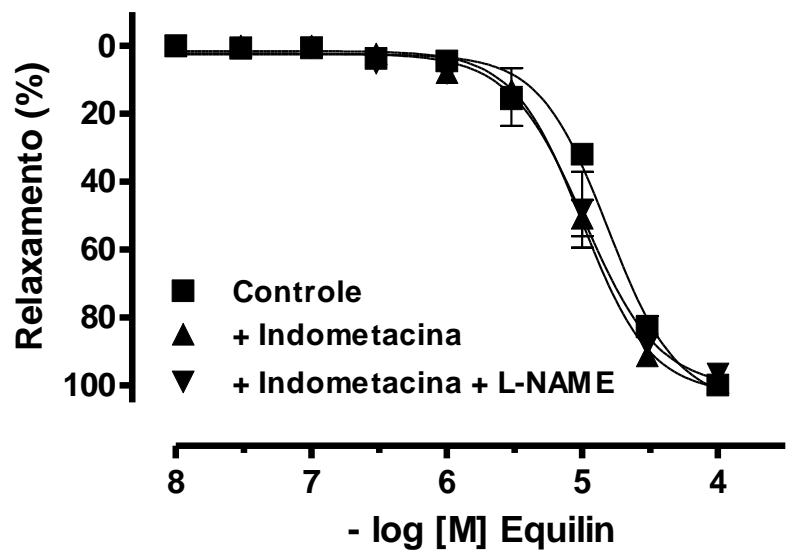

B

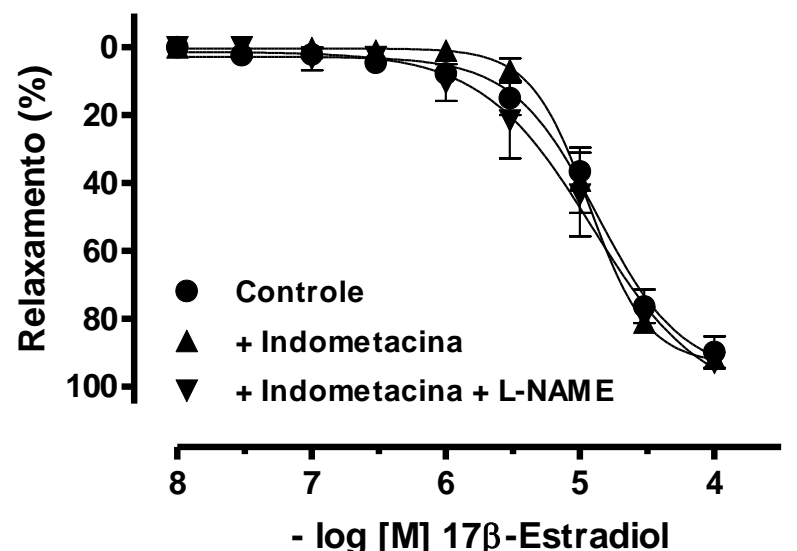

Cada curva representa a média \pm epm. O número de ratas utilizadas em cada grupo foi de 6 . COX: ciclooxigenase.

L-NAME: Nw-nitro-L-arginine methyl ester.

NOS: óxido nítrico sintase.

Fonte: Filgueira (2012) 
Tabela 9 - Resposta relaxante do equilin e do 17ß-estradiol em artérias mesentéricas de resistência de ratas intactas na ausência (controle) ou presença (30 minutos de incubação) de indometacina (inibidor da COX - $10 \mu \mathrm{M}$ ) ou indometacina + LNAME (inibidor da NOS - $100 \mu \mathrm{m}$ ).

\begin{tabular}{ccccc}
\hline & \multicolumn{2}{c}{ Equilin } & \multicolumn{2}{c}{$17 \beta$-Estradiol } \\
& $\mathrm{R}_{\mathrm{MAX}}$ & $\mathrm{pD}_{2}$ & $\mathrm{R}_{\mathrm{MAX}}$ & $\mathrm{pD}_{2}$ \\
Controle & $99,94 \pm 0,57$ & $4,79 \pm 0,02$ & $92,67 \pm 2,05$ & $4,75 \pm 0,08$ \\
+ Indometacina & $99,25 \pm 0,13$ & $5,00 \pm 0,05$ & $86,71 \pm 3,20$ & $4,95 \pm 0,09$ \\
+ Indometacina + L-NAME & $96,62 \pm 1,22$ & $4,98 \pm 0,06$ & $93,07 \pm 1,46$ & $4,91 \pm 0,10$ \\
\hline
\end{tabular}

Os valores de $\mathrm{R}_{\operatorname{MAX}}$ (Resposta máxima) e $\mathrm{pD}_{2}$ (-log EC50) representam a média \pm epm. O número de ratas utilizadas em cada grupo foi de 6.

EC50: concentração que promove $50 \%$ da $R_{\text {MAX. }}$

COX: ciclooxigenase.

L-NAME: Nw-nitro-L-arginine methyl ester.

NOS: óxido nítrico sintase.

Fonte: Filgueira (2012) 


\subsection{Efeito do Equilin sobre os Canais de Potássio}

O relaxamento vascular ao equilin não foi alterado pelo TEA (bloqueador inespecífico de canal de $\mathrm{K}^{+}, 1 \mathrm{mM}$ ), ChTX (bloqueador de canal de $\mathrm{K}^{+}$de alta e intermediária condutância ativado por cálcio, $100 \mathrm{nM}$ ) + apamina (bloqueador de canal de $\mathrm{K}^{+}$de baixa condutância ativado por cálcio, $100 \mathrm{nM}$ ), IbTX (IbTX bloqueador de canal de $\mathrm{K}^{+}$de alta condutância ativado por cálcio, $100 \mathrm{nM}$ ), glibenclamida (bloqueador de canal de $\mathrm{K}^{+}$sensível ao ATP, $10 \mu \mathrm{M}$ ) ou 4-AP (bloqueador de canal de $\mathrm{K}^{+}$dependente de voltagem, $1 \mathrm{mM}$ ) (Figura 10A, Tabela 10). $O$ mesmo achado foi observado com a resposta promovida pelo $17 \beta$-estradiol (Figura 10B, Tabela 10). Nenhuma diferença foi observada nos valores de $\mathrm{pD}_{2}$ entre as diferentes curvas (Tabela 10).

Figura 10 - Resposta relaxante do equilin (A) e do 17ß-estradiol (B) em artérias mesentéricas de resistência de ratas intactas na ausência (controle) ou presença (30 minutos de incubação) de bloqueadores dos canais de potássio. Após uma pré-contração estável com o mimético do tromboxano (U46619 - $1 \mu \mathrm{M})$, os compostos foram adicionados ao banho de orgão em doses crescentes.

A

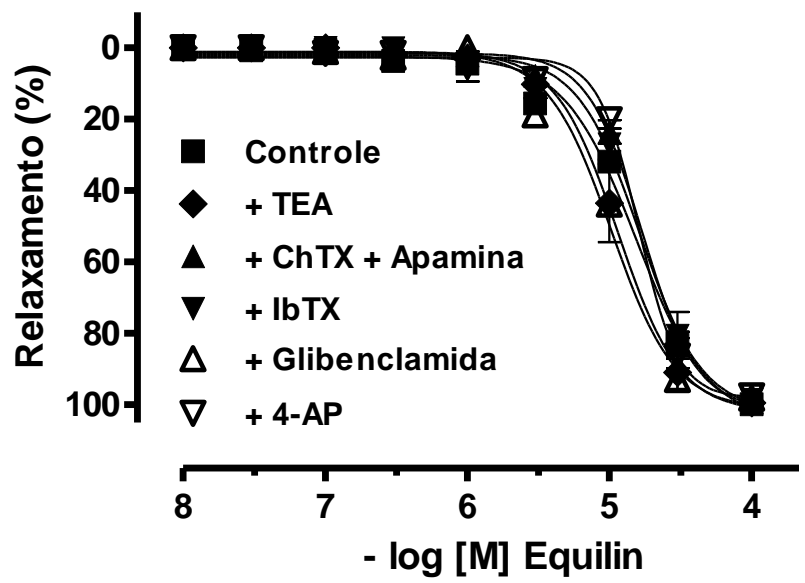

B

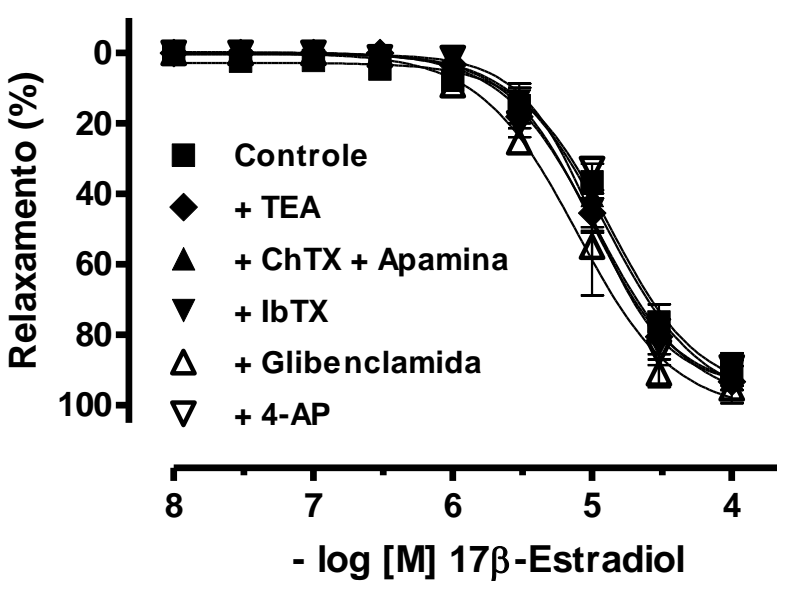

Cada curva representa a média \pm epm. O número de ratas utilizadas em cada grupo foi de 6 . TEA: Tetraetilamônio (1 mM). ChTX: Caribdotoxina (100 nM). IbTX: Iberiotoxina (100 nM). 4-AP: 4-aminopiridina (1 $\mathrm{mM})$. Apamina (100 nM). Glibenclamida (100 $\mu \mathrm{M})$. Fonte: Filgueira (2012) 
Tabela 10 - Resposta relaxante do equilin e do 17ß-estradiol em artérias mesentéricas de resistência de ratas intactas na ausência (controle) e presença (30 minutos de incubação) de bloqueadores dos canais de potássio.

\begin{tabular}{ccccc}
\hline & \multicolumn{2}{c}{ Equilin } & \multicolumn{2}{c}{$17 \beta$-Estradiol } \\
& $\mathrm{R}_{\mathrm{MAX}}$ & $\mathrm{pD}_{2}$ & $\mathrm{R}_{\mathrm{MAX}}$ & $\mathrm{pD}_{2}$ \\
Controle & $99,94 \pm 0,57$ & $4,79 \pm 0,02$ & $92,67 \pm 2,05$ & $4,75 \pm 0,08$ \\
+ TEA & $99,45 \pm 0,61$ & $4,96 \pm 0,09$ & $93,36 \pm 6,17$ & $4,96 \pm 0,06$ \\
+ ChTX + Apamina & $99,40 \pm 0,49$ & $4,77 \pm 0,03$ & $92,37 \pm 3,41$ & $4,95 \pm 0,12$ \\
+ IbTx & $98,62 \pm 0,82$ & $4,78 \pm 0,06$ & $90,79 \pm 2,77$ & $4,98 \pm 0,04$ \\
+ Glibenclamida & $98,28 \pm 1,05$ & $4,98 \pm 0,06$ & $95,48 \pm 0,41$ & $5,09 \pm 0,15$ \\
+ 4-AP & $97,64 \pm 0,39$ & $4,79 \pm 0,04$ & $89,27 \pm 1,09$ & $4,87 \pm 0,03$ \\
\hline
\end{tabular}

Os valores de $\mathrm{R}_{\operatorname{MAX}}\left(\right.$ Resposta máxima) e $\mathrm{pD}_{2}$ (-log $\left.\mathrm{EC} 50\right)$ representam a média \pm epm.

O número de ratas utilizadas em cada grupo foi de 6 .

EC50: concentração que promove $50 \%$ da $R_{\text {MAX }}$.

TEA: Tetraetilamônio (1 mM).

ChTX: Caribdotoxina (100 nM).

IbTX : Iberiotoxina (100 nM).

4-AP: 4-aminopiridina(1 mM).

Apamina (100 nM).

Glibenclamida (100 $\mu \mathrm{M})$.

Fonte: Filgueira (2012) 


\subsection{Efeito Vasorelaxante do Equilin Frente a Diferentes Agentes Pré-contráteis}

O equilin promoveu vasorelaxamento em preparações pré-contraídas tanto com U46619 (mimético do tromboxano $A_{2}, 1 \mu \mathrm{M}$ ) quanto com endotelina-1 (10 nM). Além disso, este efeito foi observado em segmentos vasculares pré-contraídos com solução despolarizante $(\mathrm{KCl}, 120 \mathrm{mM})$. O efeito vasorelaxante promovido tanto pelo equilin quanto pelo $17 \beta$-estradiol não diferente frente aos agentes pré-contráteis utilizados (Figura 11, Tabela 11). Nenhuma diferença foi observada nos valores de $\mathrm{pD}_{2}$ entre as diferentes curvas (Tabela 11).

Figura 11 - Resposta relaxante do equilin e do 17ß-estradiol em artérias mesentéricas de resistência de ratas intactas pré-contraídas com U46619 (1 $\mu \mathrm{M})$ (A), endotelina-1 (10 nM) (B) ou cloreto de potássio (120 mM) (C).
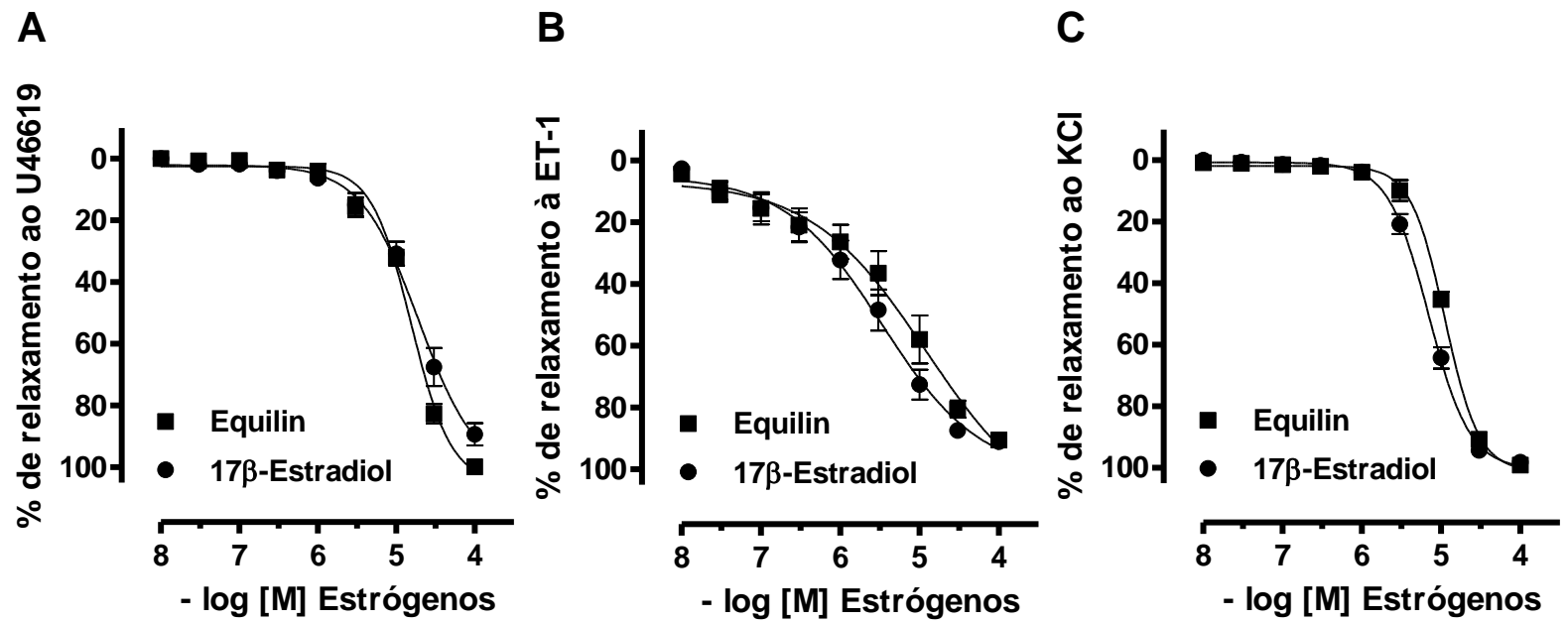

Os resultados são representados como média \pm epm. O número de ratas utilizadas em cada grupo foi de 6 .

ET-1: Endotelina-1.

$\mathrm{KCl}$ : Cloreto de Potássio.

Fonte: Filgueira (2012) 
Tabela 11 - Resposta relaxante do equilin e do $17 \beta$-estradiol em artérias mesentéricas de resistência de ratas intactas pré-contraídas com U46619 $(1 \mu \mathrm{M})$, endotelina-1 (10 $\mathrm{nM})$ ou cloreto de potássio (120 mM).

\begin{tabular}{ccccc}
\hline & \multicolumn{2}{c}{ Equilin } & \multicolumn{2}{c}{$17 \beta$-Estradiol } \\
U46619 & $\mathrm{R}_{\mathrm{MAX}}$ & $\mathrm{pD}_{2}$ & $\mathrm{R}_{\mathrm{MAX}}$ & $\mathrm{pD}_{2}$ \\
Endotelina-1 & $99,94 \pm 0,57$ & $4,79 \pm 0,02$ & $92,67 \pm 2,05$ & $4,75 \pm 0,08$ \\
Cloreto de Potássio & $91,84 \pm 1,40$ & $5,15 \pm 0,06$ & $91,13 \pm 1,42$ & $5,17 \pm 0,11$ \\
\hline
\end{tabular}

Os valores de $\mathrm{R}_{\mathrm{MAX}}\left(\right.$ Resposta máxima) e $\mathrm{pD}_{2}$ (-log $\mathrm{EC50)}$ representam a média \pm epm. O número de ratas utilizadas em cada grupo foi de 6 .

EC50: concentração que promove $50 \%$ da $\mathrm{R}_{\mathrm{MAX}}$.

Fonte: Filgueira (2012) 


\subsection{Efeito do Equilin Sobre os Canais de Cálcio}

A incubação com equilin na concentração de $1 \mu \mathrm{M}$ não afetou a contração máxima ao cálcio em anéis de artéria mesentérica sem endotélio de ratas intactas. Entretanto, nas concentrações de $10 \mu \mathrm{M}$ e $100 \mu \mathrm{M}$, houve diminuição significativa da resposta máxima ao cálcio (Figura 12A, Tabela 12). O mesmo efeito foi observado com o $17 \beta$-estradiol (Figura 12B, Tabela 12), porém, as incubações com $10 \mu \mathrm{M}$ e $100 \mu \mathrm{M}$ produziram um bloqueio maior quando comparado àquele promovido com o equilin (Tabela 12).

Figura 12 - Curvas concentração-efeito ao cloreto de cálcio em artérias mesentéricas de resistência sem endotélio de ratas intactas incubadas (nas concentrações de $1,10$ e $100 \mu \mathrm{M})$ com equilin (A) ou $17 \beta$-estradiol (B). Os dados são expressos como porcentagem de contração ao $\mathrm{KCl}(120 \mathrm{mM})$.

A

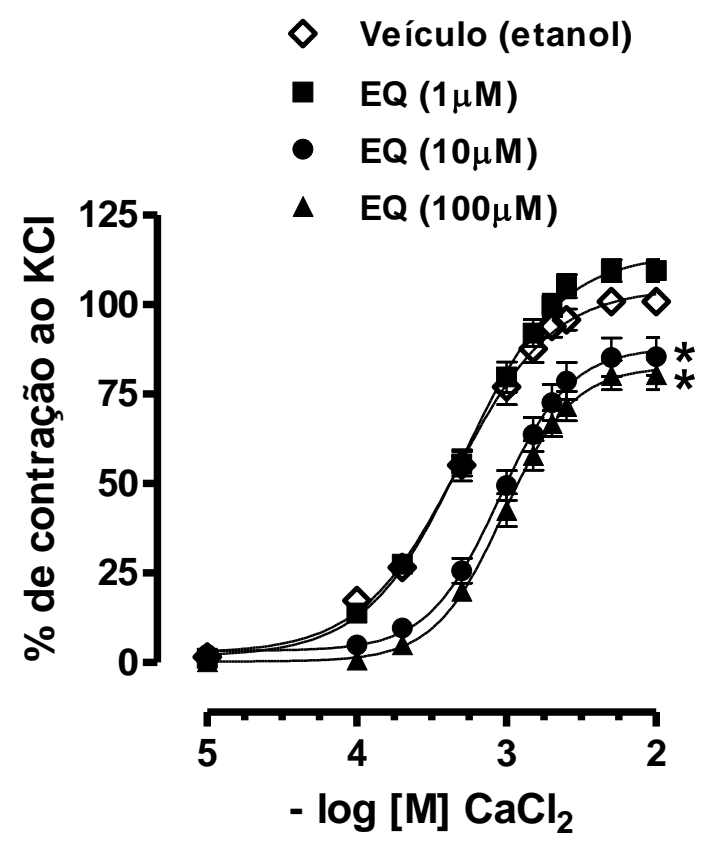

B

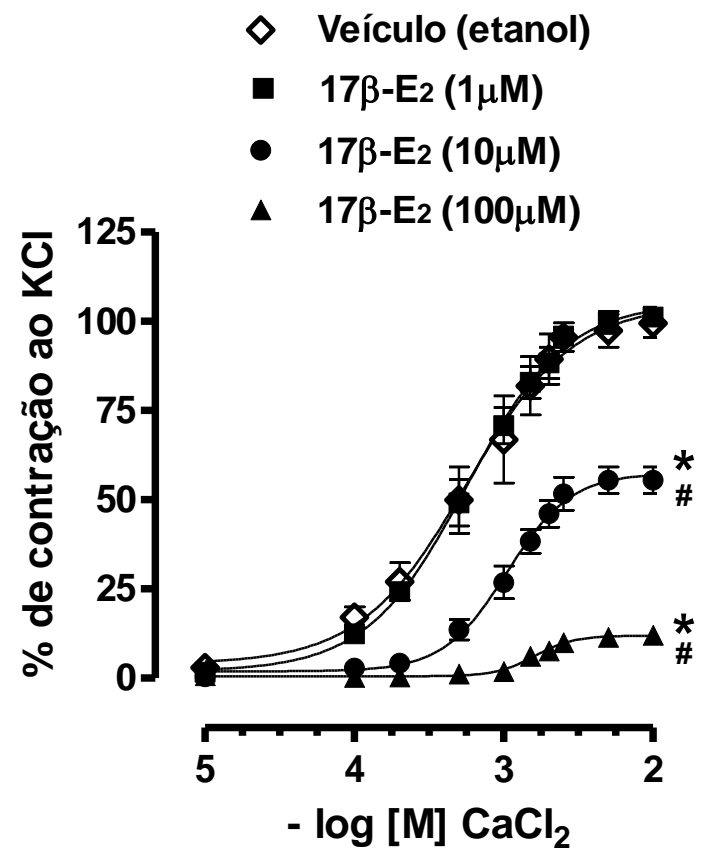

Os resultados são representados como média \pm epm. O número de ratas utilizadas em cada grupo foi de 6. ${ }^{*} p<0,05$ vs veículo; ${ }^{\#} p<0,05$ vs $E Q$.

$\mathrm{KCl}$ : Cloreto de Potássio.

$\mathrm{CaCl}_{2}$ : Cloreto de cálcio.

EQ: Equilin.

$17 \beta-E_{2}: 17 \beta$-Estradiol.

Fonte: Filgueira (2012) 
Tabela 12 - Curvas concentração-efeito ao cloreto de cálcio (\% a contração com KCl 120 $\mathrm{mM}$ ) em artérias mesentéricas de resistência de ratas intactas incubadas (nas concentrações de 1, 10 e $100 \mu \mathrm{M})$ com equilin ou $17 \beta$-estradiol.

\begin{tabular}{ccc}
\hline & Equilin & $17 \beta$-Estradiol \\
& $\mathrm{R}_{\mathrm{MAX}}$ & $\mathrm{R}_{\mathrm{MAX}}$ \\
Veículo (etanol) & $101,30 \pm 2,29$ & $99,48 \pm 3,92$ \\
$1 \mu \mathrm{M}$ & $109,50 \pm 3,07$ & $101,3 \pm 2,74$ \\
$10 \mu \mathrm{M}$ & $85,50 \pm 5,27^{\star}$ & $55,47 \pm 3,71^{*}$ \\
$100 \mu \mathrm{M}$ & $80,46 \pm 4,20^{*}$ & $12,08 \pm 1,50^{*}$ \\
\hline
\end{tabular}

Os valores de $\mathrm{R}_{\text {MAX }}$ (Resposta máxima) representam a média \pm epm.

O número de ratas utilizadas em cada grupo foi de 6.

${ }^{*} \mathrm{p}<0,05$ vs veículo do respectivo grupo.

${ }^{\#} \mathrm{p}<0,05$ vs respectiva concentração da $\mathrm{R}_{\text {MAX }}$ do equilin.

$\mathrm{KCl}$ : Cloreto de Potássio.

Fonte: Filgueira (2012) 


\subsection{Efeito do Equilin sobre os Canais de Cálcio do Tipo-L}

A incubação com equilin ou $17 \beta$-estradiol promoveu diminuição da contração máxima ao BAY K 8644 em segmentos de artéria mesentérica sem endotélio de ratas intactas. Assim como observado com o cálcio, na concentração de $1 \mu \mathrm{M}$, ambas as incubações (com equilin ou com 17ß-estradiol) não promoveram efeito na resposta vasoconstritora ao BAY K 8644 (Figura 13A e B, Tabela 13). Entretanto, nas concentrações de $10 \mu \mathrm{M}$ e $100 \mu \mathrm{M}$, houve uma diminuição significativa da resposta máxima ao BAY K 8644 (Figura 13A e B, Tabela 13). Nota-se ainda que as incubações com 17ß-estradiol nas concentrações de $10 \mu \mathrm{M}$ e $100 \mu \mathrm{M}$ produziram um bloqueio maior quando comparado àquele promovido com o equilin (Tabela 13). Foi observado um bloqueio total na incubação com o $17 \beta$-estradiol na concentração máxima $(100 \mu \mathrm{M})$.

Figura 13 - Curvas concentração-efeito ao Bay K 8644 em artérias mesentéricas de resistência sem endotélio de ratas intactas incubadas (nas concentrações de 1,10 e $100 \mu \mathrm{M}$ ) com equilin (A) ou 17ß-estradiol (B). Os dados são expressos como porcentagem de contração ao KCl (120 mM).

A

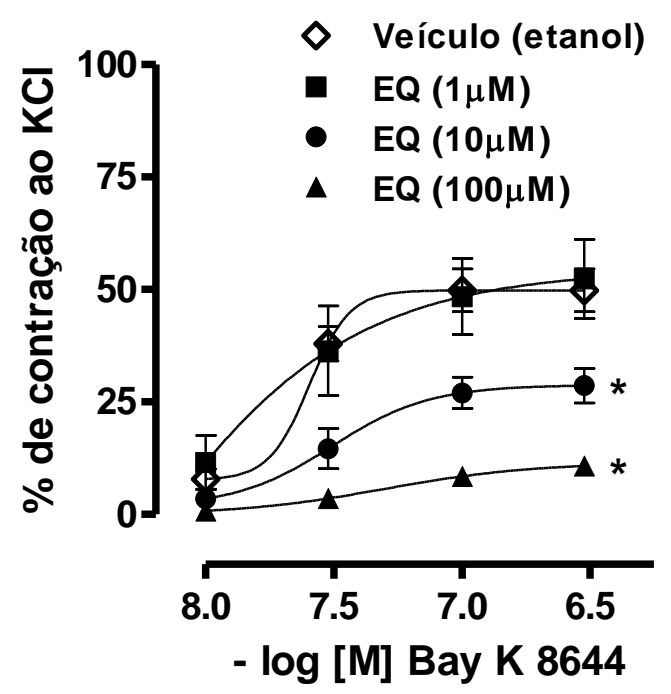

B

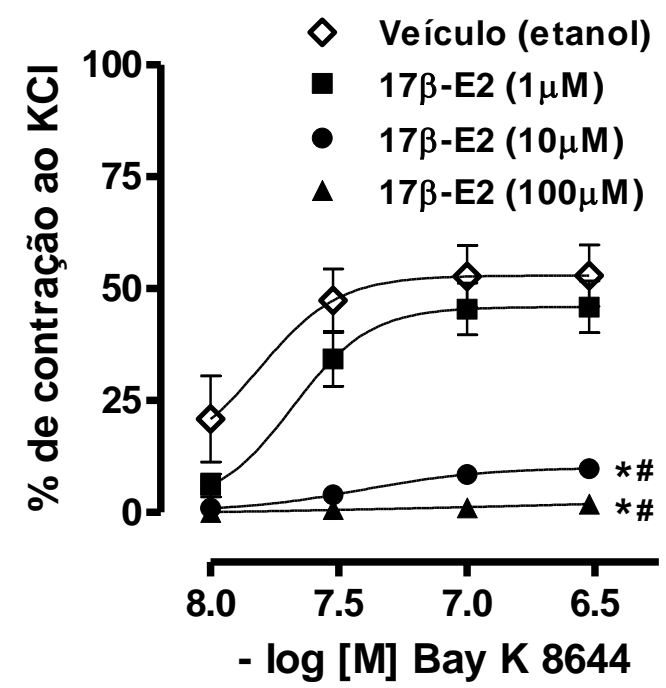

Os resultados são representados como média \pm epm. O número de ratas utilizadas em cada grupo foi de 6 . ${ }^{*} p<0,05$ vs veículo; ${ }^{*} p<0,05$ vs EQ.

$\mathrm{KCl}$ : Cloreto de Potássio.

$\mathrm{EQ}$ : Equilin.

$17 \beta-E_{2}: 17 \beta$-Estradiol.

Fonte: Filgueira (2012) 
Tabela 13 - Curvas concentração-efeito ao Bay K 8644 (\% a contração com KCl 120 mM) em artérias mesentéricas de resistência de ratas intactas incubadas (nas concentrações de 1, 10 e $100 \mu \mathrm{M}$ ) com equilin ou $17 \beta$-estradiol.

\begin{tabular}{ccc}
\hline & Equilin & $17 \beta$-Estradiol \\
Veículo (etanol) & $\mathrm{R}_{\mathrm{MAX}}$ & $\mathrm{R}_{\mathrm{MAX}}$ \\
$1 \mu \mathrm{M}$ & $49,79 \pm 4,79$ & $52,89 \pm 6,87$ \\
$10 \mu \mathrm{M}$ & $56,03 \pm 3,41$ & $45,89 \pm 5,78$ \\
$100 \mu \mathrm{M}$ & $28,61 \pm 3,87^{\star}$ & $9,78 \pm 1,64^{*}$ \\
\hline
\end{tabular}

Os valores de $\mathrm{R}_{\text {MAX }}$ (Resposta máxima) representam a média \pm epm.

O número de ratas utilizadas em cada grupo foi de 6 .

${ }^{*} \mathrm{p}<0,05$ vs veículo do respectivo grupo.

${ }^{\#} \mathrm{p}<0,05$ vs respectiva concentração da $\mathrm{R}_{\mathrm{MAX}}$ do equilin.

$\mathrm{KCl}$ : Cloreto de Potássio.

Fonte: Filgueira (2012) 


\subsection{Efeito do Equilin Sobre a Liberação de Cálcio do Retículo Sarcoplasmático}

A incubação com equilin $(100 \mu \mathrm{M})$ ou com veículo (etanol) não modificou a contração induzida pela cafeína $(20 \mathrm{mM})$, que via receptores de rianodina, promove liberação de $\mathrm{Ca}^{2+}$ dos estoques intracelulares (retículo sarcoplasmático) (Figura 14, Tabela 14). O mesmo resultado foi observado após incubação com o 17ß-estradiol (100 $\mu \mathrm{M})$ (Figura 14, Tabela 14).

Figura 14 - Resposta contrátil induzida pela cafeína $(20 \mathrm{mM})$ na ausência (controle - barra quadriculada) ou presença de equilin (100 $\mu \mathrm{M}$ - barra branca), 17ß-estradiol (100 $\mu \mathrm{M}$ - barra preta) ou veículo (etanol - barras riscadas), em artérias mesentéricas de resistência sem endotélio de ratas intactas.

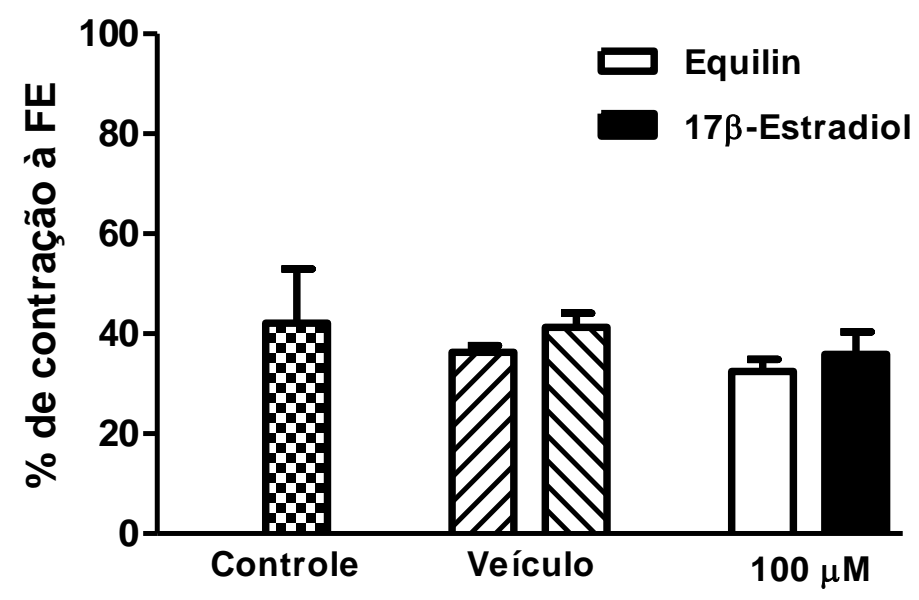

Os dados são expressos como porcentagem de contração a FE $(1 \mu \mathrm{M})$. Os resultados são representados como média \pm epm. O número de ratas utilizadas em cada grupo foi de 6 . FE: Fenilefrina.

Fonte: Filgueira (2012) 
Tabela 14 - Resposta contrátil induzida pela cafeína $(20 \mathrm{mM})$ em artérias mesentéricas de resistência de ratas intactas na ausência (controle) ou presença de equilin $(100 \mu \mathrm{M}), 17 \beta$-estradiol $(100 \mu \mathrm{M})$ ou veículo (etanol).

\begin{tabular}{cc}
\hline Incubações & Resposta induzida pela cafeína \\
\hline Controle & $42,09 \pm 10,83$ \\
Veículo (etanol) & $36,32 \pm 1,30$ \\
Equilin $(100 \mu \mathrm{M})$ & $32,45 \pm 2,42$ \\
Veículo (etanol) & $41,27 \pm 2,85$ \\
$17 \beta$-Estradiol $(100 \mu \mathrm{M})$ & $35,91 \pm 4,50$ \\
\hline
\end{tabular}

Os valores da resposta contrátil induzida pela cafeína representam a média \pm epm.

Os dados são expressos como porcentagem de contração a fenilefrina (1 $\mu \mathrm{M})$.

O número de ratas utilizadas em cada grupo foi de 6 .

Fonte: Filgueira (2012) 


\section{DISCUSSÃO}

Demonstramos neste trabalho que o efeito relaxante promovido pelo equilin em artérias mesentéricas de resistência de ratas espontaneamente hipertensas é caracterizado como agudo, não-genômico e independente da presença das células endoteliais. Adicionalmente, mostramos que esta ação vasorelaxante induzida pelo equilin ocorre através do bloqueio de influxo de cálcio, mais especificamente, canais de cálcio dependentes de voltagem do tipo $L$.

Mulheres no período pós-menopausa, fase esta associada com diminuição dos níveis hormonais, apresentam maior risco de desenvolvimento de DCVs, com a HA ganhando atenção especial. O modelo experimental de hipertensão utilizado no presente estudo (SHR) apresenta características similares àquelas encontradas na HA primária, tipo mais comum de hipertensão em humanos, justificando assim a escolha deste modelo para o desenvolvimento do presente trabalho. Além disso, neste modelo experimental observa-se níveis pressóricos aumentados nos machos em relação às fêmeas. Outra semelhança importante, além desta diferença sexual, é o fato das fêmeas após remoção cirúrgica dos ovários apresentarem aumento da $\mathrm{PA}^{10}$, o que mimetiza as modificações que podem ser encontradas nas mulheres pós-menopausadas ou que tiveram os ovários removidos cirurgicamente ${ }^{5}$.

A eficácia do procedimento cirúrgico (ovariectomia) realizado em nosso estudo foi verificada avaliando a massa corpórea e o peso uterino dos animais. $O$ aumento do peso corpóreo acompanhado da redução significativa do peso uterino nas ratas ovariectomizadas, parâmetros já esperados devido à experiência prévia de outros estudos realizados em nosso grupo de pesquisa ${ }^{84-85}$, comprovaram a eficácia da ovariectomia. Além disso, em estudo paralelo a este, utilizando também ratas SHR, verificamos uma diminuição significativa do peso uterino e aumento do peso corporal, além da diminuição abrupta dos níveis hormonais (sham: $20 \pm 3 \mathrm{pg} / \mathrm{mL}$ vs ovariectomizadas: $4 \pm 1 \mathrm{pg} / \mathrm{mL})^{86}$. Outros trabalhos da literatura demonstraram dados que corroboram aqueles obtidos neste estudo ${ }^{87-88}$. É importante salientar ainda que estudos com mulheres também demonstraram que estas apresentam ganho de peso e acúmulo de gordura abdominal de modo mais acelerado durante o período da menopausa ${ }^{89}$, semelhantemente ao observado no modelo experimental utilizado em nosso estudo. 
Diversos estudos têm demonstrado efeitos benéficos de compostos estrogênicos, reduzindo por exemplo, a incidência de doenças coronarianas em mulheres menopausadas ${ }^{12-15}$. Reforçando estes dados, estudos prévios realizados pelo nosso grupo demonstraram o efeito benéfico do $17 \beta$-estradiol em diferentes modelos de hipertensão arterial ${ }^{10-11}$. De fato, não há dúvidas de que, dentre os hormônios sexuais femininos, o $17 \beta$-estradiol tem sido o principal alvo de investigação, sendo descrito como o hormônio feminino mais potente e presente em maior concentração na circulação. Por isso, grande parte dos estudos que avaliaram o efeito vasodilatador dos estrógenos, utilizaram o 17ß-estradiol como ferramenta principal das investigações ${ }^{75-76,90-92}$. Embora estes estudos anteriores tenham avaliado as ações vasculares de compostos estrogênicos, não há até o presente momento, estudos investigando os efeitos vasculares diretos do equilin em artérias mesentéricas de resistência, que representam um território vascular importante para o controle da resistência vascular periférica. Neste sentido, nosso estudo apresenta resultados importantes referentes à ação de outro composto estrogênico, o equilin, que parece apresentar efeitos vasculares tão relevantes quanto aqueles promovidos pelo $17 \beta$-estradiol.

Os estudos que investigaram a ação de outras substâncias estrogênicas diferentes do $17 \beta$-estradiol, normalmente utilizaram este último como controle, uma vez que os mecanismos envolvidos em seus efeitos já se encontram bem descritos na literatura. Teoh et al. (2009) ${ }^{76}$ avaliaram a resposta relaxante de artérias coronárias de porcos a alguns estrógenos como a estrona, o 17a-estradiol e também o estrógeno sintético dietilestilbestrol (DES), comparando com o 17ß-estradiol. Estes autores, embora não tenham avaliado os mecanismos envolvidos na ação vascular direta dos mesmos, demonstraram que todos esses compostos apresentaram um efeito vasodilatador, sendo que a estrona e o DES foram menos efetivos do que o $17 \beta$-estradiol em aumentar a resposta vasodilatora e diminuir a resposta contrátil a diferentes agentes farmacológicos. Ainda no mesmo trabalho, o relaxamento vascular da estrona foi de aproximadamente 34\%, resposta semelhante àquela encontrada em nosso estudo (intactas e ovariectomizadas: $41 \%$ ), sugerindo que a ação vascular apresentada por este hormônio ocorre de modo independente da preparação vascular e/ou da espécie animal, porém com eficácia inferior à do $17 \beta$ estradiol. 
Os resultados observados com o efeito vasodilatador do $17 \alpha$-estradiol (intactas: 56\% e ovariectomizadas: $71 \%$ ) foram diferentes daquele encontrado por Teoh et al. (2009) ${ }^{76}$, onde o efeito relaxante deste mesmo hormônio foi em torno de 22\%. Além disso, em estudo de Naderali et al. $(1999)^{75}$, utilizando artérias mesentéricas de resistência, porém de ratos normotensos, demonstrou-se uma ação vasodilatadora para o $17 \alpha$-estradiol semelhante à do $17 \beta$-estradiol (100\%), efeito este superior ao encontrado em nosso estudo. A discrepância entre os resultados pode ser explicada pela diferença do modelo e espécie animal ou até mesmo pela diferença sexual dos animais. Como comentado, Teoh et al. utilizaram artérias coronárias de porcos enquanto Naderali et al. usaram ratos Wistar (normotensos), diferentemente de nosso estudo, onde os experimentos foram realizados em artérias mesentéricas de ratas SHR.

Em nosso trabalho, demonstramos que altas concentrações (3-100 $\mu \mathrm{M})$ de equilin promoveram vasodilatação em artérias mesentéricas de ratas SHR, que se mostrou ser dependente de concentração. Em virtude do fato da resposta vasorelaxante promovida pelo equilin ter sido a maior em relação aos outros hormônios avaliados (estrona e 17a-estradiol, figura 4), e aliado ao fato de que o $17 \beta$-estradiol apresenta seus efeitos bem caracterizados em diferentes vasos sanguíneos de diversas espécies, decidimos avaliar o mecanismo de ação vascular envolvido no relaxamento mediado pelo equilin comparando com o efeito do $17 \beta$ estradiol.

Observamos em nosso estudo que o efeito vasorelaxante do equilin foi semelhante ao do $17 \beta$-estradiol (figura 4), tanto em artérias mesentéricas de resistência de ratas intactas quanto de ratas ovariectomizadas. Os efeitos vasculares do $17 \beta$-estradiol e de outros estrógenos como, por exemplo, o tamoxifeno e o raloxifeno, que pertencem à classe dos SERMs, têm sido extensivamente investigados. Entretanto, pelo nosso conhecimento, há apenas um trabalho na literatura ${ }^{93}$, até o presente momento, que investigou a ação do equilin sobre a vasculatura, estrógeno este, como já comentado, responsável por $24 \%$ da composição do Premarin. Neste estudo citado, ratas Sprague-Dawley previamente ovariectomizadas foram tratadas (via gavagem) com veículo e com cinco diferentes estrógenos, dentre eles, o equilin. Estudando a reatividade vascular a três agentes vasoconstritores no leito arteriolar mesentérico isolado e perfundido dessas ratas, o trabalho de Mark et al. (2007) ${ }^{93}$ demonstrou que o tratamento crônico com equilin, 
além de promover aumento dos níveis pressóricos desses animais, também aumentou a sensibilidade aos agentes vasoconstritores testados. O tamoxifen e o etilinilestradiol promoveram efeitos semelhantes aos do equilin. As aparentes divergências entre os resultados observados por estes autores e aqueles verificados no presente estudo podem ser explicadas por fatores como a espécie animal utilizada (ratas Sprague-Dawley versus ratas SHR); o território vascular estudado (leito arteriolar mesentérico isolado e perfundido versus artérias mesentéricas de resistência); ou o tipo de tratamento utilizado (tratamento crônico in vivo versus ação vascular aguda in vitro).

De modo semelhante ao observado com o $17 \beta$-estradiol, observamos no presente estudo que o efeito vasorelaxante do equilin ocorre de modo agudo (6-8 minutos a cada concentração), sugerindo que sua ação vascular direta não tem participação de mecanismos que envolvam síntese protéica e/ou transcrição gênica. Estudos anteriores já demonstraram que o 17ß-estradiol tem um efeito vasorelaxante direto e rápido, possivelmente mediado por ação não-genômica ${ }^{75,94-}$ ${ }^{96}$. Estes trabalhos também demostraram que o efeito vasorelaxante do $17 \beta$-estradiol não foi modificado frente à inibição de síntese protéica ou da transcrição gênica.

Bhavnani (2003) demonstrou que todos os compostos presentes no Premarin são biologicamente ativos e podem interagir com ERa e ER $\beta^{97}$. A presença dos ERs já foi descrita em vasos sanguíneos ${ }^{40-43}$ e demonstrou-se que a ovariectomia reduz o número desses receptores em artérias mesentéricas ${ }^{98}$. No estudo de Bhavnani (2003), a interação dos diferentes estrógenos foi comparada com o 17ß-estradiol, e o equilin apresentou afinidade reduzida pelo ERa e pelo ER $\beta$, assim como a estrona e o $17 \alpha$-estradiol. Com base nestes dados, hipotetizamos que os diferentes efeitos (demonstradas pela resposta máxima) promovidos por cada um desses hormônios no presente estudo poderiam ocorrer pela diferente afinidade destes com os ERs. Entretanto, de modo similar ao observado com o 17ß-estradiol, o antagonismo destes receptores pela incubação com o composto ICI 182,780, não alterou o efeito vasorelaxante promovido pelo equilin, excluindo a participação de receptores clássicos para estrógeno no efeito vasodilatador do equilin. Este dado sugere ainda que os possíveis efeitos benéficos do equilin poderiam ocorrer independentemente da quantidade de receptores expressos, o que se torna de grande relevância em condições onde exista a ausência endógena de hormônios, como a menopausa em mulheres. 
De grande relevância, é importante ressaltar estudos prévios que demonstraram que o 17ß-estradiol é capaz de modular a expressão de ER em diferentes tecidos, incluindo vasos sanguíneos. Portanto, respostas dependentes de ERs podem ser intimamente relacionadas aos níveis hormonais ${ }^{99}$. De fato, estudos anteriores demonstraram que variações nos níveis de hormônios sexuais são capazes de alterar a resposta de vasos sanguíneos à subsequente aplicação de $17 \beta$-estradiol ${ }^{100}$. Além disso, demonstrou-se que a vasodilatação a agonistas seletivos de ERa é abolida em aorta de fêmeas submetidas à ovariectomia ${ }^{101}$. Com base nestes estudos, o presente trabalho investigou se a mudança nos níveis hormonais promovida pela ovariectomia seria capaz de afetar a resposta vascular induzida pelo equilin. Entretanto, nossos dados demonstraram que a ovariectomia não alterou o efeito vasodilatador promovido pelo equilin. Além disso, não verificamos nenhuma diferença entre as respostas ao equilin nas artérias mesentéricas de resistência isoladas de ratas intactas e ovariectomizadas quando na presença de antagonista de ERs. Deste modo, a ausência de participação de ERs nos efeitos promovidos pelo equilin (de modo semelhante ao 17 $\beta$-estradiol) poderia justificar a semelhança nas respostas mediadas tanto pelo equilin quanto pelo $17 \beta$-estradiol nas artérias mesentéricas de resistência dos grupos estudados. Diante destes resultados, a sequência de experimentos do presente estudo foi realizada apenas com o grupo de ratas intactas.

A ausência de participação dos receptores clássicos para estrógeno na vasodilatação induzida pelo equilin não descarta a afinidade deste com outros receptores envolvidos nos efeitos dos hormônios estrogênicos. Neste sentido, a descoberta do novo receptor estrogênico (GPER ou GPR30) e que parece estar envolvido nas ações vasculares dos estrógenos, abriu uma nova linha para estudos que avaliam o mecanismo de ação vascular dos hormônios sexuais femininos. Neste sentido, estudo recente demonstrou que o composto G-15, um antagonista do GPER, atenuou a vasodilatação induzida tanto pelo $17 \beta$-estradiol quanto pelo agonista do GPER em artéria mesentérica de resistência de ratas mRen2.Lewis (modelo de hipertensão dependente de estrógeno e de angiotensina II) ${ }^{102}$. Com base nesses estudos e considerando a semelhança do mecanismo de ação do equilin e do $17 \beta$-estradiol, podemos inferir uma provável participação do GPER no efeito promovido pelo equilin. 
A presença do GPER explica ainda a ativação de vias de sinalização intracelulares de forma independente de receptores clássicos para estrógenos, dentre as quais destaca-se a via adenilato ciclase/AMPc/PKA ${ }^{103-105}$. A participação desta cascata de sinalização na vasodilatação induzida pelo equilin foi avaliada no presente estudo, entretanto nossos dados demonstraram que, semelhantemente ao observado com o 17ß-estradiol, as enzimas adenilato ciclase e PKA não estão envolvidas no efeito vasodilatador do equilin.

De modo bastante interessante, os dados do presente estudo demonstraram que o equilin promoveu vasodilatação de maneira totalmente independente da presença do endotélio, indicando que o efeito deste hormônio ocorre mediante ação direta nas células do músculo liso vascular. Como esperado, o efeito do $17 \beta-$ estradiol também demonstrou ser independente de endotélio corroborando resultados observados em diversos trabalhos utilizando artérias isoladas de ratos ${ }^{73}$, ${ }^{106}$, coelhos $^{107}$, porcos $^{72,108}$ ou humanos ${ }^{109}$.

A ativação e o aumento da expressão da eNOS pelo $17 \beta$-estradiol têm sido relatados no sistema cardiovascular ${ }^{55}$. Mais recentemente, estudos têm fornecido também evidência para um papel importante da nNOS em células endoteliais e em células do músculo liso vascular ${ }^{110-112}$. De acordo com o trabalho de White et al. $(2002)^{113}$, o estrógeno é capaz de aumentar a intensidade de fluorescência induzida pelo NO em cultura de células musculares lisas de artérias coronárias de humanos na ausência de endotélio. Este poderia proporcionar um mecanismo para explicar o efeito relaxante do estrógeno por meio de um mecanismo dependente de NO e independente do endotélio. Entretanto, os dados do presente estudo demonstraram que em artérias mesentéricas, a inibição farmacológica da via NO/cGMP/PKG com L-NAME, ODQ e KT 5823, respectivamente, não afetou o relaxamento induzido pelo equilin ou pelo $17 \beta$-estradiol, sugerindo que a cascata dependente de NO não participa do relaxamento promovido pelo equilin.

É importante considerar que o bloqueio farmacológico de um sistema pode ativar mecanismos compensatórios. No caso específico do nosso estudo, além do NO, os prostanóides vasodilatadores são também fatores importantes no relaxamento vascular. Apesar de apresentarem mecanismos de ação distintos, há evidências de uma inter-relação complexa e bem integrada entre estes mediadores, de modo a garantir a manutenção do tônus vascular, podendo também ocorrer como mecanismo compensatório que é ativado quando a expressão ou atividade de um 
dos mediadores está diminuída. A este respeito, é importante destacar que a inibição simultânea da NOS e da COX com uma combinação de L-NAME e indometacina não alterou as respostas relaxantes induzidas pelo equilin ou pelo $17 \beta$-estradiol, excluindo assim um papel para o NO e/ou para os prostanóides vasodilatadores nos efeitos promovidos por estes compostos.

De modo diferente do observado no presente trabalho, Wingrove et al. $(1999)^{114}$ avaliaram o efeito de diferentes estrogénos encontrados no Premarin, utilizando culturas de células endoteliais de artéria coronária humana, e demonstraram que o equilin apresenta a capacidade de estimular a expressão de eNOS. As diferenças encontradas entre os resultados deste estudo e aqueles obtidos em nosso trabalho, poderiam ser explicadas pelo tipo diferente de território vascular bem como por diferença na espécie estudada. Além disso, nesse estudo, os autores avaliaram o efeito do equilin após 24 horas de incubação, evento este que nos sugere um efeito genômico do equilin, o que não explicaria o mecanismo não-genômico proposto em nosso estudo. De fato, os estudos que investigaram a ação dos estrógenos na expressão da NOS e na geração e/ou biodisponibilidade do NO, avaliaram o efeito da administração crônica (tratamento in vivo) deste hormônio, o que pode constituir não apenas ação vascular direta destes compostos, mas também consequência de suas ações metabólicas ou genômicas ${ }^{115-116}$. Por outro lado, como já citado, estudos que avaliaram o tratamento in vitro de preparações vasculares em banhos de órgãos isolados, observaram uma ação vasodilatadora independente de $\mathrm{NO}^{75,94}$. Estes dados nos levam a sugerir que o efeito promovido pelo equilin, pelo menos in vitro, de fato, não envolve a participação do NO.

Tem sido demonstrado que a abertura de canais de potássio pode estar envolvida na vasodilatação independente de NO ou de prostanóides mediada por compostos estrogênicos ${ }^{74,113}$. Os canais de $\mathrm{K}^{+}$envolvidos no relaxamento do músculo liso vascular incluem: canais de $\mathrm{K}^{+}$ativados por cálcio, canais de $\mathrm{K}^{+}$ dependentes de voltagem, canais de $\mathrm{K}^{+}$sensíveis a ATP e canais retificadores de $\mathrm{K}^{+117}$.

A primeira evidência de que o estrógeno atua hiperpolarizando o músculo liso vascular por aumentar a condutância ao $\mathrm{K}^{+}$foi concedida pelo estudo de Harder $\mathrm{e}$ Coulson em 1979 ${ }^{118}$. A partir deste estudo, outros trabalhos que avaliaram a resposta vasorelaxante do $17 \beta$-estradiol em artérias coronárias de porcos ${ }^{74}$ ou em artérias uterinas de ovelhas ${ }^{119}$ demonstraram o envolvimento de canais de $\mathrm{K}^{+}$ 
ativados por cálcio. Além disso, Tep-areenan et al. $(2003)^{96}$ demonstraram que no leito arteriolar mesentérico de ratos Wistar, a ativação de canais de $\mathrm{K}^{+}$ativados por cálcio e dependentes de voltagem está envolvida no efeito relaxante promovido pelo $17 \beta$-estradiol. Entretanto, em nosso estudo, demonstramos que o efeito do equilin não está relacionado com aumento do efluxo de $\mathrm{K}^{+}$através de canais de $\mathrm{K}^{+}$de baixa, intermediária e alta condutância ativados por cálcio, nem através de canais de $\mathrm{K}^{+}$sensíveis ao ATP ou de canais de $\mathrm{K}^{+}$dependentes de voltagem, uma vez que as drogas farmacológicas que bloqueiam estes canais não alteraram a resposta vascular do equilin. Os mesmos resultados foram observados com o 17 $\beta$-estradiol, indicando mais uma vez, mecanismo de ação similar destes dois compostos. É importante ressaltar que os resultados obtidos em nosso estudo com o $17 \beta$-estradiol são diferentes daqueles observados nos estudos anteriormente descritos. Estas diferenças provavelmente se devem ao tipo de preparação e/ou o modelo animal utilizado para tal investigação.

O efeito vasorelaxante dos estrógenos tem sido atribuído à capacidade destes compostos de reduzir as concentrações de cálcio intracelular ${ }^{70-73}$. O cálcio representa um papel fundamental na contração induzida por diversos agentes em quase todas células de músculo liso. A ativação de receptores pode liberar cálcio dos estoques intracelulares e/ou promover influxo de cálcio a partir do meio extracelular. O influxo de cálcio ocorre predominantemente via canais de cálcio operados por voltagem (VOCCs - voltage-operated calcium channels) ou canais de cálcio operados por receptor (ROCCs - receptor-operated calcium channels). A contração de artérias induzida pelo $\mathrm{KCl}$ se dá pela despolarização da membrana causando entrada de cálcio através de VOCCs, com ativação de quinase de cadeia leve de miosina (MLC - myosin light chain) dependente de cálcio e aumento na fosforilação da MLC. Por outro lado, a contração a agonistas de receptores acoplados a proteína G é mediada por aumento nos níveis de cálcio intracelular através do influxo de cálcio do meio extracelular via ROCCs, bem como através da liberação de cálcio dos estoques intracelulares ${ }^{120}$. É importante ressaltar ainda estudos que demonstram que o $\mathrm{KCl}$ pode também estimular sistemas complexos de sinalização do cálcio e não apenas promover seu efeito por ativar VOCCs ${ }^{120}$. Esta contração ao $\mathrm{KCl}$ pode ocorrer por exemplo através da sensibilização do cálcio via translocação e ativação de quinases, incluindo ROK (Rhoa kinase) ${ }^{121}$ e proteína quinase $\mathrm{C}^{122}$. 
O fato, por nós observado, de que o equilin promoveu sua ação vasorelaxante em artérias mesentéricas de resistência pré-contraídas tanto pelo $\mathrm{KCl}$ quanto por agonistas de receptores acoplados a proteína G (os compostos U46619 e ET-1), indica que o equilin teve seu efeito vasodilatador via bloqueio do influxo de cálcio pela ativação tanto de VOCCs quanto de ROCCs.

Evidências adicionais de que o efeito vasorelaxante do equilin envolve o bloqueio do influxo de cálcio foram proporcionadas em nosso estudo pela realização de curvas concentração-efeito ao cloreto de cálcio em artérias mesentéricas de resistência (com endotélio removido) em meio despolarizante e livre de cálcio. Verificamos que o equilin, assim como o 17ß-estradiol, bloqueou a contração induzida pelo cloreto de cálcio. Este resultado nos indica que o equilin, de fato, promove relaxamento de artérias mesentéricas por bloquear o influxo de cálcio extracelular.

Em estudo realizado por Tosun et al. $(1998)^{123}$, demonstrou-se que a contração mediada pelo receptor prostanóide depende do influxo de cálcio extracelular através de canais de cálcio do tipo L. O (S)-(-)-Bay K 8644 é um ativador específico destes canais ${ }^{124}$. A incubação prévia com equilin (10 $\mu \mathrm{M}$ e 100 $\mu \mathrm{M})$ reduziu o efeito do Bay K 8644 de maneira dependente de concentração. Estas observações nos indicam que o equilin promove seus efeitos bloqueando especificamente canais de cálcio do tipo $L$, de modo semelhante ao $17 \beta$-estradiol. Este efeito promovido pelo $17 \beta$-estradiol está de acordo com o observado em artéria mesentérica superior, caudal e em aorta de ratos, assim como nas artérias coronária e carótida de coelhos ${ }^{75,96,107,125-126}$. Entretanto, pelo nosso conhecimento, este é o primeiro estudo a demonstrar o efeito do equilin como bloqueador de canais de cálcio do tipo L.

Embora tenha sido demonstrado no presente estudo que o equilin bloqueia o influxo de cálcio extracelular, este hormônio não promove seu efeito através do bloqueio da liberação de cálcio dos estoques intracelulares em células do músculo liso vascular, uma vez que se mostrou incapaz de bloquear a contração transitória induzida pela cafeína. Deste modo, podemos sugerir que o equilin promove seu efeito vasorelaxante predominantemente devido ao bloqueio do influxo de cálcio pela membrana celular. Esta propriedade poderia constituir um dos principais mecanismos de relaxamento independente de endotélio induzido pelo equilin em preparações de artérias mesentéricas de resistência de ratas SHR. 
É importante mencionar que o efeito promovido pelo $17 \beta$-estradiol foi semelhante ao induzido pelo equilin. Confirmando nossos dados, diversos estudos demonstraram que o $17 \beta$-estradiol promove seu efeito vasorelaxante através do bloqueio de influxo de cálcio e que este efeito não envolve o bloqueio da contração transitória promovida pela liberação de cálcio dos estoques intracelulares ${ }^{70-73}$. 


\section{CONCLUSÕES}

Os resultados apresentados neste estudo permitem-nos concluir que o efeito vascular promovido pelo equilin em artérias mesentéricas de resistência de ratas geneticamente hipertensas é caracterizado como agudo e provavelmente nãogenômico, além de não envolver a participação de receptores estrogênicos bem como a via adenilato ciclase/PKA. Além disso, este efeito é independente da presença do endotélio e da via NO/GMPc/PKG. A resposta vasodilatadora do equilin não envolve a liberação de prostanóides vasodilatadores e nem a ativação de diferentes canais de $\mathrm{K}^{+}$. Este efeito vasorelaxante induzido pelo equilin ocorre independente do bloqueio da liberação de cálcio intracelular e se deve predominantemente ao bloqueio do influxo de cálcio, principalmente bloqueando canais de cálcio do tipo L. Assim, podemos concluir que o efeito vasodilatador do equilin em artérias de resistência de ratas hipertensas poderia promover uma ação benéfica ao sistema vascular. 


\section{REFERÊNCIAS*}

1. Shelfer L. The alchemy of Jargon: etymologies of urologic neologisms. Number 3: the genesis of steroid terminology. Prostate. 2009;69(3):228-30.

2. White RE. Estrogen and vascular function. Vascul Pharmacol. 2002;38(2):7380.

3. Kearney PM, Whelton M, Reynolds K, Muntner P, Whelton PK, He J. Global burden of hypertension: analysis of worldwide data. Lancet. 2005;365(9455):217-23.

4. Pereira M, Lunet $\mathrm{N}$, Azevedo $\mathrm{A}$, Barros $\mathrm{H}$. Differences in prevalence, awareness, treatment and control of hypertension between developing and developed countries. J Hypertens. 2009;27(5):963-75.

5. Thompson J, Khalil RA. Gender differences in the regulation of vascular tone. Clin Exp Pharmacol Physiol. 2003;30(1-2):1-15.

6. Chen YF, Meng QC. Sexual dimorphism of blood pressure in spontaneously hypertensive rats is androgen dependent. Life Sci. 1991;48(1):85-96.

7. Ouchi Y, Share L, Crofton JT, litake K, Brooks DP. Sex difference in the development of deoxycorticosterone-salt hypertension in the rat. Hypertension. 1987;9(2):172-7.

8. Rowland NE , Fregly MJ. Role of gonadal hormones in hypertension in the Dahl salt-sensitive rat. Clin Exp Hypertens A. 1992;14(3):367-75.

9. Ashton N, Balment RJ. Sexual dimorphism in renal function and hormonal status of New Zealand genetically hypertensive rats. Acta Endocrinol (Copenh). 1991;124(1):91-7.

10. Dantas AP, Franco Mdo C, Silva-Antonialli MM, Tostes RC, Fortes ZB, Nigro $D$, et al. Gender differences in superoxide generation in microvessels of hypertensive rats: role of NAD(P)H-oxidase. Cardiovasc Res. 2004;61(1):22-9.

11. Montezano AC, Callera GE, Mota AL, Fortes ZB, Nigro D, Carvalho MH, et al. Endothelin-1 contributes to the sexual differences in renal damage in DOCAsalt rats. Peptides. 2005;26(8):1454-62.

12. Bush TL, Barrett-Connor E, Cowan LD, Criqui MH, Wallace RB, Suchindran $\mathrm{CM}$, et al. Cardiovascular mortality and noncontraceptive use of estrogen in women: results from the Lipid Research Clinics Program Follow-up Study. Circulation. 1987;75(6):1102-9.

\footnotetext{
* De acordo com:

International Commitee of Medical Journal Editors. Uniform requirements for manuscripts submitted to Biomedical Journal: sample references. Available from: http://www.icmje.org [2011 Jul 15].
} 
13. Stampfer MJ, Colditz GA, Willett WC, Manson JE, Rosner B, Speizer FE, et al. Postmenopausal estrogen therapy and cardiovascular disease. Ten-year follow-up from the nurses' health study. N Engl J Med. 1991;325(11):756-62.

14. Varas-Lorenzo C, Garcia-Rodriguez LA, Perez-Gutthann S, Duque-Oliart A. Hormone replacement therapy and incidence of acute myocardial infarction. A population-based nested case-control study. Circulation. 2000;101(22):25728.

15. Mosca L, Manson JE, Sutherland SE, Langer RD, Manolio T, Barrett-Connor E. Cardiovascular disease in women: a statement for healthcare professionals from the American Heart Association. Writing Group. Circulation. 1997;96(7):2468-82.

16. Stampfer MJ, Colditz GA. Estrogen replacement therapy and coronary heart disease: a quantitative assessment of the epidemiologic evidence. Prev Med. $1991 ; 20(1): 47-63$.

17. Hulley S, Grady D, Bush T, Furberg C, Herrington D, Riggs B, et al. Randomized trial of estrogen plus progestin for secondary prevention of coronary heart disease in postmenopausal women. Heart and Estrogen/progestin Replacement Study (HERS) Research Group. JAMA. 1998;280(7):605-13.

18. Rossouw JE, Anderson GL, Prentice RL, LaCroix AZ, Kooperberg C, Stefanick ML, et al. Risks and benefits of estrogen plus progestin in healthy postmenopausal women: principal results From the Women's Health Initiative randomized controlled trial. JAMA. 2002;288(3):321-33.

19. Grady D, Herrington D, Bittner V, Blumenthal R, Davidson M, Hlatky M, et al. Cardiovascular disease outcomes during 6.8 years of hormone therapy: Heart and Estrogen/progestin Replacement Study follow-up (HERS II). JAMA. 2002;288(1):49-57.

20. Anderson GL, Limacher M, Assaf AR, Bassford T, Beresford SA, Black H, et al. Effects of conjugated equine estrogen in postmenopausal women with hysterectomy: the Women's Health Initiative randomized controlled trial. JAMA. 2004;291(14):1701-12.

21. Windler E, Zyriax BC, Eidenmuller B, Boeing H. Hormone replacement therapy and risk for coronary heart disease. Data from the CORA-study--a case-control study on women with incident coronary heart disease. Maturitas. 2007;57(3):239-46.

22. Clarkson TB, Appt SE. Controversies about HRT--lessons from monkey models. Maturitas. 2005;51(1):64-74.

23. Rosenfeld ME, Kauser K, Martin-McNulty B, Polinsky P, Schwartz SM, Rubanyi GM. Estrogen inhibits the initiation of fatty streaks throughout the vasculature but does not inhibit intra-plaque hemorrhage and the progression of established lesions in apolipoprotein $E$ deficient mice. Atherosclerosis. 2002;164(2):251-9. 
24. Hanke H, Kamenz J, Hanke S, Spiess J, Lenz C, Brehme U, et al. Effect of 17-beta estradiol on pre-existing atherosclerotic lesions: role of the endothelium. Atherosclerosis. 1999;147(1):123-32.

25. Dubey RK, Imthurn B, Barton M, Jackson EK. Vascular consequences of menopause and hormone therapy: importance of timing of treatment and type of estrogen. Cardiovasc Res. 2005;66(2):295-306.

26. Brzezinski A, Danenberg HD. Estrogen, progesterone, and cardiovascular health: when shall we complete the puzzle? Menopause. 2005;12(5):488-91.

27. Ostrzenski A, Ostrzenska KM. WHI clinical trial revisit: imprecise scientific methodology disqualifies the study's outcomes. Am J Obstet Gynecol. 2005;193(5):1599-604; discussion 1605-6.

28. Ruggiero RJ, Likis FE. Estrogen: physiology, pharmacology, and formulations for replacement therapy. J Midwifery Womens Health. 2002;47(3):130-8.

29. Berrodin TJ, Chang KC, Komm BS, Freedman LP, Nagpal S. Differential biochemical and cellular actions of Premarin estrogens: distinct pharmacology of bazedoxifene-conjugated estrogens combination. Mol Endocrinol. 2009;23(1):74-85.

30. Rosenfeld CR, Killam AP, Battaglia FC, Makowski EL, Meschia G. Effect of estradiol-17, on the magnitude and distribution of uterine blood flow in nonpregnant, oophorectomized ewes. Pediatr Res. 1973;7(3):139-48.

31. Mendelsohn ME, Karas $\mathrm{RH}$. The protective effects of estrogen on the cardiovascular system. N Engl J Med. 1999;340(23):1801-11.

32. Bhalla RC, Toth KF, Bhatty RA, Thompson LP, Sharma RV. Estrogen reduces proliferation and agonist-induced calcium increase in coronary artery smooth muscle cells. Am J Physiol. 1997;272(4 Pt 2):H1996-2003.

33. Morales DE, McGowan KA, Grant DS, Maheshwari S, Bhartiya D, Cid MC, et al. Estrogen promotes angiogenic activity in human umbilical vein endothelial cells in vitro and in a murine model. Circulation. 1995;91(3):755-63.

34. Krasinski K, Spyridopoulos I, Asahara T, van der Zee R, Isner JM, Losordo DW. Estradiol accelerates functional endothelial recovery after arterial injury. Circulation. 1997;95(7):1768-72.

35. Spyridopoulos I, Sullivan AB, Kearney M, Isner JM, Losordo DW. Estrogenreceptor-mediated inhibition of human endothelial cell apoptosis. Estradiol as a survival factor. Circulation. 1997;95(6):1505-14.

36. Nathan L, Pervin S, Singh R, Rosenfeld M, Chaudhuri G. Estradiol inhibits leukocyte adhesion and transendothelial migration in rabbits in vivo : possible mechanisms for gender differences in atherosclerosis. Circ Res. 1999;85(4):377-85. 
37. Caulin-Glaser T, Watson CA, Pardi R, Bender JR. Effects of 17beta-estradiol on cytokine-induced endothelial cell adhesion molecule expression. J Clin Invest. 1996;98(1):36-42.

38. Walter P, Green S, Greene G, Krust A, Bornert JM, Jeltsch JM, et al. Cloning of the human estrogen receptor cDNA. Proc Natl Acad Sci $U S A$. $1985 ; 82(23): 7889-93$.

39. Kuiper GG, Enmark E, Pelto-Huikko M, Nilsson S, Gustafsson JA. Cloning of a novel receptor expressed in rat prostate and ovary. Proc Natl Acad Sci U S A. 1996;93(12):5925-30.

40. Karas $\mathrm{RH}$, Patterson BL, Mendelsohn ME. Human vascular smooth muscle cells contain functional estrogen receptor. Circulation. 1994;89(5):1943-50.

41. Register TC, Adams MR. Coronary artery and cultured aortic smooth muscle cells express mRNA for both the classical estrogen receptor and the newly described estrogen receptor beta. J Steroid Biochem Mol Biol. 1998;64(34):187-91.

42. Andersson C, Lydrup ML, Ferno M, Idvall I, Gustafsson J, Nilsson BO. Immunocytochemical demonstration of oestrogen receptor beta in blood vessels of the female rat. J Endocrinol. 2001;169(2):241-7.

43. Lin AL, Shain SA. Estrogen-mediated cytoplasmic and nuclear distribution of rat cardiovascular estrogen receptors. Arteriosclerosis. 1985;5(6):668-77.

44. Toran-Allerand CD, Guan X, MacLusky NJ, Horvath TL, Diano S, Singh M, et al. ER-X: a novel, plasma membrane-associated, putative estrogen receptor that is regulated during development and after ischemic brain injury. $J$ Neurosci. 2002;22(19):8391-401.

45. Revankar CM, Cimino DF, Sklar LA, Arterburn JB, Prossnitz ER. A transmembrane intracellular estrogen receptor mediates rapid cell signaling. Science. 2005;307(5715):1625-30.

46. Effects of estrogen or estrogen/progestin regimens on heart disease risk factors in postmenopausal women. The Postmenopausal Estrogen/Progestin Interventions (PEPI) Trial. The Writing Group for the PEPI Trial. JAMA. 1995;273(3):199-208.

47. Koh KK, Cardillo C, Bui MN, Hathaway L, Csako G, Waclawiw MA, et al. Vascular effects of estrogen and cholesterol-lowering therapies in hypercholesterolemic postmenopausal women. Circulation. 1999;99(3):35460 .

48. Espeland MA, Hogan PE, Fineberg SE, Howard G, Schrott H, Waclawiw MA, et al. Effect of postmenopausal hormone therapy on glucose and insulin concentrations. PEPI Investigators. Postmenopausal Estrogen/Progestin Interventions. Diabetes Care. 1998;21(10):1589-95. 
49. Evans EM, Van Pelt RE, Binder EF, Williams DB, Ehsani AA, Kohrt WM. Effects of HRT and exercise training on insulin action, glucose tolerance, and body composition in older women. J Appl Physiol. 2001;90(6):2033-40.

50. Jensen LB, Vestergaard P, Hermann AP, Gram J, Eiken P, Abrahamsen B, et al. Hormone replacement therapy dissociates fat mass and bone mass, and tends to reduce weight gain in early postmenopausal women: a randomized controlled 5-year clinical trial of the Danish Osteoporosis Prevention Study. J Bone Miner Res. 2003;18(2):333-42.

51. Paech K, Webb P, Kuiper GG, Nilsson S, Gustafsson J, Kushner PJ, et al. Differential ligand activation of estrogen receptors ERalpha and ERbeta at AP1 sites. Science. 1997;277(5331):1508-10.

52. Matthews J , Gustafsson JA. Estrogen signaling: a subtle balance between ER alpha and ER beta. Mol Interv. 2003;3(5):281-92.

53. Simoncini T, Genazzani AR. Direct vascular effects of estrogens and selective estrogen receptor modulators. Curr Opin Obstet Gynecol. 2000;12(3):181-7.

54. MacRitchie AN, Jun SS, Chen Z, German Z, Yuhanna IS, Sherman TS, et al. Estrogen upregulates endothelial nitric oxide synthase gene expression in fetal pulmonary artery endothelium. Circ Res. 1997;81(3):355-62.

55. Rubanyi GM, Freay AD, Kauser K, Sukovich D, Burton G, Lubahn DB, et al. Vascular estrogen receptors and endothelium-derived nitric oxide production in the mouse aorta. Gender difference and effect of estrogen receptor gene disruption. J Clin Invest. 1997;99(10):2429-37.

56. Jun SS, Chen Z, Pace MC, Shaul PW. Estrogen upregulates cyclooxygenase-1 gene expression in ovine fetal pulmonary artery endothelium. J Clin Invest. 1998;102(1):176-83.

57. Stewart KG, Zhang $\mathrm{Y}$, Davidge ST. Estrogen decreases prostaglandin $\mathrm{H}$ synthase products from endothelial cells. J Soc Gynecol Investig. 1999;6(6):322-7.

58. Akishita M, Kozaki K, Eto M, Yoshizumi M, Ishikawa M, Toba K, et al. Estrogen attenuates endothelin-1 production by bovine endothelial cells via estrogen receptor. Biochem Biophys Res Commun. 1998;251(1):17-21.

59. Farhat MY, Abi-Younes S, Ramwell PW. Non-genomic effects of estrogen and the vessel wall. Biochem Pharmacol. 1996;51(5):571-6.

60. Prossnitz ER, Maggiolini M. Mechanisms of estrogen signaling and gene expression via GPR30. Mol Cell Endocrinol. 2009;308(1-2):32-8.

61. Chen Z, Yuhanna IS, Galcheva-Gargova Z, Karas RH, Mendelsohn ME, Shaul PW. Estrogen receptor alpha mediates the nongenomic activation of endothelial nitric oxide synthase by estrogen. J Clin Invest. 1999;103(3):401-6. 
62. Chen DB, Bird IM, Zheng J, Magness RR. Membrane estrogen receptordependent extracellular signal-regulated kinase pathway mediates acute activation of endothelial nitric oxide synthase by estrogen in uterine artery endothelial cells. Endocrinology. 2004;145(1):113-25.

63. Haynes MP, Sinha D, Russell KS, Collinge M, Fulton D, Morales-Ruiz M, et al. Membrane estrogen receptor engagement activates endothelial nitric oxide synthase via the PI3-kinase-Akt pathway in human endothelial cells. Circ Res. 2000;87(8):677-82.

64. Hisamoto K, Ohmichi M, Kurachi H, Hayakawa J, Kanda Y, Nishio Y, et al. Estrogen induces the Akt-dependent activation of endothelial nitric-oxide synthase in vascular endothelial cells. J Biol Chem. 2001;276(5):3459-67.

65. Simoncini T, Hafezi-Moghadam A, Brazil DP, Ley K, Chin WW, Liao JK. Interaction of oestrogen receptor with the regulatory subunit of phosphatidylinositol-3-OH kinase. Nature. 2000;407(6803):538-41.

66. Meyer MR, Baretella O, Prossnitz ER, Barton M. Dilation of epicardial coronary arteries by the $\mathrm{g}$ protein-coupled estrogen receptor agonists $\mathrm{G}-1$ and ICI 182,780. Pharmacology. 2010;86(1):58-64.

67. Yu X, Ma H, Barman SA, Liu AT, Sellers M, Stallone JN, et al. Activation of G protein-coupled estrogen receptor induces endothelium-independent relaxation of coronary artery smooth muscle. Am J Physiol Endocrinol Metab. $2011 ; 301(5): E 882-8$.

68. Haas E, Bhattacharya I, Brailoiu E, Damjanovic M, Brailoiu GC, Gao X, et al. Regulatory role of $G$ protein-coupled estrogen receptor for vascular function and obesity. Circ Res. 2009;104(3):288-91.

69. Traupe T, D'Uscio LV, Muenter K, Morawietz H, Vetter W, Barton M. Effects of obesity on endothelium-dependent reactivity during acute nitric oxide synthase inhibition: modulatory role of endothelin. Clin Sci (Lond). 2002;103 Suppl 48:13S-15S.

70. Crews JK, Khalil RA. Antagonistic effects of 17 beta-estradiol, progesterone, and testosterone on $\mathrm{Ca} 2+$ entry mechanisms of coronary vasoconstriction. Arterioscler Thromb Vasc Biol. 1999;19(4):1034-40.

71. Prakash YS, Togaibayeva AA, Kannan MS, Miller VM, Fitzpatrick LA, Sieck GC. Estrogen increases Ca2+ efflux from female porcine coronary arterial smooth muscle. Am J Physiol. 1999;276(3 Pt 2):H926-34.

72. Han SZ, Karaki H, Ouchi Y, Akishita M, Orimo H. 17 beta-Estradiol inhibits $\mathrm{Ca} 2+$ influx and $\mathrm{Ca} 2+$ release induced by thromboxane $\mathrm{A} 2$ in porcine coronary artery. Circulation. 1995;91(10):2619-26.

73. Kitazawa T, Hamada E, Kitazawa K, Gaznabi AK. Non-genomic mechanism of 17 beta-oestradiol-induced inhibition of contraction in mammalian vascular smooth muscle. J Physiol. 1997;499 ( Pt 2):497-511. 
74. White RE, Darkow DJ, Lang JL. Estrogen relaxes coronary arteries by opening BKCa channels through a cGMP-dependent mechanism. Circ Res. 1995;77(5):936-42.

75. Naderali EK, Walker AB, Doyle P, Williams G. Comparable vasorelaxant effects of 17alpha- and 17beta-oestradiol on rat mesenteric resistance arteries: an action independent of the oestrogen receptor. Clin Sci (Lond). 1999;97(6):649-55.

76. Teoh H, Quan A, Leung SW, Man RY. Vascular effects of estrone and diethylstilbestrol in porcine coronary arteries. Menopause. 2009;16(1):104-9.

77. Barbagallo M, Dominguez LJ, Licata G, Shan J, Bing L, Karpinski E, et al. Vascular Effects of Progesterone : Role of Cellular Calcium Regulation. Hypertension. 2001;37(1):142-147.

78. Minshall RD, Pavcnik D, Browne DL, Hermsmeyer K. Nongenomic vasodilator action of progesterone on primate coronary arteries. $J$ Appl Physiol. 2002;92(2):701-8.

79. Montgomery S, Shaw L, Pantelides N, Taggart M, Austin C. Acute effects of oestrogen receptor subtype-specific agonists on vascular contractility. $\mathrm{Br} \mathrm{J}$ Pharmacol. 2003;139(7):1249-53.

80. Nandur R, Kumar K, Villablanca AC. Cardiovascular actions of selective estrogen receptor modulators and phytoestrogens. Prev Cardiol. 2004;7(2):739.

81. Tham DM, Gardner CD, Haskell WL. Clinical review 97: Potential health benefits of dietary phytoestrogens: a review of the clinical, epidemiological, and mechanistic evidence. J Clin Endocrinol Metab. 1998;83(7):2223-35.

82. Ososki $A L$, Kennelly EJ. Phytoestrogens: a review of the present state of research. Phytother Res. 2003;17(8):845-69.

83. Mulvany MJ , Halpern W. Contractile properties of small arterial resistance vessels in spontaneously hypertensive and normotensive rats. Circ Res. 1977;41(1):19-26.

84. Dantas AP, Scivoletto R, Fortes ZB, Nigro D, Carvalho MH. Influence of female sex hormones on endothelium-derived vasoconstrictor prostanoid generation in microvessels of spontaneously hypertensive rats. Hypertension. 1999;34(4 Pt 2):914-9.

85. Silva-Antonialli MM, Tostes RC, Fernandes L, Fior-Chadi DR, Akamine EH, Carvalho $\mathrm{MH}$, et al. A lower ratio of AT1/AT2 receptors of angiotensin II is found in female than in male spontaneously hypertensive rats. Cardiovasc Res. 2004;62(3):587-93.

86. Filgueira FP, Ceravolo GS, Lobato NS, Fortes ZB, Tostes RC, Dantas APV, et al. Conjugated Equine Estrogen Improves Vascular Reactivity and Metabolic Parameters in Ovariectomized SHR. Hypertension. 2009;54(4):E79-E79. 
87. Liu ML, Xu X, Rang WQ, Li YJ, Song HP. Influence of ovariectomy and 17beta-estradiol treatment on insulin sensitivity, lipid metabolism and postischemic cardiac function. Int J Cardiol. 2004;97(3):485-93.

88. Giachini FR, Lima VV, Filgueira FP, Dorrance AM, Carvalho MH, Fortes ZB, et al. STIM1/Orai1 contributes to sex differences in vascular responses to calcium in spontaneously hypertensive rats. Clin Sci (Lond). 2012;122(5):21526.

89. Tchernof A, Calles-Escandon J, Sites CK, Poehlman ET. Menopause, central body fatness, and insulin resistance: effects of hormone-replacement therapy. Coron Artery Dis. 1998;9(8):503-11.

90. Browne M, Connolly C, Docherty JR. Vascular actions of 17 beta-oestradiol in rat aorta and mesenteric artery. J Auton Pharmacol. 1999;19(5):291-9.

91. Keung W, Vanhoutte PM, Man RY. Nongenomic responses to 17betaestradiol in male rat mesenteric arteries abolish intrinsic gender differences in vascular responses. Br J Pharmacol. 2005;146(8):1148-55.

92. Tsang SY, Yao X, Chan HY, Wong CM, Chen ZY, Au CL, et al. Contribution of $\mathrm{K}+$ channels to relaxation induced by 17 beta-estradiol but not by progesterone in isolated rat mesenteric artery rings. J Cardiovasc Pharmacol. 2003;41(1):413.

93. Mark CJ, Tatchum-Talom R, Martin DS, Eyster KM. Effects of estrogens and selective estrogen receptor modulators on vascular reactivity in the perfused mesenteric vascular bed. Am J Physiol Regul Integr Comp Physiol. 2007;293(5):R1969-75.

94. Shaw L, Taggart MJ, Austin C. Mechanisms of 17 beta-oestradiol induced vasodilatation in isolated pressurized rat small arteries. $\mathrm{Br} \mathrm{J}$ Pharmacol. 2000;129(3):555-65.

95. Teoh H, Quan A, Leung SW, Man RY. Differential effects of 17beta-estradiol and testosterone on the contractile responses of porcine coronary arteries. $\mathrm{Br}$ J Pharmacol. 2000;129(7):1301-8.

96. Tep-areenan P, Kendall DA, Randall MD. Mechanisms of vasorelaxation to 17beta-oestradiol in rat arteries. Eur J Pharmacol. 2003;476(1-2):139-49.

97. Bhavnani BR. Estrogens and menopause: pharmacology of conjugated equine estrogens and their potential role in the prevention of neurodegenerative diseases such as Alzheimer's. J Steroid Biochem Mol Biol. 2003;85(2-5):47382.

98. Wu S, Ruan Y, Zhu X, Lai W. Estrogen receptors and the activity of nitric oxide synthase in the artery of female rats receiving hormone replacement therapy. Horm Res. 2000;53(3):144-7. 
99. Ihionkhan CE, Chambliss KL, Gibson LL, Hahner LD, Mendelsohn ME, Shaul PW. Estrogen causes dynamic alterations in endothelial estrogen receptor expression. Circ Res. 2002;91(9):814-20.

100. Shaw L, Taggart M, Austin C. Effects of the oestrous cycle and gender on acute vasodilatory responses of isolated pressurized rat mesenteric arteries to 17 beta-oestradiol. Br J Pharmacol. 2001;132(5):1055-62.

101. Bolego C, Cignarella A, Sanvito P, Pelosi V, Pellegatta F, Puglisi L, et al. The acute estrogenic dilation of rat aorta is mediated solely by selective estrogen receptor-alpha agonists and is abolished by estrogen deprivation. J Pharmacol Exp Ther. 2005;313(3):1203-8.

102. Lindsey SH, Carver KA, Prossnitz ER, Chappell MC. Vasodilation in response to the GPR30 agonist G-1 is not different from estradiol in the mRen2.Lewis female rat. J Cardiovasc Pharmacol. 2011;57(5):598-603.

103. Ding Q, Gros R, Limbird LE, Chorazyczewski J, Feldman RD. Estradiolmediated ERK phosphorylation and apoptosis in vascular smooth muscle cells requires GPR 30. Am J Physiol Cell Physiol. 2009;297(5):C1178-87.

104. Filardo EJ, Quinn JA, Frackelton AR, Jr., Bland KI. Estrogen action via the G protein-coupled receptor, GPR30: stimulation of adenylyl cyclase and cAMPmediated attenuation of the epidermal growth factor receptor-to-MAPK signaling axis. Mol Endocrinol. 2002;16(1):70-84.

105. Hsieh YC, Yu HP, Frink M, Suzuki T, Choudhry MA, Schwacha MG, et al. G protein-coupled receptor 30-dependent protein kinase A pathway is critical in nongenomic effects of estrogen in attenuating liver injury after traumahemorrhage. Am J Pathol. 2007;170(4):1210-8.

106. Shan J, Resnick LM, Liu QY, Wu XC, Barbagallo M, Pang PK. Vascular effects of 17 beta-estradiol in male Sprague-Dawley rats. Am J Physiol. 1994;266(3 Pt 2):H967-73.

107. Jiang CW, Sarrel PM, Lindsay DC, Poole-Wilson PA, Collins P. Endotheliumindependent relaxation of rabbit coronary artery by 17 beta-oestradiol in vitro. Br J Pharmacol. 1991;104(4):1033-7.

108. Bell DR, Rensberger HJ, Koritnik DR, Koshy A. Estrogen pretreatment directly potentiates endothelium-dependent vasorelaxation of porcine coronary arteries. Am J Physiol. 1995;268(1 Pt 2):H377-83.

109. Mugge A, Riedel M, Barton M, Kuhn M, Lichtlen PR. Endothelium independent relaxation of human coronary arteries by 17 beta-oestradiol in vitro. Cardiovasc Res. 1993;27(11):1939-42.

110. Garcia-Duran M, de Frutos T, Diaz-Recasens J, Garcia-Galvez G, Jimenez A, Monton $\mathrm{M}$, et al. Estrogen stimulates neuronal nitric oxide synthase protein expression in human neutrophils. Circ Res. 1999;85(11):1020-6. 
111. Han G, Ma H, Chintala R, Miyake K, Fulton DJ, Barman SA, et al. Nongenomic, endothelium-independent effects of estrogen on human coronary smooth muscle are mediated by type I (neuronal) NOS and PI3kinase-Akt signaling. Am J Physiol Heart Circ Physiol. 2007;293(1):H314-21.

112. Lekontseva O, Chakrabarti S, Jiang Y, Cheung CC, Davidge ST. Role of neuronal nitric-oxide synthase in estrogen-induced relaxation in rat resistance arteries. J Pharmacol Exp Ther. 2011;339(2):367-75.

113. White RE, Han G, Maunz M, Dimitropoulou C, El-Mowafy AM, Barlow RS, et al. Endothelium-independent effect of estrogen on $\mathrm{Ca}(2+)$-activated $\mathrm{K}(+)$ channels in human coronary artery smooth muscle cells. Cardiovasc Res. 2002;53(3):650-61.

114. Wingrove CS, Garr E, Pickar JH, Dey M, Stevenson JC. Effects of equine oestrogens on markers of vasoactive function in human coronary artery endothelial cells. Mol Cell Endocrinol. 1999;150(1-2):33-7.

115. Hayashi T, Yamada K, Esaki T, Kuzuya M, Satake S, Ishikawa T, et al. Estrogen increases endothelial nitric oxide by a receptor-mediated system. Biochem Biophys Res Commun. 1995;214(3):847-55.

116. Dantas AP, Tostes RC, Fortes ZB, Costa SG, Nigro D, Carvalho MH. In vivo evidence for antioxidant potential of estrogen in microvessels of female spontaneously hypertensive rats. Hypertension. 2002;39(2 Pt 2):405-11.

117. Miller C. An overview of the potassium channel family. Genome Biol. 2000;1(4):REVIEWS0004.

118. Harder DR, Coulson PB. Estrogen receptors and effects of estrogen on membrane electrical properties of coronary vascular smooth muscle. J Cell Physiol. 1979;100(2):375-82.

119. Rosenfeld CR, White RE, Roy T, Cox BE. Calcium-activated potassium channels and nitric oxide coregulate estrogen-induced vasodilation. Am J Physiol Heart Circ Physiol. 2000;279(1):H319-28.

120. Ratz $\mathrm{PH}$, Berg $\mathrm{KM}$, Urban $\mathrm{NH}$, Miner AS. Regulation of smooth muscle calcium sensitivity: $\mathrm{KCl}$ as a calcium-sensitizing stimulus. Am J Physiol Cell Physiol. 2005;288(4):C769-83.

121. Sakamoto K, Hori M, Izumi M, Oka T, Kohama K, Ozaki H, et al. Inhibition of high $\mathrm{K}+$-induced contraction by the ROCKs inhibitor $\mathrm{Y}-27632$ in vascular smooth muscle: possible involvement of ROCKs in a signal transduction pathway. J Pharmacol Sci. 2003;92(1):56-69.

122. Ratz PH , Miner AS. Role of protein kinase Czeta and calcium entry in $\mathrm{KCl}$ induced vascular smooth muscle calcium sensitization and feedback control of cellular calcium levels. J Pharmacol Exp Ther. 2009;328(2):399-408. 
123. Tosun M, Paul RJ, Rapoport RM. Role of extracellular Ca++ influx via L-type and non-L-type $\mathrm{Ca}++$ channels in thromboxane A2 receptor-mediated contraction in rat aorta. J Pharmacol Exp Ther. 1998;284(3):921-8.

124. Brown AM, Kunze DL, Yatani A. The agonist effect of dihydropyridines on $\mathrm{Ca}$ channels. Nature. 1984;311(5986):570-2.

125. Gonzales RJ , Kanagy NL. Endothelium-Independent Relaxation of Vascular Smooth Muscle by 17beta-Estradiol. J Cardiovasc Pharmacol Ther. 1999;4(4):227-234.

126. Salom JB, Burguete MC, Perez-Asensio FJ, Centeno JM, Torregrosa G, Alborch E. Acute relaxant effects of 17-beta-estradiol through non-genomic mechanisms in rabbit carotid artery. Steroids. 2002;67(5):339-46. 


\section{APÊNDICE A - Artigos de Periódicos}

\section{ARTIGOS COMPLETOS PUBLICADOS EM PERIÓDICOS:}

Artigo 1 Filgueira FP, Lobato NS, DosSantos RA, Oliveira MA, Akamine EH, Tostes RC, Fortes ZB, Carvalho MHC. Endogenous testosterone increases leukocyte-endothelial cell interaction in spontaneously hypertensive rats. Life Sci. 2012;90(17-18):689-94.

Artigo 2 Oliveira LM, Rodrigues AG, Silva EF, Castro $\mathrm{CH}$, Pedrino GR, Carvalho MHC, Cerqueira LB, Pontarolo R, Costa EA, Campos FR, Filgueira FP, Ghedini PC. Endothelium-dependent vasorelaxant effect of butanolic extract from Caryocar brasiliense Camb. leaves in rat thoracic aorta. Evid Based Complement Alternat Med. 2012 (no prelo)

Artigo 3 Lobato NS, Filgueira FP, Akamine EH, Tostes RC, Carvalho MHC, Fortes ZB. Mechanisms of endothelial dysfunction in obesity-associated hypertension. Braz J Med Biol Res. 2012;45(5):392-400.

Artigo 4 Lobato NS, Neves KB, Filgueira FP, Fortes ZB, Carvalho MH, Webb RC, Oliveira AM, Tostes RC. The adipokine chemerin augments vascular reactivity to contractile stimuli via activation of the MEK-ERK1/2 pathway. Life Sci. 2012 (no prelo).

Artigo 5 Giachini FR, Lima VV, Filgueira FP, Dorrance AM, Carvalho MH, Fortes ZB, Webb RC, Tostes RC. STIM1/Orai1 contributes to sex differences in vascular responses to calcium in spontaneously hypertensive rats. Clin Sci. (Lond) 2012;122(5):215-26.

Artigo 6 Lobato NS, Filgueira FP, Hagihara GN, Akamine EH, Pariz JR, Tostes RC, Carvalho MH, Fortes ZB. Improvement of metabolic parameters and vascular function by metformin in obese non-diabetic rats. Life Sci. 2012;90(5-6):228-35.

Artigo 7 Lobato NS, Filgueira FP, Akamine EH, Davel AP, Rossoni LV, Tostes RC, Carvalho MH, Fortes ZB. Obesity induced by neonatal treatment with monosodium glutamate impairs microvascular reactivity in adult rats: Role of NO and prostanoids. Nutr Metab Cardiovasc Dis. 2011;21(10):808-16.

Artigo 8 Zanoni FL, Benabou S, Greco KV, Moreno AC, Cruz JW, Filgueira FP, Martinez MB, Figueiredo LF, Silva MR, Sannomiya P. Mesenteric microcirculatory dysfunctions and translocation of indigenous bacteria in a rat model of strangulated small bowel obstruction. Clinics (Sao Paulo). 2009;64(9):911-9. 


\section{ARTIGOS SUBMETIDOS PARA PUBLICAÇÃO:}

Artigo 1 Ceravolo GS, Filgueira FP, Costa TJ, Lobato NS, Chignalia AZ, Araujo PX, Tostes RC, Dantas AP, Fortes ZB, Carvalho MHC. Conjugated Equine Estrogen treatment corrected the exacerbated aorta oxidative stress in ovariectomized SHR. Steroids.

Artigo 2 Lobato NS, Filgueira FP, Prakash R, Giachini FR, Ergul A, Carvalho MHC, Webb RC, Tostes RC, Fortes ZB. Obesity decreases the vascular relaxation to anandamide, a cannabinoid agonist. Clin Sci (Lond).

\section{ARTIGOS A SEREM SUBMETIDOS PARA PUBLICAÇÃO:}

Artigo 1 Filgueira FP, Lobato NS, Ceravolo GS, Dantas AP, Fortes ZB, Webb RC, Tostes RC, Carvalho MHC. Equilin, an equine estrogen, evokes relaxation in mesenteric arteries of hypertensive rats by inhibiting extracellular calcium entry.

Artigo 2 Filgueira FP, Lobato NS, Carneiro FS, Hannan JL, Carneiro ZN, Fortes ZB, Webb RC, Carvalho MHC, Tostes RC. Effects of natriuretic peptides on intracavernous pressure and cavernous muscle strips from hypertensive rats. 